\title{
Financial reforms and out-of-pocket payments in the Russian healthcare sector
}

Citation for published version (APA):

Gordeev, V. S. (2014). Financial reforms and out-of-pocket payments in the Russian healthcare sector. [Doctoral Thesis, Maastricht University]. Maastricht University. https://doi.org/10.26481/dis.20141030vg

Document status and date:

Published: 01/01/2014

DOI:

10.26481/dis.20141030vg

Document Version:

Publisher's PDF, also known as Version of record

\section{Please check the document version of this publication:}

- A submitted manuscript is the version of the article upon submission and before peer-review. There can be important differences between the submitted version and the official published version of record.

People interested in the research are advised to contact the author for the final version of the publication, or visit the DOI to the publisher's website.

- The final author version and the galley proof are versions of the publication after peer review.

- The final published version features the final layout of the paper including the volume, issue and page numbers.

Link to publication

\footnotetext{
General rights rights.

- You may freely distribute the URL identifying the publication in the public portal. please follow below link for the End User Agreement:

www.umlib.nl/taverne-license

Take down policy

If you believe that this document breaches copyright please contact us at:

repository@maastrichtuniversity.nl

providing details and we will investigate your claim.
}

Copyright and moral rights for the publications made accessible in the public portal are retained by the authors and/or other copyright owners and it is a condition of accessing publications that users recognise and abide by the legal requirements associated with these

- Users may download and print one copy of any publication from the public portal for the purpose of private study or research.

- You may not further distribute the material or use it for any profit-making activity or commercial gain

If the publication is distributed under the terms of Article $25 \mathrm{fa}$ of the Dutch Copyright Act, indicated by the "Taverne" license above, 


\section{FINANCIAL REFORMS AND OUT-OF-POCKET PAYMENTS IN THE RUSSIAN HEALTHCARE SECTOR}


Financial reforms and out-of-pocket payments in the Russian healthcare sector.

(C) Vladimir Sergeevich Gordeev, 2014

All rights reserved. No part of this publication may be reproduced, stored in a retrieval system, or transmitted in any form or by any means, electronic, mechanical, photocopying, recording or otherwise, without written permission from the author.

ISBN: 978-94-6259-425-8

Cover design by: Inge Zlatkou

Printed by: Ipskamp Drukkers BV 


\section{Financial reforms and out-of-pocket payments in the Russian healthcare sector}

Dissertation

to obtain the degree of Doctor at Maastricht University, on the authority of the Rector Magnificus, Prof. dr. L. L. G. Soete in accordance with the decision of the Board of the Deans, to be defended in public on Thursday 30 October 2014, at 10.00 hours

by Vladimir Sergeevich Gordeev 


\section{Supervisor:}

Prof. Dr. W. Groot

\section{Co-supervisor:}

Dr. M. Pavlova

\section{Assessment Committee:}

Prof. Dr. G. G. van Merode (chair)

Prof. Dr. M.J. Ellman (Universiteit van Amsterdam)

Prof. Dr. J.A.M. Maarse

Prof. Dr. M. McKee (London School of Hygiene and Tropical Medicine)

Prof. Dr. J.G.A. van Mierlo

\section{Acknowledgement of funding:}

The study is financed by the European Commission under the 7th Framework Programme, Theme 8 Socio-economic Sciences and Humanities, Project ASSPRO CEE 2007 (Grant Agreement no. 217431). The views expressed in this dissertation are the sole responsibility of the authors and do not necessarily reflect the views of the European Commission or its services. 


\section{Contents}

$\begin{array}{lll}\text { Chapter } 1 \quad \text { General introduction } & 7\end{array}$

Chapter 2 Two decades of reforms. Appraisal of the financial reforms in the 23

Russian public healthcare sector

Chapter 3 The impact of the 2005 social benefits reform in Russia on out-of-

pocket expenditure on prescribed outpatient pharmaceuticals: a

difference-in-differences approach

Chapter 4 Informal payments for healthcare services in Russia: an old issue in new realities

Chapter 5 Catastrophic and impoverishing effects of healthcare payments in

Russia: why forgo and go below?

$\begin{array}{lll}\text { Chapter } 6 \quad \text { General discussion } & 109\end{array}$

$\begin{array}{ll}\text { References } & 121\end{array}$

Appendix A English wording of selected questions from the questionnaires used in 135 the dissertation

Appendix B The list of publications included in the systematic literature review 145

$\begin{array}{ll}\text { Summary } & 149\end{array}$

Аннотация 159

$\begin{array}{ll}\text { Thank you words } & 169\end{array}$

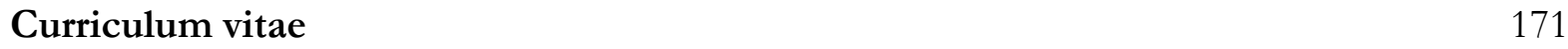



Chapter 1

General introduction 


\subsection{The scope of the dissertation}

The Russian Federation is a country with a transitional economy, where changes in the political and economic situation since 1991 (after the collapse of the USSR) have often been followed by shifts in the priorities of the government agenda. The healthcare sector has been no exception. Just as with other sectors of the Russian economy, the transition to a market-based economy has not had a smooth and carefully planned character. As a result, during the last two decades alone, the financial reforms in the Russian healthcare sector have led to numerous and quite often unrelated changes.

The list of changes in healthcare provision is significant. To name a few, a compulsory social health insurance has been implemented via a payroll-tax, replacing the previously existing tax-based system (1991-1993). The newly developed legal bases have made possible the introduction of private supplementary insurance (1993) and paid services (1996). In 1998, the content of the Program of State Guarantees for Medical Care Provision Free-of-Charge (Guaranteed Package Program) has been formulated. The budgetary responsibilities for financing social protection mandates have been delineated between federal and regional funding (2005). The financing of social and healthcare obligations has been frequently revised and accompanied by a constant shift between multi- and single-channel financing (1991-2012).

The overall number of changes implemented during the transition period is impressive, particularly when taking into account the relatively short-term implementation period of these changes. At the same time, the chaotic and rather inconsistent character of the implementation of the financial reforms is not so surprising, as this basically reflected the numerous reorganizations and transformations of the Ministry of Healthcare itself, following every newly appointed Minister. As a matter of fact, only the name of the Ministry itself has been changed seven times since July 1991, reflecting the inclusion and exclusion of the social development/security component. The current name of the Ministry, since May 2012, is the Ministry of Healthcare of the Russian Federation (the Ministry of Healthcare of the Russian Federation, 2013).

Overall, the numerous financial reforms have been implemented hastily and on an ad hoc basis. As a result, the various reforms have often been unrelated, unsystematic, and had a chaotic character. And since the financing and service provision in the healthcare sector are interrelated, the changes in the former have directly led to alterations in the provision of the latter and vice versa. Gradually, 
the users of the healthcare services have been the ones who experienced the effects of such gridlock. Therefore, the implementation of the Russian financial reforms has raised numerous questions that require answers from the Russian health policy-makers. In particular, questions concerning the outcomes of the financial reforms, the effects of the reforms on the functioning of the healthcare sector in general and on the general population (end-users of healthcare services) can be formulated as follows:

- Were the initial goals of the introduction of the compulsory social health insurance reforms achieved?

- Was it possible to find and implement suitable financial mechanisms of healthcare financing after two decades of reforms?

- How did the shift to a mixed type of healthcare financing affect the system's financial sustainability?

- What impact did the financial reforms have on healthcare service provision in terms of efficiency, equity and quality of the provided care?

- Was the implementation of the reforms successful?

- How big is the share of private financing in the overall financing of the healthcare system?

- What is the burden of out-of-pocket payments for healthcare services on individuals and households as a result of changes in healthcare financing?

Most of these questions have remained unanswered until now. At the same time, obtaining answers to these questions is vital before choosing the future direction of the development of the Russian healthcare sector. Following this rationale, this dissertation focuses on the questions indicated above and examines the content of the financial reforms in the Russian healthcare sector and its relation to the prevalence of changes in out-of-pocket payments made by the Russian population for the utilization of healthcare services.

\subsection{The relevance of the dissertation}

In times of austerity measures, different areas within the public sector have to compete for scarce public funds and search for more efficient ways to utilize already allocated resources. Health policymakers are forced to re-examine the healthcare sector's performance and explore new measures that ensure an optimal balance between efficiency and effectiveness, given the new circumstances. Such measures often aim at the restructuring and reorganization of the provision of healthcare 
services, which often leads to changes in the mechanisms of healthcare financing. To ensure that such measures are beneficial for the general population, healthcare policy-makers have to rely on evidence-based decision-making as a tool for policy-making. Whenever such evidence is lacking, policy-makers can use available evidence and experiences from neighboring countries that have similar socio-economic characteristics, demographic composition of the population, or share a common geographical position or have a similar historical and political background. In particular, such evidence is accumulated for countries with a transitional economy. Typically, these countries have a rich history of numerous and continuous reforms that can be seen and examined as "natural experiments".

The Russian Federation is one of the ex-Soviet countries with a transitional economy that has a rich history of "natural experiments" implemented during healthcare sector restructuring, with, in particular, numerous changes in healthcare sector financing and provision. Such changes in the provision of social and healthcare services, coupled with the considerable share of out-of-pocket expenditures for healthcare services, have placed an additional burden on the budgets of many Russian households (previously not experienced during the Soviet era), and potentially affected the efficiency, equity and quality of the care provided. However, despite the numerous changes to Russian healthcare financing, the empirical evidence on the effects of the financial reforms is still scarce or lacking. Therefore, the Russian healthcare sector is a good candidate for a case-study.

This dissertation adds to the body of the empirical evidence that can be used for evidence-based healthcare policy-making by Russian healthcare policy-makers in the future. Moreover, due to numerous reforms, adjustments and experimenting with healthcare financing, the Russian experience can be used to draw relevant lessons for policy-makers in other countries that implemented similar reform measures or shared the Soviet legacy, and are still in search for the optimal model of healthcare development and financing. As such, despite the focus being solely on the Russian healthcare sector, the topics addressed in this dissertation are relevant for other countries with transitional economies, especially neighboring ex-Soviet countries.

\subsection{Financial reforms in the Russian healthcare sector}

After the fall of the Soviet system and its planned economy, most of the sectors of the Russian economy tried to adopt the principle of an open, market-based economy. However, the Russian healthcare sector has been fiercely limited in its options for further development mainly due to the 
large obligations that resulted from numerous in-kind healthcare and social privileges, and benefits. The Russian healthcare sector has also faced numerous practical problems inherited from the previous Soviet "Semashko" model of healthcare and social security provision, and financing.

More specifically, the sector has had to deal with underfunding and the presence of informal payments. The lack of a strong and well-developed alternative market for healthcare services provision (i.e. a private healthcare sector) has been coupled with outdated equipment in the public healthcare setting and poor quality of care provided. A shortage of pharmaceuticals and medical personnel, and an outdated medical study curriculum, also added to the crisis. An absence of effective mechanisms to equalize medical care across regions and a lack of working mechanisms to ensure adequate quality, efficiency and equity in healthcare provision, have made addressing already existing inter-regional inequalities across income groups in terms of financing and access to healthcare services, even harder.

The healthcare financing reforms started when Russian healthcare policy-makers opted for a transition to an insurance-based healthcare system. The reforms of 1991-1993 officially introduced and put in practice a system of social health insurance, mandatory for all citizens, by creating appropriate health insurance funds and supporting structures (Government of the Russian Federation, Federal Law No. 1499-1, 1991). The subsequent search for an optimal model of financing, that followed the initial healthcare financing reorganization, had become a very challenging task for the Russian government in the 1990s. This was mainly due to the problems described above.

Also, there have been a number of important political hurdles that regulated the essence of the public healthcare provision and significantly limited the range of the financial tools available for implementation. In particular, according to the Russian Constitution, all citizens have the right to access medical care provided at state and municipal medical facilities free-of-charge and are guaranteed equal access to it (Government of the Russian Federation, the Constitution of the Russian Federation, 1993). In practice that meant, for example, that the introduction of the copayment mechanism as a tool to mitigate the effect of underfunding would have directly contradicted the principle of the free-of-charge healthcare provision, assured legislatively. Therefore, the implementation of co-payments to generate additional revenues was not possible and, technically, illegal. 
Faced with unaffordable State guarantees, secured by legislation, the Russian government has had to make appropriate adjustments in the financing of the public healthcare sector. The revenues generated by the introduction of compulsory social health insurance in 1991-1993 had a somewhat stabilizing influence in the 1990s when government expenditure on healthcare was declining (Chernichovsky et al., 1996a; Chernichovsky et al., 1996b; Shishkin, 1998). Nevertheless, these funds alone have not been sufficient to sustain the financing of the public healthcare system and more changes were necessary. Following the legal bases for chargeable health services in 1996 (Government of the Russian Federation, Government resolution No. 27, 1996), the Russian government formulated the content of the Guaranteed Package Program (Government of the Russian Federation, Government resolution no. 1096, 1998). This program outlined the list of medical and medication assistance that should be provided free-of-charge and covered by means of compulsory social health insurance. From a financial point of view, such a program could be seen as an attempt to specify and financially quantify existing State guarantees and responsibilities.

A consistent lack of sufficient financial means has led to a consecutive revision of the principles of social and healthcare benefits provision, including the provision of pharmaceuticals and a review of the mechanisms of inter-regional resource allocation and corresponding reimbursement. Initial changes in the percentage of the unified social tax attributed to compulsory social health insurance contributions, has eventually led to a gradual introduction of a separate compulsory social health insurance contribution (premium) paid by the insured (a 5.1\% payroll-tax in 2013) (Government of the Russian Federation, Federal Law No. 212, 2009). Nonetheless, some issues, namely informal payments, have not been addressed officially and have therefore remained out of sight of policymakers until the present moment.

The implementation of the financial reforms in healthcare provision went side by side with alterations to the actual figures of healthcare financing by the State. As can be seen in Figure 1.1, in the 1990s and 2000s, total healthcare expenditure has ranged from 6.0\% (1995-2000) to 5.7\% of GDP (2001-2012) and has been steadily rising from 2004 onwards from 5.2\% to 6.3\% of GDP in 2012, with an exception of 2008 when total healthcare expenditure decreased to 5.1\% of GDP. Nonetheless, general government expenditure on healthcare as a percentage of total healthcare expenditure has gradually declined during the last 15 years from $73.9 \%$ (1995) to 61.0\% (2012) (Table 1.1). The gaps in public financing have been filled by increased levels of private expenditure (including out-of-pocket payments). Thus, despite the established insurance-based model of 
healthcare financing and social security based on a solidarity principle, the State has shifted the burden of healthcare financing directly onto households.

The share of private expenditure on healthcare services and pharmaceuticals increased from 1994 onwards and has slightly declined in the period 2004-2009, only to increase again as of 2010. By 2012, the share of private expenditure was one and half times higher than what it used to be in $1995,39.0 \%$ compared to $26.1 \%$ of total health expenditure, respectively. The biggest share of private expenditure has been attributed to out-of-pocket payments. During the last 15 years, the share of out-of-pocket payments as a percentage of private expenditure has increased by ca. $23 \%$, reaching $87.9 \%$ in 2012. The role of private health insurance, another financing agent contributing towards private expenditure on healthcare, has fluctuated between $6 \%$ and $11.4 \%$. The share of private health insurance has averaged $6.8 \%$ and $9.2 \%$ of private expenditure in 1995-2000 and 2001-2011, respectively, constituting only 6.9\% of private expenditure in 2012.

Figure 1.1 Health expenditure, total (\% of GDP)

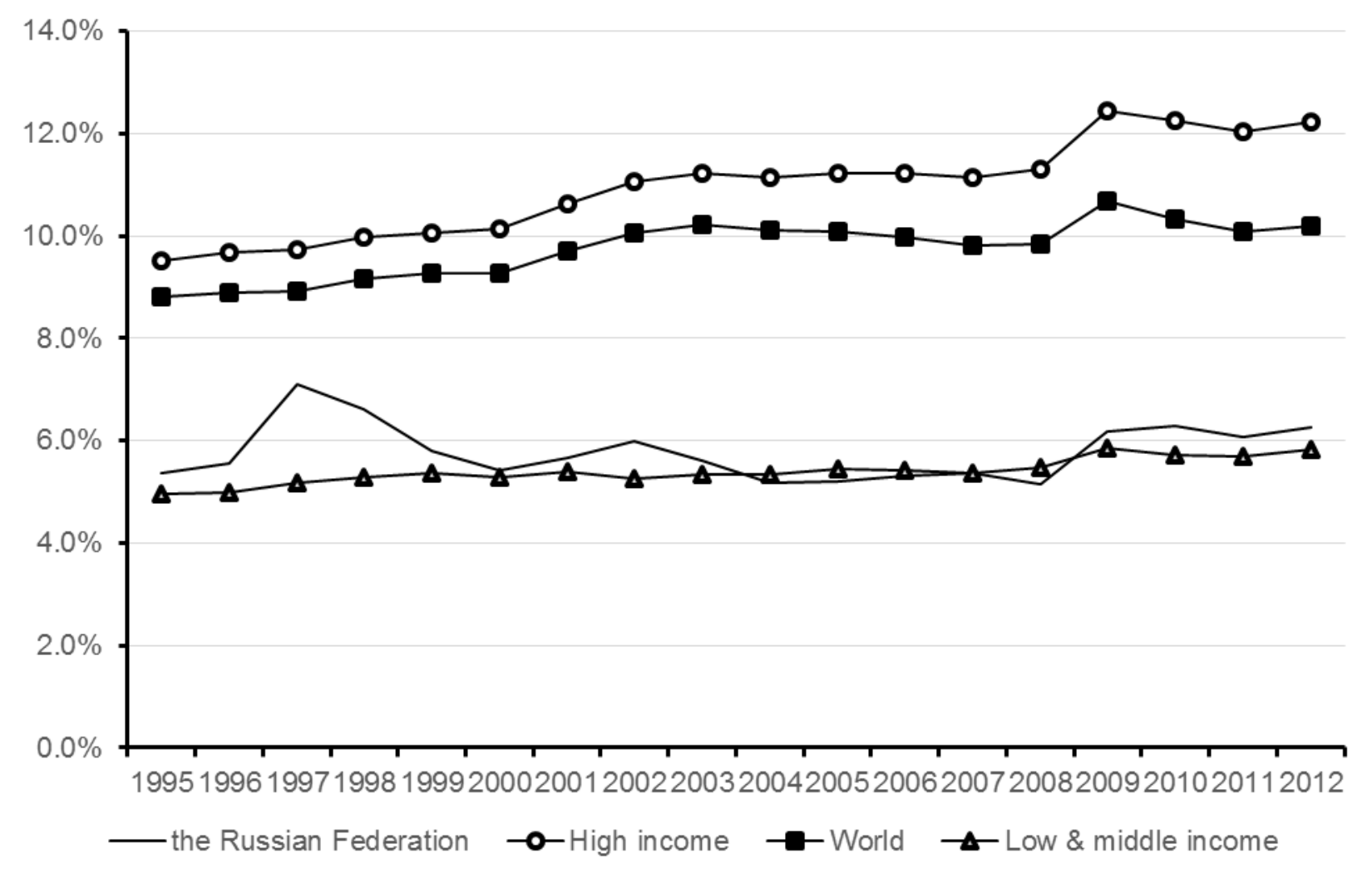

Source: based on estimates by the World Bank, 2013. 
Table 1.1 Financing agents in national expenditure on healthcare in the Russian Federation

\begin{tabular}{|c|c|c|c|c|c|c|c|c|c|c|c|c|c|c|c|c|c|c|}
\hline Year & 1995 & 1996 & 1997 & 1998 & 1999 & 2000 & 2001 & 2002 & 2003 & 2004 & 2005 & 2006 & 2007 & 2008 & 2009 & 2010 & 2011 & 2012 \\
\hline \multicolumn{19}{|c|}{ measurement as $\%$ of Total Health Expenditure* } \\
\hline $\begin{array}{l}\text { General government } \\
\text { expenditure }\end{array}$ & 73.9 & 71.4 & 70.8 & 65.1 & 61.9 & 59.9 & 58.7 & 59.0 & 58.8 & 59.6 & 62.0 & 63.2 & 64.2 & 66.5 & 67.0 & 58.7 & 59.7 & 61.0 \\
\hline Social security funds & 25.5 & 25.5 & 21.7 & 23.7 & 22.2 & 24.2 & 23.2 & 23.9 & 23.3 & 23.5 & 26.0 & 26.8 & 24.9 & 28.5 & 30.1 & 26.2 & 28.1 & 28.7 \\
\hline Ministry of Healthcare & 3.0 & 2.2 & 5.2 & 4.3 & 3.7 & 3.0 & 3.5 & 4.3 & 4.7 & 5.1 & 7.4 & 8.6 & 9.0 & 9.4 & 10.0 & 9.5 & 9.3 & 9.5 \\
\hline $\begin{array}{l}\text { General government } \\
\text { revenues }\end{array}$ & 45.4 & 43.7 & 43.9 & 37.1 & 36.0 & 32.7 & 32.0 & 30.8 & 30.8 & 31.0 & 28.6 & 27.8 & 30.3 & 28.6 & 26.9 & 23.0 & 22.3 & 22.8 \\
\hline Private expenditure & 26.1 & 28.6 & 29.2 & 34.9 & 38.1 & 40.1 & 41.3 & 41.0 & 41.2 & 40.4 & 38.0 & 36.8 & 35.8 & 33.5 & 33.0 & 41.3 & 40.3 & 39.0 \\
\hline $\begin{array}{l}\text { Out-of-pocket } \\
\text { expenditure }\end{array}$ & 16.9 & 18.1 & 18.1 & 23.0 & 27.5 & 30.0 & 30.5 & 30.9 & 32.8 & 33.2 & 31.3 & 30.0 & 29.7 & 27.3 & 27.2 & 36.3 & 35.4 & 34.3 \\
\hline Private health insurance & 1.6 & 2.0 & 2.0 & 2.2 & 2.6 & 3.2 & 4.7 & 4.1 & 4.2 & 3.5 & 3.1 & 3.7 & 3.4 & 3.6 & 3.5 & 2.9 & 2.8 & 2.7 \\
\hline $\begin{array}{l}\text { Non-profit institutions } \\
\text { serving households (e.g. } \\
\text { NGOs) }\end{array}$ & 2.8 & 2.9 & 2.5 & 2.4 & 1.8 & 1.7 & 1.8 & 2.0 & 2.0 & 1.9 & 1.8 & 1.5 & 1.4 & 1.3 & 1.2 & 1.0 & 0.9 & 0.9 \\
\hline Other private sources & 4.8 & 5.6 & 6.6 & 7.3 & 6.2 & 5.2 & 4.3 & 4.0 & 2.2 & 1.8 & 1.8 & 1.6 & 1.3 & 1.3 & 1.1 & 1.1 & 1.2 & 1.1 \\
\hline External resources & 0.1 & 0.5 & 0.4 & 0.6 & 0.8 & 0.2 & 0.2 & 0.2 & 0.2 & 0.1 & 0.0 & 0.1 & 0.0 & 0.0 & 0.0 & 0.0 & 0.0 & 0.0 \\
\hline
\end{tabular}

Source: based on National Health Accounts estimations for the Russian Federation by WHO (2013).

Notes: *- the sum of general government, private expenditures, and external resources on healthcare may not add up to $100 \%$ because of rounding. 
Overall, the reforms in the financing of the Russian healthcare sector, that started right after the fall of the Soviet regime, actually continue till the present moment. After nearly 25 years of experimenting, the Russian government is still searching for the optimal scheme of healthcare financing. This is not surprising, as a well-functioning healthcare sector that can effectively secure the wealth and health of the nation is vital for the economy of any country. World-wide there is no consensus regarding the optimal scheme of healthcare sector financing (private, public or publicprivate mix) or the optimal level of expenditure that would secure optimal healthcare provision (The World Bank, 2013). Countries continue to employ single or multi-channel financing mechanisms, rely on general revenues or revenues from social and private health insurances, and use a variety of other mechanisms to generate additional financial resources (e.g. community funding, user fees and out-of-pocket payments). The level of financing mainly depends on the economic development of the country. In high-income countries, total health expenditure on average constitutes up to 12-13\% of a country's total GDP (Figure 1.1). In low-income countries, however, the healthcare sector is quite often underfinanced and expenditures can be as low as $2 \%$ of GDP. In the Russian Federation, which is a high-income country (as of December 2013), the overall level of healthcare financing approximates $5 \%$ of GDP, which is lower than in other Eurasian countries (ca. $10 \%$ of GDP).

\subsection{The current model of healthcare provision and financing in the Russian} Federation

During the last two decades, the Russian government has introduced and adopted a number of significant changes which differentiate the current model of healthcare provision and financing from the previous "Semashko" model. During the Soviet era, healthcare provision had a central planning character and was fully financed by the State. Unlike the "Semashko" model, as outlined above, the current model of healthcare financing in the Russian Federation incorporates both public and private financing. In general, the healthcare system is funded by several streams of revenue depending on the funding agent: budgets at the federal, regional and local levels (raised by taxes); extra-budgetary funds (mandatory health, pension, and social insurance contributions paid on payrolls); and private funding (out-of-pocket payments, voluntary private health insurance and NGO funds). A schematic representation of public healthcare financing can be found in Figure 1.2. The system is overly complex, with almost $60 \%$ of public healthcare expenditure being administered by federal, regional and municipal budgets. The remainder goes thought the compulsory social health insurance system (federal and regional funds) (Tompson, 2007). 
Figure 1.2 Public healthcare financing in the Russian Federation

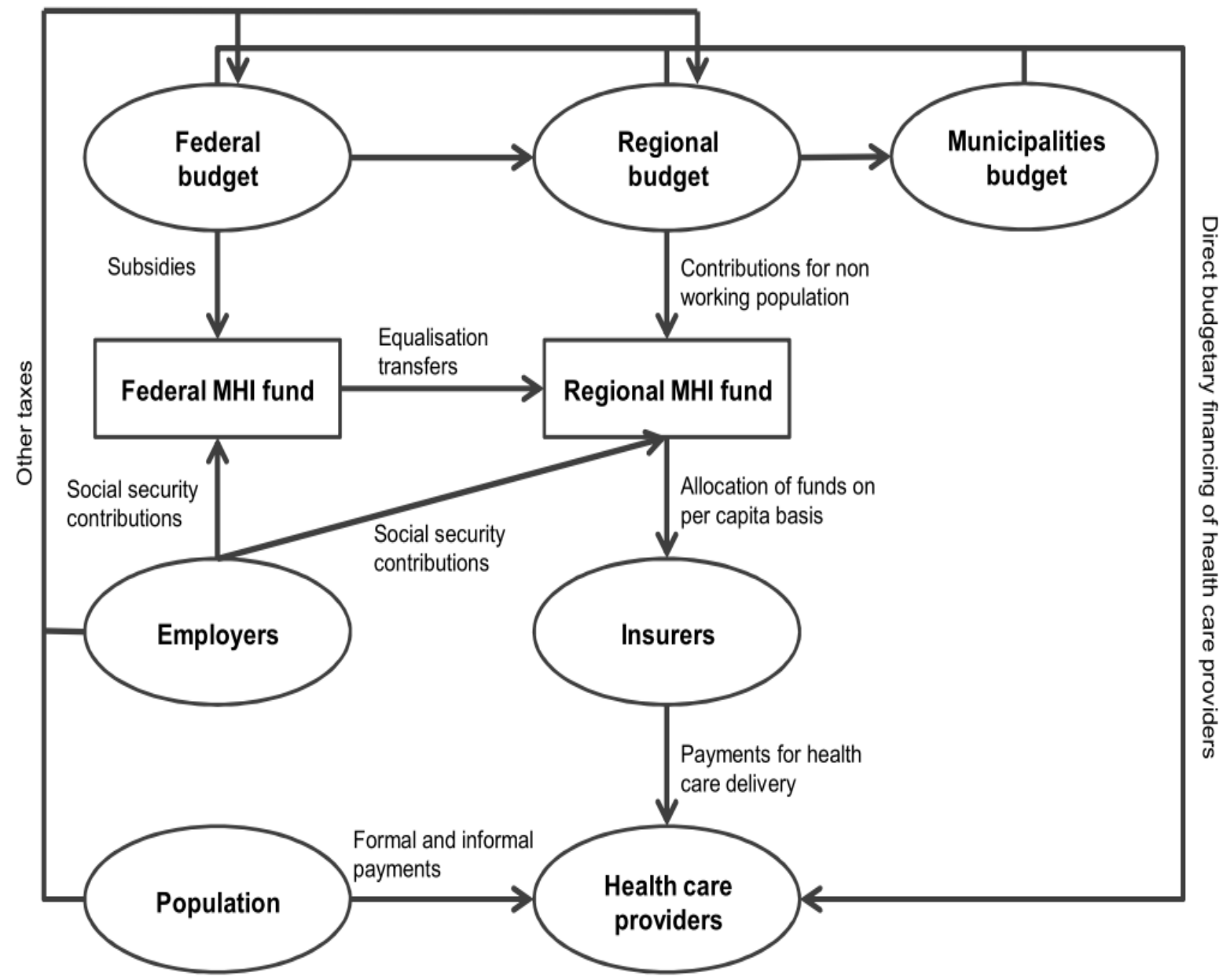

Source: adapted from Tompson (2007).

Notes: MHI - compulsory social health insurance.

Out-of-pocket payments include official payments made via the cashier office in healthcare establishments, quasi-formal payments and informal payments. In this dissertation, the following definition of informal payments is used for out-of-pocket payments: "monetary hand-to-hand monetary transactions in cash or in a form of gifts in kind, given directly to the medical personnel that bypass the official cash registry of the healthcare establishment". This definition is based on the formulation used in the questionnaire of the Russia Longitudinal Monitoring Survey - Higher School of Economics (RLMS-HSE) - a dataset that is used for the empirical analyses in this dissertation. Informal payments are often made as an expression of gratitude or are paid for services that should have been otherwise provided free-of-charge (RLMS-HSE, 2013). Currently, informal payments are not officially addressed by Russian health policy-makers. 
The emerged mixed model of healthcare financing in Russia, in principle, reflects its model of healthcare provision that consists of a public (State) and private sector. As already mentioned, Russian citizens are entitled to free-of-charge healthcare provision within the range of the services defined in the State Guaranteed Package Program. All other medical services (dental care; pharmaceuticals and medical devices in outpatient care; routine medical examinations and tests required for formal certificates; additional non-essential treatments and auxiliary services at hospitals; cosmetic surgery; etc.) are paid for by out-of-pocket payments (official chargeable fees and informal payments) and by voluntary private health insurance for supplementary coverage.

According to Russian legislation, healthcare entities, irrespective of the form of ownership, have the right to participate in the system of public healthcare provision. However, only a limited number of private healthcare providers have managed to exercise this right due to various legislative and bureaucratic hurdles. A complete shift towards the single-channel model of the financing that had started in 2010-2011 (when all reimbursements go through the federal social insurance fund) can, theoretically, give private healthcare providers an entry point into the market of public healthcare services. By bringing private actors into the market of public healthcare services, it is expected that a more fair competition and subsequent quality development of healthcare services can be achieved. However, whether the single-channel model of public healthcare financing would indeed be helpful to achieve such goals, is still uncertain.

\subsection{The research aim and objectives of the dissertation}

As outlined earlier, despite the numerous financial reforms in the Russian healthcare sector, there is still a lack of empirical studies that examine this issue. Many questions regarding the effects of changes in financing, and its relation to the burden of out-of-pocket payments for healthcare users, remain unanswered. To cover this gap in the body of empirical evidence, the goal of this dissertation is to study the changes in out-of-pocket payments in the Russian healthcare system against the background of the financial reforms of the Russian healthcare sector. To achieve the goal of the dissertation, several aims are defined.

The first aim is to examine the effects of the financial reforms in the Russian public healthcare sector at the macro-level: the financial sustainability (system funding), efficiency, equity, and quality of care provision (based on the existing evidence). By looking at the existing evidence, it is possible to conduct an appraisal of the financial reforms in the Russian public healthcare sector. Such an 
appraisal would help to determine whether the main goals of the reforms have actually been achieved. It also allows the drawing of possible policy implications and to formulate recommendations for health policy-makers regarding the course of future financial healthcare reforms.

The second aim of the dissertation is to examine in more detail the potential effects of selected reforms on the provision of healthcare services and onto healthcare users. This is done by examining the change in the provision of in-kind benefits (in particular, provision of pharmaceuticals) in the period 2004-2006 when most of these benefits were monetized and replaced by an in-cash provision. The change in the provision of such in-kind benefits potentially impacts out-of-pocket expenditure on prescribed or recommended pharmaceuticals. The study of the experience of the monetization can be used by the Russian policy-makers when planning further reforms in the Russian Federation. This is particularly relevant, as monetization of other social benefits (i.e. housing) is on the governmental agenda.

The third and fourth aims are narrowed down to users' out-of-pocket payments (including informal payments) and their effects on households (catastrophic and impoverishing effect). In particular, the third research aim focuses on a long-lasting phenomenon in the financing of the Russian healthcare system - informal payments. While existing in the healthcare sector since the Soviet era mostly in the form of in-kind gifts, at present, informal payments (both cash and in-kind) help patients to obtain necessary and/or better quality services. And since the problem of informal payments is not on the agenda of Russian health policy-makers, prior to any policy recommendations, it is important to examine the scale and scope of informal payments. Answering the question regarding the reasons for their existence and examining in detail how informal payments occur, it is possible to give a clear indication to health policy-makers on how relevant this issue is and why.

The fourth aim is to examine the relationship between out-of-pocket payments made by healthcare users and households' poverty. By looking at the catastrophic and impoverishing effects of out-ofpocket payments, it is possible to provide more evidence for policy-makers that supports or opposes the implementation of targeted social assistance and the necessity of eliminating poverty. 


\subsection{Research approach and data}

The first research aim is approached by means of a systematic literature review. The empirical analyses related to aims two, three and four are performed using data from the all-Russia national representative RLMS-HSE survey (RLMS-HSE, 2013). The RLMS-HSE is a series of nationally representative surveys designed to monitor the effects of reforms on the health and economic welfare of households and individuals in the Russian Federation. Data have been collected 19 times since 1992. Since 1997, a multi-stage probability sample has been employed. Data from the RLMSHSE can be used in two types of analyses: repeated cross-section analysis and longitudinal analysis. The RLMS-HSE survey is carried out by face-to-face interviews, with data for the children's questionnaires obtained from adults in the household. The survey contains data on the utilization and out-of-pocket payments for all types of healthcare services (outpatient non-dental, dental, check-up, and inpatient), as well as prescribed and recommended pharmaceuticals. For the analysis in this dissertation, individual and household level data from rounds 10-20 (2001-2011) have been used. The sample size varied depending on the year of data collection. The target sample size set by the RLMS-HSE team was 4,000 dwelling units. A more detailed description of the data can be found on the official website of the survey (http://www.cpc.unc.edu/projects/rlms-hse). The wording of the questions used in this dissertation, can be found in Appendix A.

\subsection{The outline of the dissertation}

This dissertation is based on a series of studies that examine the effects of the financial reforms in the Russian public healthcare sector.

Chapter 2 provides the appraisal of the financial reforms in the Russian public healthcare sector and is related to the first aim of the dissertation. The chapter provides background information and outlines key milestones of the Russian healthcare reforms and changes in healthcare financing over the last two decades. It provides a review of the empirical evidence of the effects of the financial reforms in the Russian public healthcare sector on financial sustainability (system funding), efficiency, equity, and quality of provided care. The chapter is based on a systematic literature review of the empirical evidence on the effects of the financial reforms in the Russian public healthcare sector. The list of publications included in the review was refined by a set of limitations and relevance criteria. 
Chapter 3 is related to the second aim of the dissertation. Using RLMS-HSE data, it evaluates the monetization of the social benefits reform of 2005, which cashed-out most of the in-kind benefits and affected the provision of prescribed and recommended outpatient pharmaceuticals. In particular, the chapter draws upon the evaluation of the impact of the social benefits reform of 2005 on out-of-pocket expenditure on prescribed or recommended pharmaceuticals. The analysis is based on a difference-in-differences method applying zero-inflated models. Additional analysis examines whether the annual choice between in-kind and in-cash provision of prescribed and recommended outpatient pharmaceuticals (possible as of 2006) had any significant impact as well.

Chapter 4 examines the issue of informal payments for healthcare services in Russia and provides input for the third objective of the dissertation. This chapter contains the results on the scale and scope of informal payments in the Russian healthcare sector and their determinants in 2009, based on data in the RLMS-HSE dataset. Results are compared to previous studies about informal payments for Russia and other Central and Eastern European (CEE) countries. A detailed description of the process of paying informally (actors involved, settings, and reasons) is given, including identified patterns of paying informally, assessed by the means of cluster analysis. Two types of models are used to analyze informal payments: a two-part model (a combination of probit and generalized linear model with gamma distribution and log link function), and a sample selection model using maximum likelihood (full-information maximum-likelihood). The chapter also elaborates on the reasons for the persistent existence of informal payments in the Russian healthcare sector and its implications for Russian health policy-makers.

Chapter 5 relates to the fourth aim of the dissertation and analyzes how exposure of the Russian healthcare users to catastrophic payments of healthcare services changed during the last decade (2001-2011). The incidence and intensity of catastrophic payments are characterized by headcount, overshoot, and mean positive overshoot. The impoverishing impact of out-of-pocket expenditure are assessed by distribution-sensitive measures (concentration index), while measures of poverty are based on poverty headcounts, poverty gap, normalized poverty gap and normalized mean positive poverty gap. A long-term perspective is applied in the analysis, which has been rarely done in previous research in this area.

Chapter 6 outlines the main findings of the dissertation based on the empirical analysis in the previous chapters. Following the general conclusions, the chapter further elaborates on possible policy implications of the studies. It calls for the attention of Russian health policy-makers to 
address urgent matters currently existing in the Russian healthcare sector, and suggests utilizing an evidence-based policy-making approach and conducting timely impact evaluation analyses of the financial reforms in the healthcare sector. 
Chapter 2

Two decades of reforms. Appraisal of the financial reforms in the Russian public healthcare sector

This chapter draws upon:

Gordeev, V.S., Pavlova, M., Groot, W. (2011). Two decades of reforms. Appraisal of the financial reforms in the Russian public healthcare sector. Health Policy, 102(2-3), 270-277. 


\begin{abstract}
This chapter reviews the empirical evidence on the outcomes of the financial reforms in the Russian public healthcare sector. A systematic literature review identified 37 relevant publications that presented empirical evidence on changes in quality, equity, efficiency and sustainability in public healthcare provision due to the Russian public healthcare financial reforms.

Evidence suggests that there are substantial inter-regional inequalities across income groups both in terms of financing and access to public healthcare services. There are large efficiency differences between regions, along with inter-regional variations in payment and reimbursement mechanisms. Informal and quasi-formal payments limit access to public healthcare services and undermine overall financial sustainability. The public healthcare sector is still underfinanced, although the implementation of health insurance has given some promise for future increases of efficiency.

Future reforms should focus on the implementation of cost-efficiency and cost-control mechanisms; provide incentives for a better allocation and distribution of resources; tackle problems in equity in access and financing; implement a system of quality controls; and stimulate healthy competition between insurance companies. Overall, the available empirical data are not sufficient for an evidence-based evaluation of the reforms. More studies on the quality, equity, efficiency and sustainability impact of the reforms are needed.
\end{abstract}




\subsection{Introduction}

For many years, centralized, so-called "normative" financing was the main mechanism used to finance the public healthcare sector in Russia. Since the collapse of the Soviet Union in 1991, numerous healthcare reforms have taken place in the Russian Federation (see Chapter 1). The core of financial healthcare reforms focused on shifting the Russian public healthcare sector away from the hierarchical and strongly centralized model of healthcare provision to a more decentralized and insurance-based system of healthcare provision. However, the OECD states that the Russian public healthcare system remains "half-reformed" (OECD, 2006), and the transition process is still unfinished. Does this mean that the goals of the financial reforms in the Russian public healthcare sector have not yet been achieved?

This chapter aims to review the empirical evidence on the outcomes of the financial reforms in the Russian public healthcare sector and to serve as a basis for an evidence-based evaluation of these reforms. To achieve this, the chapter first outlines the content of the financial reforms in the Russian public healthcare sector and the implementation of social health insurance. The review of the financial reforms is followed by a description of quality, equity and efficiency criteria that are used for the appraisal of these reforms. Next, a systematic literature review focused on the empirical evidence available for these criteria is presented and discussed. Finally, the chapter provides conclusions and policy recommendations.

\subsection{Background}

In the early 1990s, the Russian public healthcare sector opted for a transition to an insurance-based system - a common trend in the CEE transition economies (Rechel \& McKee, 2009; Wagstaff \& Moreno-Serra, 2009). The overall objectives were: to provide additional non-budget revenues for the public healthcare sector and to encourage efficiency by separating public healthcare financing from the provision of public healthcare services.

\subsubsection{Key players in the Russian public healthcare system}

The first piece of legislation on social health insurance (i.e. the Law on Health Insurance of the Citizens of the Russian Federation) was ratified in June 1991 (Government of the Russian Federation, Federal Law No. 1499-1, 1991). The law stipulated the design of a compulsory social 
health insurance for all citizens as a form of social protection and guarantee of the entitlements in the public healthcare sector. The compulsory social health insurance aimed to guarantee access for all citizens to public healthcare services across all regions of the Russian Federation regardless of their place of permanent residence. It was only in 1993 that the compulsory social health insurance was actually implemented after amendments in the law on social health insurance that established social health insurance institutions - the Federal Compulsory Health Insurance Fund and 87 Territorial Compulsory Health Insurance Funds. In 2008, the number of the Territorial Compulsory Health Insurance Funds was reduced to 85 due to a decrease in the number of regions in the Russian Federation. The role of the Federal Compulsory Health Insurance Fund was to manage the compulsory social health insurance while the role of the Territorial Compulsory Health Insurance Funds was to collect and manage the contributions for the compulsory social health insurance per region (Government of the Russian Federation, Federal Law No. 5487-1, 1993). The Territorial Compulsory Health Insurance Funds were expected to redistribute the compulsory social health insurance funds to independent third-party payers, who would then contract for care with the providers.

The role of third-party payers was reserved for independent insurance companies, which did not exist when the Territorial Compulsory Health Insurance Funds were established, but were expected to emerge in the future. Meanwhile, the Territorial Compulsory Health Insurance Funds were allowed to play this role (Government of the Russian Federation, Federal Law No. 1499-1, 1991; Blam \& Kovalev, 2006). The third-party payers could freely choose between healthcare providers, but were entitled to protect the interests of the insured patients and to control the volume, time (access and duration) and quality of medical care. Any healthcare institution, whether privately or state owned, and which had a proper license and accreditation, could be contracted by the Territorial Compulsory Health Insurance Funds. Thus, the compulsory social health insurance funds could be channeled to healthcare providers via the Territorial Compulsory Health Insurance Fund. The creation of the Federal Compulsory Health Insurance Fund and the Territorial Compulsory Health Insurance Funds marked the first step towards a purchaser-provider separation in the public healthcare sector.

Presently, about 106 insurance companies and 246 branches of insurance companies are operating as third-party payers together with the 84 Territorial Compulsory Health Insurance Funds and mediate between healthcare providers, patients and/or their employers (Federal Compulsory Health Insurance Fund, 2010). 


\subsubsection{Provision of public healthcare services in Russia}

The group of healthcare providers consists of: "licensed medical facilities, scientific-research and medical institutes, other facilities, individuals (or group of individuals) that provide medical assistance" (Government of the Russian Federation, Federal Law No. 1499-1, 1991). As of 2009, the overall number of healthcare facilities that had contracts and were participating in the compulsory social health insurance system was 8142 (Federal Compulsory Health Insurance Fund, 2010).

In 1998, the Ministry of Healthcare accepted a Program of State Guarantees for the provision of free medical care (i.e. ambulance, outpatient/polyclinic and hospital care) to citizens. The program was designed to assure the constitutional right of citizens for free medical care (as stated in Government of the Russian Federation, Constitution of the Russian Federation, 1993) by creating the Guaranteed Package Program and guaranteeing equal access to it. The Guaranteed Package Program incorporated and stipulated medical and medication assistance covered by the compulsory social health insurance funds and was mandatory for all regions of the Russian Federation. Based on the Guaranteed Package Program, the local authorities developed the Territorial compulsory social health insurance programs. The latter could not be lower or worse than the volumes and conditions guaranteed by the Guaranteed Package Program designed by the state and regulated by maximum tariffs for healthcare services. The Territorial compulsory social health insurance programs could include additional services, but these would have to be covered by local regional sources.

In 2007, a new pilot project started in 19 regions of the Russian Federation aiming to improve the quality of care and transition of the public healthcare sector to a single-channel financing model via the Territorial Compulsory Health Insurance Funds (Government of the Russian Federation, Government resolution no. 296, 2007). The project is financed by federal funds that are transferred to the Territorial Compulsory Health Insurance Funds, in combination with funds that were left over from the previous year in both the Federal Compulsory Health Insurance Fund and the Territorial Compulsory Health Insurance Funds. Regions that participate in the pilot should match the funding with contributions from the regional budgets. 


\subsubsection{Funding of the Russian public healthcare system}

Since the introduction of the legislation on healthcare insurance, the Russian public healthcare system has had multi-channel financing. The main sources of revenue for the Territorial Compulsory Health Insurance Funds are compulsory social health insurance contributions derived from the Unified Social Tax (ESN) and health premiums paid by municipalities for the nonworking population. In 2009, the Territorial Compulsory Health Insurance Funds received in total 153.1 billion Rubles (€3.87 billion) from the ESN (Federal Compulsory Health Insurance Fund, 2010). Other sources of healthcare financing include: "financial contributions by state and public organizations, as well as business organizations, out-of-pocket payments, gratuitous or charitable installments, donations, revenues from securities, credits from banks and other creditors, and other sources that are not forbidden by the legislation of the Russian Federation and the republics of the Russian Federation" (Government of the Russian Federation, Federal Law No. 1499-1, 1991). In 1996, the government officially introduced and defined "chargeable" services (Government of the Russian Federation, Government resolution no. 27, 1996). Currently, the only officially authorized patient charges for typical hospital and ambulatory services are (without exemptions): outpatient drugs, routine ophthalmological services, dental care, most medical aids and prostheses, and payments for services excluded from the Guaranteed Package Program.

In 2001, when the ESN was introduced, the compulsory social health insurance contributions were set at a 3.6\% rate of payroll tax, and were later adjusted to $2.8 \%$, with $0.8 \%$ being apportioned to the Federal Compulsory Health Insurance Fund and 2\% to the Territorial Compulsory Health Insurance Funds. Since 2006, the rate increased to 3.1\%, with $1.1 \%$ apportioned to the Federal Compulsory Health Insurance Fund and 2\% apportioned to the Territorial Compulsory Health Insurance Funds (OECD, 2006; Tax code of the Russian Federation, 1998). As of 2011, the ESN was abolished and replaced by separate taxes. The compulsory social health insurance contribution is expected to increase to a 5.1\% rate of payroll tax (Government of the Russian Federation, Federal Law No. 212, 2009).

The number of citizens insured under the compulsory social health insurance was 142.3 million people (almost $97.4 \%$ of the population) in 2009. About $41 \%$ of the insured were employed or self-employed and the non-working group accounted for about 59\% (i.e. children, students, pensioners, and the handicapped). The revenue for the compulsory social health insurance in 2009 
amounted to 551.5 billion Rubles (€13.94 billion) (Federal Compulsory Health Insurance Fund, 2010).

\subsection{Materials and methods}

To review the empirical evidence on the effects of the financial reforms in the Russian public healthcare sector, a literature review was carried out. The indicators used in this chapter to identify evidence for the analytical appraisal of the reforms include (Hurst, 1992; WHO, 1999.): financial sustainability, allocative and technical efficiency, equity in access and finance, and quality of care. Thus, six main keywords were used for the literature review: 'Russia'; 'Healthcare Reforms'; 'Financing'; 'Efficiency'; 'Equity'; 'Quality'. Synonyms and variations in spelling were considered. A truncation function was used to include all possible word combinations. The search for relevant publications with the above-mentioned keywords was conducted in the following databases: PubMed; ScienceDirect; and Google Scholar.

The list of publications obtained was further refined by a set of limitation and relevance criteria. The language of publications was limited to English and Russian. Another limitation criterion was to exclude articles that addressed the periods of the Russian healthcare reforms prior to 1991. In case of duplicate publications, preference was given to original studies and publications in peerreviewed journals. Publications were selected as relevant if they presented empirical evidence and results of the original studies on quality, equity, efficiency and sustainability in public healthcare provision due to the Russian healthcare reforms (micro-level parameters), as well as studies focusing on the patients' and physicians' attitudes towards the reforms. Based on the findings of the Government Social Research (Campbell et al., 2007) about what policy-makers considered as "evidence", the following range of sources were considered as such: quantitative/statistical evidence, economic evidence, survey, attitudinal and behavioral evidence, qualitative evidence, international evidence, social experiments/controlled trials, systematic reviews/meta-analysis, and consultations.

\subsection{Results}

The initial search yielded 63 articles and reports in English and 75 articles in Russian. However, most articles and reports gave only a description of the reforms focusing on the implementation aspects and/or figures from annual Federal Compulsory Health Insurance Fund statistics reports 
without additional analysis. They mainly included discussions and authors' personal views and perceptions about the ongoing changes and possible future improvements. Only 31 articles and reports in English and 6 articles in Russian met the relevance criteria (presenting evidence-based data) and were included in the literature review.

The characteristics of the publications included in the review are presented in Table 2.1. As indicated in the table, there is a growing number of evidence-based publications on the Russian public healthcare reforms since 1999. In English-language publications, attention is given to the entire reform period starting from 1991. The Russian articles mainly focus on the recent reforms after 1998 when the Guaranteed Package Program was implemented.

The publications mainly report data collected in the principal cities of the Russian Federation (Moscow, St. Petersburg, Sverdlovsk, Yekaterinburg, etc.), while inter-regional comparisons are lacking. Most of the publications aim to study the macro-parameters of the public healthcare system. The impact of the introduction of the compulsory social health insurance is also seldom stated as a direct aim of the study. As indicated in Table 2.1, the major findings reported in the publications are divided into the following sub-groups: financial sustainability, effects on efficiency, equity and quality of care. Each of these sub-groups is discussed separately.

\subsection{Overview of the results and discussion}

In 1991, the Russian public healthcare reforms faced challenges inherited from the previous Soviet healthcare system: an absence of effective mechanisms to equalize medical care across regions as well as inter-regional inequalities across income groups both in terms of financing and access to healthcare services. At present, the Russian Federation still faces challenges in terms of overall health indicators nationwide (i.e. life expectancy and mortality), as well as in terms of healthcare system indicators: the inter-regional variations in levels of funding, equity and access, quality and other indicators (Twigg, 2001; Tkatchenko et al., 2000; Liu et al., 1998). Patients were poorly informed about the reforms and mass media became the main source of information (Diukareva et al., 1997). The majority of patients accepted the necessity of the reforms, but their satisfaction with the insurance system is not high (Fotaki, 2006). Furthermore, there is a lack of continuity in the reforms (Twigg, 2002). The priorities of the reforms still appear to depend on the Heads of the Ministry of Healthcare and corroborate a principle that was and still is put into practice - "new lords, new laws". 
Table 2.1 Characteristics of evidence-based publications included in the review

\begin{tabular}{|c|c|c|}
\hline Characteristics of publications & $\begin{array}{l}\text { Number of } \\
\text { publications }\end{array}$ & References \\
\hline \multicolumn{3}{|l|}{ Year of publication } \\
\hline 1991-1998 & 7 & $\begin{array}{l}\text { English: } 18,22,24,32,33 \text { and } 44 \\
\text { Russian: } 19 \\
\text { English: } 1,2,6,16,17,20,21,26,27,28,29,34,35,36,37,38 \text {, } \\
39,40,41,42,43,45,46,49 \text { and } 51\end{array}$ \\
\hline 1998-2009 & 30 & Russian: 30, 47, 48, 50 and 52 \\
\hline \multicolumn{3}{|c|}{ Period addressed (data collection) } \\
\hline & & English: $17,18,22,24,32,33,35,42$ and 44 \\
\hline 1991-1998 & 10 & Russian: 19 \\
\hline 1998-2009 & 18 & $\begin{array}{l}\text { English: } 1,20,21,27,28,37,38,39,40,41,43,49 \text { and } 51 \\
\text { Russian: } 30,47,48,50 \text { and } 52\end{array}$ \\
\hline 1991-2000s & 9 & English: 2, 6, 16, 26, 29, 34, 36, 45 and 46 \\
\hline \multicolumn{3}{|l|}{ Type of publication } \\
\hline & & $\begin{array}{l}\text { English: } 2,6,16,17,18,20,21,22,24,28,33,34,35,36,37 \text {, } \\
38,39,41,44,45,49 \text { and } 51\end{array}$ \\
\hline Journal article & 28 & Russian: $19,30,47,48,50$ and 52 \\
\hline Report & 7 & English: 1, 26, 29, 32, 40, 43 and 46 \\
\hline Policy note & 1 & English: 27 \\
\hline Unpublished manuscript & 1 & English: 42 \\
\hline \multicolumn{3}{|l|}{ User perspective } \\
\hline & & English: 20, 33, 40 and 44 \\
\hline Population perspective & 8 & Russian: 19, 30, 47 and 48 \\
\hline & & English: 21, 35 and 51 \\
\hline Doctor's perspective & 7 & Russian: $19,48,50$ and 52 \\
\hline \multicolumn{3}{|l|}{ Type of empirical data } \\
\hline & & English: 7, 18, 24, 26, 27, 28 and 46 \\
\hline \multirow[t]{2}{*}{ General statistics } & 8 & Russian: 30 \\
\hline & & $\begin{array}{l}\text { English: 1, 6, 20, 21, 22, 27, 29, 32, 33, 35, 36, 37, 38, 39, 40, } \\
41,42,43,44,49 \text { and } 51\end{array}$ \\
\hline \multirow[t]{2}{*}{ Survey/poll/interviews } & 25 & Russian: 19, 47, 50 and 52 \\
\hline & & English: 2, 16, 17 and 45 \\
\hline Mass media/publications review & 5 & Russian: 48 \\
\hline Case studies & 3 & English: 34, 36 and 49 \\
\hline \multicolumn{3}{|l|}{ Classification of major findings } \\
\hline Financial sustainability & 13 & $\begin{array}{l}\text { English: } 1,2,6,21,22,23,24,25,26,27,29 \text { and } 32 \\
\text { Russian: } 30\end{array}$ \\
\hline Effects on efficiency & 8 & English: 1, 21, 26, 27, 28, 33, 34 and 35 \\
\hline Equity of care & 25 & $\begin{array}{l}\text { English: } 1,4,6,7,16,21,22,26,27,28,29,32,33,36,37,38, \\
\text { 39, 40, 41, 42, 43, 44, 45, } 46 \text { and } 49 \\
\text { English: 1, 4, 20, 21, 33, 40, 41, 44, } 49 \text { and } 51\end{array}$ \\
\hline Quality of care & 15 & Russian: $19,47,48,50$ and 52 \\
\hline
\end{tabular}

Note: The list of publications included in the review can be found in Appendix B. 


\subsubsection{Effects on financial sustainability (system funding)}

The transition to a solely insurance-based system in the Russian public healthcare sector continues. The implementation of the compulsory social health insurance had a positive and stabilizing influence during the financial crises and helped maintain the sustainability of the system financing (Chernichovsky et al., 1996a; Chernichovsky et al., 1996b; Shishkin, 1998). Nevertheless, the compulsory social health insurance funds remain insufficient to cover the necessary system costs (Twigg, 2002; Twigg, 1998; Tompson, 2007; World Bank, 2008). This indicates that shifting solely to single-channel financing (i.e. only via compulsory social health insurance funds) is unfeasible at present. Moreover, practical experience from CEE countries with transitional economies suggests that a multiple-channel model of financing could be more politically feasible (Rechel \& McKee, 2009).

Government expenditure on healthcare was declining in the 1990s and rose in real terms only since 2006 (World Bank, 2008). The share of the federal budget for healthcare financing remained at about the same level during the past decade and fluctuated between $2.7 \%$ and $3.6 \%$ of GDP (Besstremyannaya, 2009a). The current health expenditure-to-GDP ratio in Russia is typical for a middle-income country (OECD, 2006; Tompson, 2007; World Bank, 2008; Tragakes \& Lessof, 2003; Starodubov \& Flek, 2007). Moreover, the healthcare sector is financed at a level of only about $40-50 \%$ of actual needs (Starodubov \& Flek, 2007). The gaps in system funding are being filled by legal out-of-pocket payments, as well as questionable quasi-formal payments. The share of out-of-pocket expenditure as a percentage of total expenditure on health increased from $30.0 \%$ (2000) to 35.4\% (2011) (WHO, 2013). Informal (under-the-table) payments were also reported as substantial, i.e. in 1997, 15.4\% of household expenditures on medication and medical services were made informally (Boikov et al., 1997; Feeley et al., 1999). Overall, the share of household income spent on healthcare services and medication increased in the period from 1994 to 2005 (Blam \& Kovalev, 2006; WHO, 2013).

\subsubsection{Effects on efficiency}

The introduction of a healthcare insurance mechanism established the purchaser-provider separation in the Russian public healthcare sector. However, this initial measure alone did not provide enough incentives to healthcare providers and insurance companies to plan and purchase healthcare provision efficiently (OECD, 2006; Tompson, 2007; World Bank, 2008). 
During the crisis period of the 1990s, hospitals were forced to search for more efficient ways to overcome the lack of funding due to gross short-falls in revenues compared to costs. As a result, some hospitals created and used non-market mechanisms, like manipulating debts and barter (Isakova et al., 1995; Sheaff, 2005). Still, several reports concluded that cost-control was not, and is still not, at the center of the reforms. Funds were and are poorly allocated, and inefficiently administered within regions (OECD, 2006; Tompson, 2007; World Bank, 2008). Local government expenditure on healthcare varies relative to gross regional product between $2 \%$ and $15 \%$. Despite inter-regional variation in local government spending as a percentage of GDP, outcomes in health and social protection are similar between regions, regardless of the associated level of expenditure (World Bank, 2008). This indicates significant efficiency differences between regions (World Bank, 2008) or could reflect similar spending on healthcare per capita between regions combined with regional differences in GDP per capita. Even though a rise in public healthcare funding could possibly affect macro-indicators (Besstremyannaya, 2009a), there is still a need to alter the cost structure while stimulating efficiency improvements (OECD, 2006; Tompson, 2007; World Bank, 2008).

Surveys identified that the heads of the private and state territorial insurance funds shared common issues, which they believed were impeding efficiency. The most important issue included the lack of management skills, and the prevailing and political role of the government in healthcare financing and administration, and, to a lesser extent, resistance from physicians (Twigg, 1999). In 2002, a survey was conducted to elucidate some of the sources of support for and resistance to changes in healthcare financing. The results showed that physicians, to a greater extent than heads of state territorial funds, considered that competition between providers was impossible due to a tight vertical structure (Twigg, 2002).

Overall, our review did not find publications that described the implementation of any costcontainment mechanisms or that specifically addressed allocative and technical efficiency.

\subsubsection{Effects on equity}

After 1991, free access to the majority of healthcare services remained every citizen's right. This right was later enhanced to include the right of every patient to choose between insurance companies and care providers (OECD, 2006; Government of the Russian Federation, Federal Law 
No. 1499-1, 1991). Nonetheless, and as early as 1994, it was shown that there was a lack of freedom to choose the physician and medical facility (Isakova et al., 1995). Also, the choice of insurer was actually made mainly by the employer, not by the employee (OECD, 2006; Fotaki, 2006). In the beginning, insurance coverage was largely a function of geographic location and employment status, with higher coverage among the wealthier population. This trend gradually changed to a more equal distribution (Blam \& Kovalev, 2006; Tragakes \& Lessof, 2003; Balabanova et al., 2003), and currently almost $97.4 \%$ of the Russian population is insured (Federal Compulsory Health Insurance Fund, 2010).

Nevertheless, universal access and equity in financing, and access to healthcare services, are still impeded by inequalities between income groups (social-economic status) and regions (geographical location), as well as by the presence of informal and out-of-pocket payments (OECD, 2006; Blam \& Kovalev, 2006, Tompson, 2007; Besstremyannaya, 2009a; Tragakes \& Lessof, 2003; Balabanova et al., 2003; Lohlein et al., 2003; Fotaki, 2009). Patients may receive medical services either free of charge or by paying an official formal payment (service fee), or by making a shadow payment (gift or money) (Besstremyannaya, 2009a; Fotaki, 2009; Balabanova et al., 2004; TACIS, 2000; Aarva et al., 2009). According to data from the RLMS-HSE (1992-2003), the differences in access between income groups were rising until 1998, and were still pronounced in 2002. Since 2003, significant differences exist only for medications (Blam \& Kovalev, 2006; Tragakes \& Lessof, 2003; Balabanova et al., 2003). Still, it was suggested that both formal and informal payments have led to more unequal access to public healthcare services (OECD, 2006; Tompson, 2007; World Bank, 2008; TACIS, 2000).

Out-of-pocket payments were used to gain quicker access or better quality, while some users of chargeable services had no other choice but to pay for the service, or had to pay for services that were declared as free (Fotaki, 2009; Aarva et al., 2009). Out-of-pocket payments appeared to be regressive and imposed a heavier burden on groups with a lower social-economic status. As a result, these groups tended to forgo a recommended drug, outpatient medical and diagnostic care, or reject hospital admission due to a lack of money (Boikov et al., unpublished; Balabanova et al., 2004; TACIS, 2000). Informal payments were also more frequently reported by citizens with lower social-economic status, while formal payments were more typical for groups with high income (Aarva et al., 2009). Formal payments were more common in wealthier regions, whilst informal payments were more likely in less wealthy ones. Households living in the principal cities were also likely to spend less for medical care compared to other regions, both absolutely and proportionately 
(OECD, 2006; Tompson, 2007; World Bank, 2008; Boikov et al., unpublished; TACIS, 2000; Feeley et al., unpublished).

Inter-regional variation in access could be related to regional variations in healthcare financing and the stage of implementation of healthcare reforms in a region (Twigg, 2001; Kringos et al., 2009). For example, there were variations in the costs per service and ability-to-pay for services among regions, both formally and informally (Chernichovsky et al., 1996a; Brown \& Rusinova, 1997). However, inter-regional inequalities could be also caused by geographical remoteness from the capital and the fact that a limited number of highly specialized hospitals are mainly located in the largest cities (Danishevski et al., 2006). For instance, empirical evidence indicated that modern equipment and medication had limited availability and secondary care became less accessible in rural areas (USAID, 1999).

A more specific analysis of the determinants of access to healthcare services in two rural areas showed, for instance, that income did not actually influence or determine access and demand for healthcare in some regions. At the same time, distance to the hospital reduced the probability of visiting a healthcare provider and confirmed that access to healthcare services varied between rural and urban areas. Moreover, access to healthcare services was not determined by ability to pay (Lohlein et al., 2003). Equally, heads of the Territorial Compulsory Health Insurance Funds were more confident than the head physician that high quality medical care was available regardless of ability to pay (Twigg, 2002).

\subsubsection{Effects on quality of provided care}

According to the concept of compulsory social health insurance, health insurance companies were supposed to control the volume, time and quality of the healthcare services provided, and to inform and protect the rights of the insured (OECD, 2006; Government of the Russian Federation, Federal Law No. 1499-1, 1991). However, insurers had little or no incentives to encourage better quality or greater efficiency (OECD, 2006). An economic survey conducted in 2006 showed that insurance companies were sometimes acting to uphold patients' rights ex-post when a patientprovider conflict had arisen. It was stressed that there were no actual incentives or capacities to press actively for better quality provision or greater efficiency ex-ante (OECD, 2006). 
Based on the results from several surveys, consumers and patients did not notice any or any significant changes in the quality of care since the introduction of social health insurance (Fotaki, 2006; TACIS, 2000). Consumers perceived quality of care as "poor" and were "rather dissatisfied" with their quality of care. This was due to several factors: long waiting time and queues (Isakova et al., 1995; Petrova et al., 2009); limited availability of modern medical equipment and medication, dissatisfaction with the quality of medical personnel, concern about physicians' competence and qualification (Brown \& Rusinova, 1997); high costs of pharmaceuticals, lack of necessary pharmaceuticals and equipment, bad nutrition, insufficient skills of physicians, bad sanitary conditions and others (TACIS, 2000; Kringos et al., 2009); expensive drug treatment, violation of patients' rights, propensity of under-the-table payments, and poor conditions of healthcare facilities (Filatov, 2003); the necessity to pay for a more convenient and better quality of care (Aarva et al., 2009). Other quality-related issues were a lack of evidence-based approaches in clinical decisionmaking, over-hospitalization, over-diagnosis and overmedication (Duke et al., 2006). This could be partially explained by the fact that at the beginning of the compulsory social health insurance implementation respondents from the general population were not sure that the reforms would improve quality of care (Isakova et al., 1995) and few expressed anxiety (even fear) about the situation (Brown \& Rusinova, 1997).

Similarly, surveys of providers of healthcare services revealed a lack of satisfaction with the quality of healthcare in their regions (Twigg, 2002; Akopian et al., 1999). Providers were also badly informed about healthcare documents, some process peculiarities in the new health insurance system and patients' rights, and expressed a general interest in the legal healthcare system and issues of quality of healthcare (Diukareva et al., 1997; Rekhter \& Togunov, 2006; Khisamutdinov \& Husnutdinova, 2003). Still, the vast majority of providers were in favour of ongoing economic reforms in the healthcare sector, but lacked the motivation to participate in the reforms due to various reasons (Diukareva et al., 1997; Twigg, 2002; Aarva et al., 2009; Rekhter \& Togunov, 2006; Khisamutdinov \& Husnutdinova, 2003).

\subsection{Conclusions}

In this chapter, we reviewed the empirical evidence on the effects of the financial reforms in the Russian public healthcare sector. We distinguished between the financial sustainability, efficiency, equity, and quality of care. Our review suggests that there is some evidence on the effects of the financial reforms. However, this evidence is not enough to conduct a thorough impact evaluation 
of the financial reforms. This is due to the limited number of studies and the limitations of each study (e.g. a lack of a clear indication of the validity and reliability of the analyses). However, our analysis has outlined several conclusions relevant to policy and research.

One of the positive aspects of the financial reforms is that currently most of the Russian population is being insured under compulsory social health insurance. The implementation of the compulsory social health insurance shifted public healthcare financing towards an insurance-based system and provided opportunities for future increases of efficiency by separating healthcare financing from healthcare provision. Also, the compulsory social health insurance system provided additional nonbudget revenues and helped to maintain the financial sustainability of the system. All reforms were and are aimed at maintaining free universal access to public healthcare services irrespective of place of residence and socio-economic status. Moreover, both patients and physicians expressed acceptance for the necessity of the reforms.

Still, there are many problems that require attention from the Russian government. Evidence suggests that the public healthcare sector is still underfinanced. There are substantial inter-regional inequalities across income groups both in terms of financing and access to public healthcare services. There are also large efficiency differences among regions, along with inter-regional variations in payment and reimbursement mechanisms. Informal and quasi-formal payments limit access to public healthcare services and undermine the overall financing sustainability. Patients still lack information about ongoing reforms and acquire information mainly from mass media. At the same time, patients have not yet noticed any or any significant changes in the quality of public healthcare services since the introduction of the social health insurance.

It could be argued that the content of the future reform initiatives should not only focus on an adequate level of financing and search for an optimal model of financing, but rather on the implementation of cost-efficiency and cost-control mechanisms. Future reforms should concentrate on the development of an effective and coherent framework that would tackle existing problems in equity in access and financing; provide incentives for better allocation and distribution; develop a clear policy addressing informal and quasi-formal payments; implement a system of quality controls; and stimulate healthy competition between insurance companies. There is also a need for impact evaluation analyses of these aspects of the healthcare reforms in the Russian Federation, which could serve as the basis for future evidence-based policy-making. 
Chapter 3

The impact of the 2005 social benefits reform in Russia on out-of-pocket expenditure on prescribed outpatient pharmaceuticals:

A difference-in-differences approach

Gordeev, V.S., Pavlova, M., Groot, W.

Submitted for publication 


\begin{abstract}
The social benefits reform of 2005 by the Russian government cashed-out (monetized) most of the in-kind benefits. However, the provision of prescribed outpatient pharmaceuticals to eligible federal beneficiaries remained in-kind. Nonetheless, the reform affected eligible pharmaceuticals mainly by abolishing the existing discounts, and by limiting and annually revising the list of pharmaceuticals available for in-kind outpatient provision (and by replacing the more expensive pharmaceuticals with cheaper generics). Additionally, as of 2006, federal beneficiaries were given the right to opt for in-cash in place of in-kind pharmaceutical provision.
\end{abstract}

Studies that evaluate the impact of these changes on the consumption of prescribed outpatient pharmaceuticals and related out-of-pocket expenditure during the reform and post-reform periods are still lacking.

Therefore, we evaluate the impact of the 2005 social benefits reform on out-of-pocket expenditure on prescribed or recommended pharmaceuticals base on a difference-in-differences method, using zero-inflated models. We use data from the RLMS-HSE survey. We find that the reform did not have a statistically significant impact on the amount of out-of-pocket expenditure paid by eligible beneficiaries. However, it did have a positive impact on the likelihood of incurring zero expenditure on these pharmaceuticals. The additional annual choice between in-kind and in-cash provision did not have a statistically significant impact either. There is no evidence that the reform made one better or worse off. 


\subsection{Introduction}

The ongoing debate about the provision of public services mostly revolves around two main choices: a choice between universal and targeted provision of services, and a choice between inkind and in-cash transfers (Currie and Gahvari, 2008). In most countries, a significant proportion of provision of public services occurs through in-kind rather than in-cash programs (OECD, 2007; Tesliuc, 2006). The short-term and long-term effects of in-kind programs (health, food and nutrition, housing, and childcare programs) on labor supply are well studied (Currie and Gahvari, 2008). Hitherto, studies that examine the possible effects of in-cash programs, as well as shifting between or replacing one type of provision of social and healthcare services with another (i.e. inkind with in-cash and vice versa) are scarce. In this regard, the Russian Federation could serve as a good object for study, since the government had to tackle the burden of extensive obligations in terms of in-kind provision of the public services (left over from the Soviet era), due to severe budget deficits and constraints, particularly during the transition period.

The Russian experience with the social benefits reform that took place in 2005 , is of particular interest. The reform cashed-out (monetized) most of the previously existing in-kind benefits. The changes brought by the reform affected millions of Russian beneficiaries, yet studies that evaluate and track effects of the reform during the extended post-reform period are still lacking. The studies that were conducted during the post-reform period mainly assessed the general design and reform implementation (Besstremyannaya, 2009b; Ovcharova, 2005; Volchkova et al., 2006; Alexandrova \& Struyk, 2007; Sinitsina, 2009; Wengle \& Rasell, 2008); reported on short-term adjustments that have arisen from the reform and its public perception (Besstremyannaya, 2009b; Hahulina, 2005; Alexandrova \& Struyk, 2007; Struyk et al., 2007; Wengle \& Rasell, 2008; Parfitt, 2007; Zasimova, 2010); and gave numerical estimations of benefit groups' behavior before and after the reform (Besstremyannaya, 2009b).

Following the social benefits reform of 2005, the provision of prescribed outpatient pharmaceuticals to eligible federal beneficiaries remained in-kind. However, the reform affected the eligible pharmaceutical provisions mainly by abolishing the existing discounts, and by limiting and annually revising the list of pharmaceuticals available for in-kind outpatient provision (also by replacing the more expensive pharmaceuticals with cheaper generics). Additionally, as of 2006, federal beneficiaries could also opt on a yearly basis for partial or full in-cash provision in place of in-kind benefits. 
To complement previously conducted studies and to take advantage of the available micro-level panel data, the impact of the social benefits reform of 2005 on out-of-pocket expenditure for prescribed or recommended pharmaceuticals was evaluated. Since the social benefits reform of 2005 did not introduce the targeted categorical social assistance to low-income groups within the defined benefits (Alexandrova \& Struyk, 2007), it was hypothesized that the reform did not have a significant effect on out-of-pocket expenditures on prescribed or recommended pharmaceuticals among eligible federal beneficiaries. The hypothesis was tested by creating a quasi-experimental setting and applying a difference-in-differences (DID) method, using zero-inflated models. We compare two groups - those entitled to free or discounted pharmaceutical provision at a federal level (treatment group) and those who were not entitled at a federal level (control group). We use data from the RLMS-HSE (see Chapter 1, Section 1.6). Our findings can be useful for other countries where the choice between in-kind and in-cash benefit provision is an item on the policy agenda. Also, to the best of our knowledge, no other study offers an analysis of the Russian data on social benefits using a DID approach.

\subsection{Background}

\subsubsection{The 2005 social benefits reform in the Russian Federation}

Modern Russia inherited the system of privileges in the healthcare sector and social systems as a legacy from the Soviet era. By 2004, approximately 120 types of privileges (i.e. monetary compensations, discounts for transportation, housing and medication) were used by more than 200 categories of favorable groups of citizens (beneficiaries) (Alexandrova \& Struyk, 2007; Ministry of Finances of the Russian Federations, 2012; Sinitsina, 2009). Besides "traditional" beneficiaries (pensioners, war veterans, and citizens with disabilities), privileges were awarded to citizens on the basis of meritorious service or occupation (e.g. employees of civil and armed services or those moving to strategically important or remote areas), but not based on income. As such, privileges were neither designed to serve as social assistance or relieve hardships, nor were they exclusively awarded to low-income consumers (Struyk et al., 2007; Wengle \& Rasell 2008; Besstremyannaya, 2009b).

With almost $70 \%$ of the population being entitled to some sort of privileges and over a quarter of the Russian population being eligible for in-kind benefits resulting from the privileges (World Bank, 2004; Shenberg, 2005), the system of privileges was very complex. Numerous problems with provision, effectiveness, equity in access to privileges, and transparency of the financial flows (Alexandrova \& Struyk, 2007; World Bank, 2004; Wengle \& Rasell, 2008) pointed to the necessity 
of reform. Such reform took place in 2005, following the ratification of the Federal Law No. 122 (Government of the Russian Federation, Federal Law No. 122, 2004), that was rushed through the legislative bodies in 2004 .

The 2005 social benefits reform was intended to increase consumer choice; bring financial and administrative clarity; make the system of benefits more manageable; increasing the efficiency of public expenditures on social services; fostering transparency in relations between the federal/regional budgets and service providers; and making expenditures on benefits more predictable (Alexandrova \& Struyk, 2007; Sinitsina, 2009). To do so, as of 2005, the budgetary responsibilities for financing social protection mandates were delineated between federal and regional funding, while social mandates that remained unfunded were eliminated. The categories of the beneficiaries were revised and split into "federal" and "regional" groups, according to the financial responsibilities of budgets. The federal category includes disabled WW II veterans; WW II participants; combat veterans; family members of deceased WW II invalids; disabled adults (IIII groups) and handicapped children; and victims of technogenic radiation catastrophes. The regional group includes home-front workers during WW II; labor veterans; victims of political repressions and rehabilitated persons; heroes of the Soviet Union; people employed in special risk units and doing hard manual work; and persons entitled to benefits according to professional affiliation (Federal Law No. 122, 2004).

In practice, most of the in-kind benefits at the federal level were replaced by monthly cash compensations to eligible individuals. The benefits and compensations at the regional level were to be defined by regional authorities (Alexandrova \& Struyk, 2007; Volchkova et al., 2006; Sinitsina, 2009). Thus, the exact size of the monthly cash compensations received by eligible individuals and the availability of benefits (e.g. discounted services) became dependent on regional administrations and available local funds (Wengle \& Rasell, 2008).

Despite the ambitious reform goals, it seemed that the Russian government did not make use of the data from surveys conducted prior to the implementation of the reform (Besstremyannaya, 2009b), such as data for 2003 from the National Assessment of Population Welfare and Participation in Social Programs household survey (NOBUS, 2003) and from the RLMS-HSE surveys (RLMS-HSE, 2013) ${ }^{1}$. Scientific reports with simulations and forecasts of possible gains and

\footnotetext{
${ }^{1}$ NOBUS was a country-wide nationally and regionally representative survey of 45,000 household, which specifically focused on socio-economic characteristics. Data from NOBUS could potentially have been used to predict possible consequences of the reform implementation, since it provided data regarding beneficiaries. The RLMS-HSE is a yearly national representative household survey that covers almost 15,000 respondents and 4,000 households. The RLMS-HSE data is not regionally representative.
} 
losses by beneficiaries and case studies appeared also only after the 2005 social benefits reform was actually implemented (e.g. Alexandrova \& Struyk, 2007; Besstremyannaya, 2009b; Hahulina, 2005; Ovcharova, 2005; Sinitsina, 2009; Struyk et al., 2007; Volchkova et al., 2006; Wengle and Rasell, 2008). The overall number of beneficiaries was not reduced significantly and most categories of beneficiaries remained unchanged (Wengle \& Rasell, 2008; Sinitsina, 2009). Moreover, the real number of in-kind beneficiaries exceeded the budget plans and this led to a fiscal crisis already at the beginning of 2005 (Besstremyannaya, 2009b; Alexandrova \& Struyk, 2007; Sinitsina, 2009). Demand-prediction problems later resulted in a demand-supply imbalance and corresponding budgetary deficits both on the federal and regional level.

The changes brought by the 2005 social benefits reform were implemented at short notice, with a lack of information about the changes and proper outreach, which led to waves of social unrest (Alexandrova \& Struyk, 2007; Hahulina, 2005). Therefore, it is not surprising, that the vast majority of the population believed that the reform was not well thought out and prepared; saw the reform doing more harm than good; and almost half believing that it adversely affected beneficiaries (Hahulina, 2005). Overall, previous studies suggest that the reform had very limited effects, compared to what it could have achieved (Alexandrova \& Struyk, 2007). The reform implementation did not equalize the expenditure of most risk groups with the rest of the population, but continued to favor middle and high-income consumers living in better regions (Besstremyannaya, 2009b).

\subsubsection{Provision of the in-kind outpatient prescribed pharmaceuticals}

Some "vital" privileges of federally favored groups retained their in-kind form and formed a "set of social services" (natural benefits package). This natural benefits package included two components: (a) additional free-of-charge health services (consisting of outpatient prescribed pharmaceutical provision; medical aids; specialized dietary products for handicapped children; and health-resort treatment packages) and (b) free-of-charge suburban railway commuting, as well as free-of-charge return-journey travel by intercity transport to a place of treatment. The monthly monetary value of the natural benefits package in 2005 was estimated at 450 Rubles (ca. €13): 400

Rubles for free-of-charge health services and 50 Rubles for commuting costs (ca. $€ 11.5$ and $€ 1.5$ respectively). This amount was subtracted from the monthly monetary payments described earlier and all benefits included in the package were provided in-kind. 
Although some privileges remained within the natural benefits package, the 2005 social benefits reform changed the provision of such privileges. For instance, free or discounted guaranteed provision of prescribed outpatient pharmaceuticals for federal beneficiaries was replaced with a revised and redefined but limited list of pharmaceuticals available for in-kind outpatient prescription. In 2004, the initial list contained 322 pharmaceutical items (Order No. 296, 2004). Later, mainly due to growing costs, the list was frequently revised and adjusted by extensions and/or reductions - including more vitamins and specific pharmaceuticals, and excluding expensive pharmaceuticals and/or replacing them with cheaper generics (Besstremyannaya, 2009b; Zasimova, 2010).

Mainly due to the underestimation of the number of beneficiaries, changes brought by the 2005 social benefits reform led to a severe demand-supply imbalance and an increased demand for pharmaceuticals (Parfitt, 2007; Besstremyannaya, 2009b). As of 2006, federally favored beneficiaries gained the right to choose on a yearly basis between keeping and receiving the natural benefits package in-kind and opting for partial or full monetary compensation of the latter (when refusing one or both of the components of the natural benefits package). Giving such choice further increased the demand for pharmaceuticals; leading to an adverse selection within the inkind pharmaceuticals provision system and a decrease in equity and solidarity among people (Parfitt, 2007; Besstremyannaya, 2009b). Consequently, funds available for reimbursement failed to cover supplier costs, and the first months of 2007 were marked by a shortage of pharmaceuticals across the country (Zasimova, 2010). By the end of 2007, the social service system was almost in a state of collapse (Partiff, 2007).

Overall, budget deficits led to a significant indebtedness of the federal budget towards chemists and pharmacies, which in return affected the quality of pharmaceutical assistance. In turn, this further contributed to the demand-supply imbalance. In general, there is no evidence that the population benefited from the reform (Wengle \& Rasell, 2008), as the old system of pharmaceutical provision was cheaper and the new system required more financing (Volchkova et al., 2006). With no obvious substantial benefits, this reform seemed to be an expensive policy-changing exercise

\subsection{Data}

As mentioned earlier, data from the RLMS-HSE has been used. Among others, the RLMS-HSE questionnaires contain questions related to healthcare utilization and healthcare related expenditure, including out-of-pocket expenditure on the prescribed or recommended 
pharmaceuticals in the last 30 days (RLMS-HSE, 2013). However, only two rounds of the RLMSHSE contain questions that specifically address the eligibility of federal respondents for the social benefits package, including in-kind provision of prescribed pharmaceuticals. No similar questions are available for regional beneficiaries. The $14^{\text {th }}$ round of the RLMS-HSE (2005) contains questions regarding the eligibility and the provision of the in-kind outpatient prescribed pharmaceuticals in 2005. The $16^{\text {th }}$ round of RLMS-HSE (2007) complements the $14^{\text {th }}$ round by asking similar questions regarding eligibility for the same benefits during the period of 2005-2007, and additionally by enquiring which type of provision of pharmaceuticals (in-cash or in-kind) was chosen by the eligible respondents in 2006-2007. In total, 2,553 respondents gave answers regarding their eligibility to social benefits in 2005-2007. This particular set of individuals formed the sample for analysis in this chapter.

For the analysis, we constructed a panel dataset, where reform and post-reform periods (20052007) served as the base, complemented by data for the same individuals from the pre-reform period (2003-2004). Respondents who stated that they were entitled to federal social benefits in 2005-2007, were included in the treatment group and those not entitled formed the control group. More specifically, for 2005, the treatment group included respondents eligible to receive in-kind or discounted prescribed outpatient pharmaceuticals. In 2006-2007, this group included individuals who were entitled to either in-kind or in-cash provision of the benefits, depending on the choice they made.

Socio-economic characteristics included gender, age, educational level (low, middle, and high), living alone, working status, urban/rural area, receiving pension, presence of disability and/or at least one chronic disease. To allow for a flexible relationship between the outcome of interest and age, age squared was included in the model as well. Five income quintiles were distinguished based on adult equivalent household income, which was calculated as a total household income divided by the square root of the number of household inhabitants (Atkinson, 1995). The square root of the number of household members is used to correct for economies of scale in household expenditures. The dependent variable reflected out-of-pocket expenditure on recommended or prescribed pharmaceutical in the last 30 days. Both income and expenditure values were deflated using a CPI index (Global rates, 2012). 


\subsection{Analytical methods}

The effects of the social benefits reforms of 2005 were estimated by comparing the out-of-pocket expenditure on pharmaceuticals before and after the reform, using a DID approach. The essence of the DID method is a comparison of differences in average behavior of two groups with similar characteristics in pre- and post-reform periods (Blundell \& Costa Dias, 2009). The group affected by the reform (in this analysis, the group of eligible federal beneficiaries) is referred to as a "treatment" group. Another group that is unaffected by the reform (the group of those not eligible for federal benefits) is taken as a "control" group.

Several studies in health economics used a DID approach to measure the effect of insurance reform or introduction of (co-)payments in Belgium, England, Germany and China (Cockx \& Brasseur, 2003; Farrar et al., 2009; Schreyögg \& Grabka, 2010; Winkelmann, 2004; Zhang, 2007; Zhang, 2010). In our analysis, we used the following model:

$y_{i t}=\beta_{0}+\beta_{1} d_{i}+\beta_{2} t+\beta_{3}\left(d_{i} x t\right)+\beta_{4} Q_{i t}+\varepsilon_{i t}$

where $y_{i t}$ is the outcome variable for person $i$ at time $t$ as defined above (i.e. the out-of-pocket expenditure on prescribed or recommended pharmaceuticals in the last 30 days). $\beta_{0}$ is the constant term. $d_{i}$ is the treatment vector taking the value of 1 for those eligible for benefits, and 0 for those who did not receive benefits. Thus, the coefficient $\beta_{1}$ captures possible differences between the treatment and control groups prior to the policy change. Variable $t$ is the time period dummy that takes the value 1 for observations after the reform, and 0 for observations before the reform. Coefficient $\beta_{2}$ captures the effect of aggregate factors that would cause changes in $y_{i t}$ even without the policy reform. $\beta_{3}$ is the coefficient of interest, i.e. the DID estimator, that captures the effect of the reform. If it is significant and negative, out-of-pocket expenditure in the treatment group is lower relative to the control group after the reform and vice versa. $\mathrm{Q}_{\text {it }}$ represents a variety of socioeconomics characteristics that we control for, while $\varepsilon_{i t}$ is the stochastic error term.

The DID method assumes that treatment and control groups will ideally have similar characteristics and differ only in whether or not the change of policy affects them. In practice, differences can exist in both observed and unobserved characteristics (e.g. unobservable individual effects, common macro effects, and temporary individual specific effect). Another important assumption for the DID method is that in the absence of the reform, the unobserved differences between the two groups would be the same (fixed) over time. Hence, to apply the DID method it should be 
possible to assume that there is a common time effect across groups and no composition changes within each group (Blundell \& Costa Dias, 2000; Bertrand et al., 2004). While comparing the two groups, the average change in the outcome variable is estimated before and after the reform, not the absolute differences. Thus, eventually, the difference in the changes over the time (or DID) is estimated.

We constructed two main DID estimators, each of which was related to a pre-post change in outof-pocket expenditure on the prescribed or recommended pharmaceuticals in the last 30 days for the 2004/2005 and 2004/2006 periods. The DID estimator for 2004/2005 reflects the effect of the reform upon the implementation in 2005. The alternative DID specification for 2004/2006 controls for possible bias due to a transitional period upon the reform implementation in 2005 . Additional DID estimators for the periods of 2003/2004, 2003/2005, 2005/2006, 2006/2007, as well as for the pooled data of 2003-2004/2005-2007, were constructed to check for the consistency of our results, control for possible bias in 2004 due to available information about the upcoming reform, and to test whether the common trend assumption necessary for DID estimations held true. All DID estimators were calculated with and without covariates (socio-economics characteristics). We did not distinguish between in-kind and in-cash benefit recipients for 20062007 years. The "switching" behavior between in-kind and in-cash provision occurred in less than $10.3 \%$ of cases. Thus, estimation of the effect of the choice of the specific type of benefit provision (in-cash vs. in-kind) was outside the scope of this dissertation.

The excess zeroes were an issue as ca. 34\% of the respondents received but did not pay for prescribed or recommended outpatient pharmaceuticals during the last 30 days. Therefore, our dependent variable was skewed to the right. The literature suggests several estimation techniques to deal with such type of data - such as Poisson, negative binominal, two-parts (hurdle), and zeroinflated models (Long \& Freese, 2006). The application of Poisson, negative binominal, and hurdle models implies that all respondents have some probability of paying any given amount for prescribed outpatient pharmaceuticals. Applying zero-inflated count models changes the mean structure to allow for zeroes (non-payers) to be generated by two distinct processes. Therefore, we expect to have two latent groups - those who never pay and those who might or might not pay for pharmaceuticals. Whilst choosing the best-fitted models, we based our choice on a comparison of Akaike's and Bayesian information criteria (AIC and BIC), as well Vuong and the chi-square (LR $\chi 2$ ) likelihood ratio tests for model selection, where appropriate (Long \& Freese, 2006; Vuong, 1989). In all tested models, the likelihood ratio test that alpha is significantly different from zero could 
not be rejected, suggesting that the data are over-dispersed and that zero-inflated negative binomial models are more appropriate than zero-inflated Poisson models. Similarly, the Vuong test suggested that the zero-inflated negative binomial models are a significant improvement over a standard negative binomial model. Therefore, the best-fitted models are obtained using zeroinflated negative binominal models. A similar approach for DID estimations with excess zeroes was previously used in an application to the number of physician visits (Schreyögg \& Grabka, 2010). Both descriptive and regression analyses are performed using STATA 12.

\subsection{Results}

For 2005, 2006 and 2007, the treatment group includes 1245, 1330, and 1399 respondents. Similarly, the control group includes 1290, 1206, and 1136 respondents, respectively (Table 3.1).

As reflected in Figure 3.1, 18.5\%-23.1\% of the respondents in the control group are prescribed or recommended to buy pharmaceuticals during 2002-2007. This share is higher among the treatment groups $-34.9 \%-47.6 \%$. The vast majority of respondents in both groups are able to find and buy pharmaceuticals in the last 30 days, and this trend is consistent over the years. Prescribed and recommended pharmaceuticals are slightly more accessible among those belonging to the control group. The share of those who pay for these pharmaceuticals ranges from $90.6 \%$ to $93.1 \%$ for respondents in the control group, and remains within 61.9\%-71.2\% range among respondents in the treatment group, dropping sharply only in 2005 to $42.9 \%$.

The share of beneficiaries who opt for in-cash provision increases from $43.4 \%-47.3 \%$ in 20062007 to $52.7 \%$ in 2008. Given the choice between in-kind and in-cash provision, $7.9 \%$ and $2.5 \%$ of respondents indicate that in 2007 they have opted for in-cash (in place of in-kind) and in-kind (in place of in-cash) provision of benefits, respectively. These figures are higher in 2008 and constitute $16.4 \%$ of beneficiaries who would "switch" to in-cash and 10.2\% to in-kind provision of pharmaceuticals, compared to the previous year. Overall, beneficiaries state that benefits they are entitled to (whether in-cash or in-kind), are provided "in time" in $64.5-74.1 \%$ of cases, with $8.7-7.7 \%$ of beneficiaries not using benefits, for one reason or another. 
Table 3.1 Overview of the sample in 2005

\begin{tabular}{|c|c|c|}
\hline Characteristics & Treatment group & Control group \\
\hline Number of respondents & $1255(100 \%)$ & $956(100 \%)$ \\
\hline Age (years), mean $\pm \mathrm{SD}$ & $64.15 \pm 16.06$ & $62.00 \pm 14.67$ \\
\hline Age squared, mean $\pm \mathrm{SD}$ & $4373.88 \pm 1834.11$ & $4060.06 \pm 1596.82$ \\
\hline Gender, male (N, \%) & $460(36.7 \%)$ & $301(31.5 \%)$ \\
\hline \multicolumn{3}{|l|}{ Education } \\
\hline Education, low (N, \%) & $495(39.5 \%)$ & $299(31.1 \%)$ \\
\hline Education, middle (N, \%) & $562(44.9 \%)$ & $430(45.0 \%)$ \\
\hline Education, high (N, \%) & $196(15.6 \%)$ & $226(23.7 \%)$ \\
\hline Urban, yes $(\mathrm{N}, \%)$ & $841(67.0 \%)$ & $697(72.9 \%)$ \\
\hline \multicolumn{3}{|l|}{ Family } \\
\hline Living alone, yes (N, \%) & $299(23.8 \%)$ & $185(19.3 \%)$ \\
\hline Family with adults only, yes (N, \%) & $758(60.4 \%)$ & $599(62.7 \%)$ \\
\hline Family with children, yes (N, \%) & $198(15.8 \%)$ & $172(18.0 \%)$ \\
\hline Work, yes (N, \%) & $202(16.1 \%)$ & $335(35.0 \%)$ \\
\hline Pension, yes (N, \%) & $1183(94.3 \%)$ & $832(87.0)$ \\
\hline Disability, yes $(\mathrm{N}, \%)$ & $867(69.1 \%)$ & $54(5.7 \%)$ \\
\hline Chronic sickness, yes (\%) & $1088(86.7 \%)$ & $663(69.4 \%)$ \\
\hline \multicolumn{3}{|l|}{ Household income per capita, Rubles, mean \pm SD } \\
\hline Quintile 1 & $1541.70 \pm 427.22$ & $155230 \pm 400.15$ \\
\hline Quintile 2 & $2586.28 \pm 261.21$ & $2618.07 \pm 267.23$ \\
\hline Quintile 3 & $3600.74 \pm 354.75$ & $3602.12 \pm 337.25$ \\
\hline Quintile 4 & $5100.27 \pm 565.42$ & $5091.22 \pm 603.43$ \\
\hline Quintile 5 & $10107.14 \pm 11212.15$ & $9323.37 \pm 4427.19$ \\
\hline
\end{tabular}

Source: Author's analysis of data from RLMS-HSE.

Note: $€ 1=34.14$ Rubles in 2009. 
Figure 3.1 Prescription, ability to find and payments for prescribed or recommended pharmaceuticals in the treatment and control groups

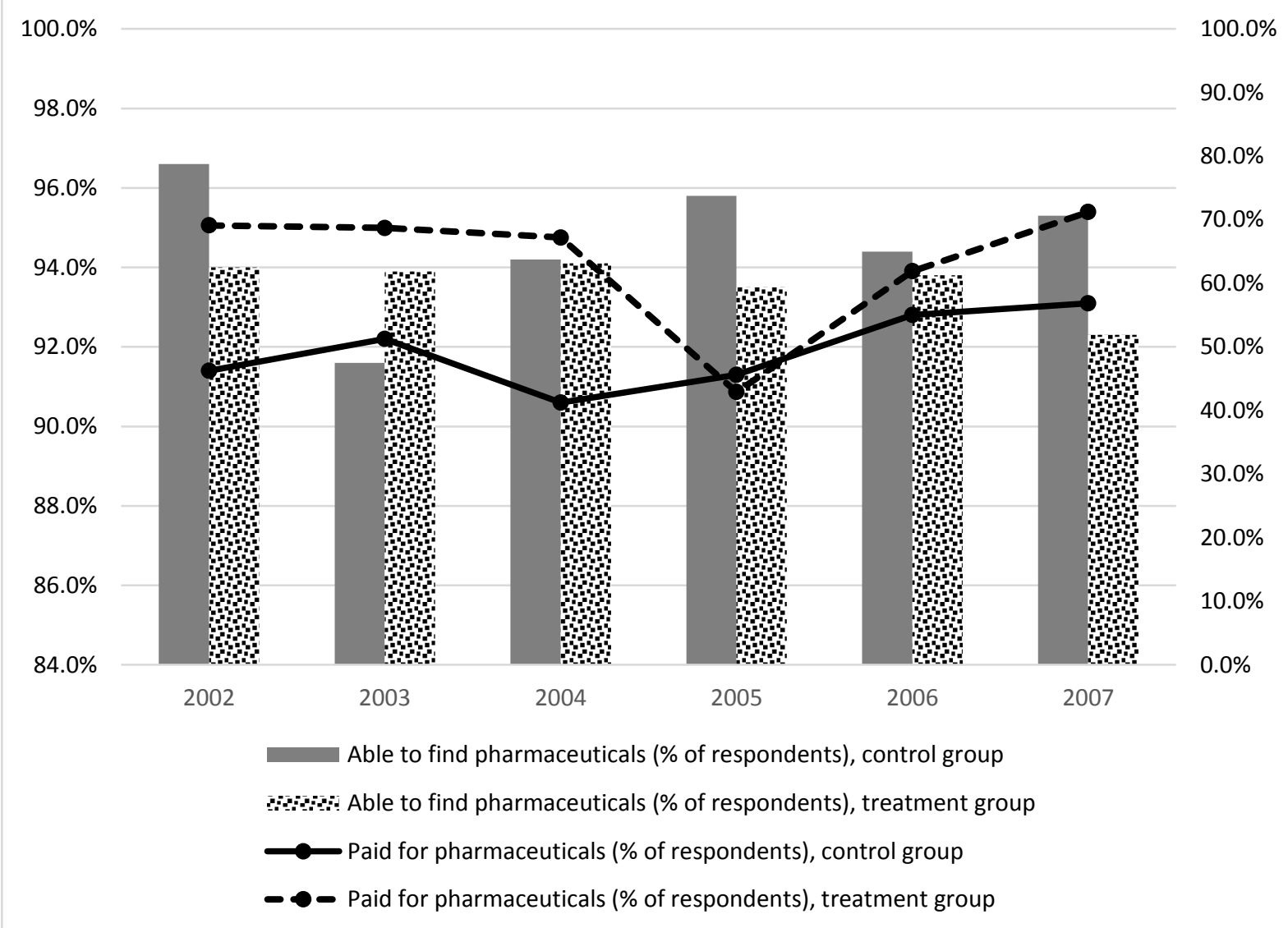

Source: Author's analysis of data from RLMS-HSE.

Figure 3.2 shows how the means for out-of-pocket expenditures on prescribed or recommended pharmaceuticals develops between 2002 and 2007 in both groups, expressed in real values of Rubles deflated using CPI to prices in 2000 (RateInflation, 2013). The black line denotes the average out-of-pocket expenditure on the prescribed or recommended pharmaceuticals in the last 30 days among those who have paid for pharmaceuticals. The grey line accounts for all users, including those who have received pharmaceuticals in-kind.

Over time, respondents in both groups pay more for prescribed or recommended pharmaceuticals. When paying in-cash, respondents belonging to the control group seem to pay less than those in the treatment group. This tendency however is different when the analysis accounts for all beneficiaries, including those who have received pharmaceuticals in-kind and, thus, incurred zero expenditure. Figure 3.2 illustrates that the mean expenditure of respondents from the treatment group over the years is lower than for control group. There is also a dip in the mean out-of-pocket 
expenditure in 2005 in the treatment group, when all users are included in the analysis. However, the decrease in the expenditure is not statistically significantly different from the previous years. This dip disappears in 2006-2007 - the period when eligible individuals from the treatment group were given a choice between the in-cash and the in-kind provision of pharmaceuticals.

Figure 3.2 Out-of-pocket expenditure on prescribed or recommended pharmaceuticals in the last 30 days (* real value, deflated to 2000 based on CPI)

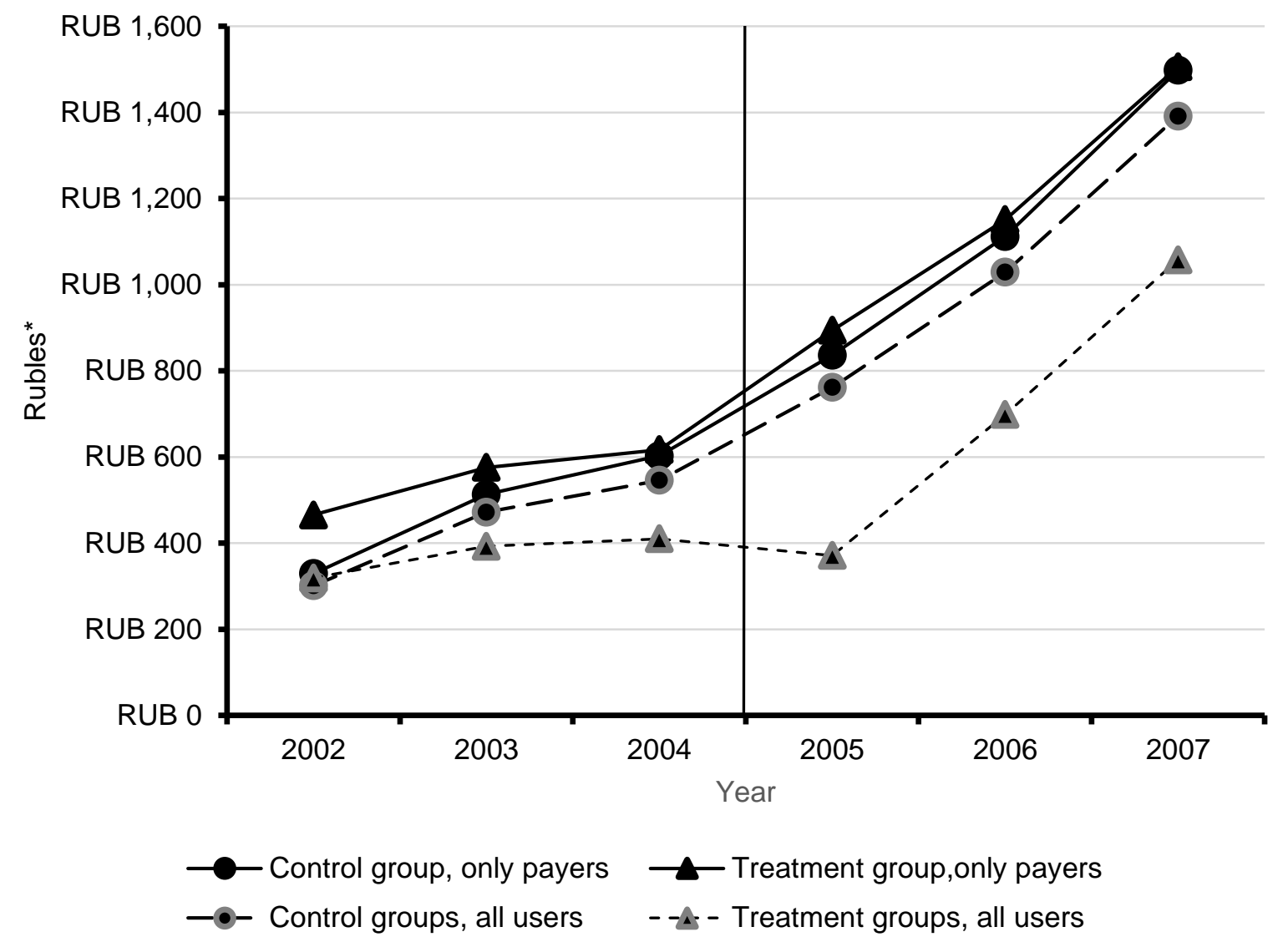

Source: Author's analysis of data from RLMS-HSE.

Table 3.2 summarizes the results of the DID estimations from various models with covariates based on individual-level data, with out-of-pocket expenditure on the prescribed or recommended pharmaceuticals in the last 30 days as a dependent variable. The table includes two parts. The first part (negative binomial regression) contains the negative binomial regression coefficients of the DID estimator for each time period, where the coefficient shows the factor change in the expected amounts of out-of-pocket payments for those who might or might not pay for pharmaceuticals (not always zero group). This coefficient can be interpreted in the same way as the coefficients from the Poisson or negative binominal regression models. The second part (inflated part) contains the results of the logistic regression for excess zeroes and coefficients for the factor change in the 
odds of always paying zero Rubles or, in other words, not paying for prescribed or recommended pharmaceuticals (always zero groups) compared with the always zero group, as well as their standard errors. The fit of the models is presented in the last column of the table. For easier interpretation, $\operatorname{Exp}(\mathrm{b})$ is given, which reflects the factor change in the expected count (negative binomial regression part) and the factor change in the odds (logit part) for a one unit increase in the dependent variable.

Table 3.2 Difference-in-differences estimates based on individual-level data

\begin{tabular}{|c|c|c|c|c|c|c|c|}
\hline \multirow[b]{2}{*}{ Years } & \multicolumn{3}{|c|}{ Negative binomial regression } & \multicolumn{3}{|c|}{ Inflated part (logit) } & \multirow{2}{*}{$\begin{array}{c}\text { Model fit } \\
\text { prob>chi2 }\end{array}$} \\
\hline & Coefficient & SE & $\operatorname{Exp}(b)$ & Coefficient & SE & $\operatorname{Exp}(b)$ & \\
\hline $2003 / 2004$ & 0.084 & 0.138 & 1.088 & -0.037 & 0.502 & 0.964 & $* * *$ \\
\hline $2004 / 2005$ & -0.084 & 0.137 & 0.919 & $2.120^{* * *}$ & 0.631 & 8.331 & $* * *$ \\
\hline $2005 / 2006$ & -0.228 & 0.146 & 0.796 & $-1.764 * * *$ & 0.613 & 0.171 & $* * *$ \\
\hline $2006 / 2007$ & -0.047 & 0.113 & 0.954 & -0.285 & 0.403 & 0.752 & $* * *$ \\
\hline $2003 / 2005$ & -0.148 & 0.148 & 0.862 & $2.483^{* * *}$ & 0.709 & 11.977 & $* * *$ \\
\hline $2004 / 2006$ & -0.078 & 0.139 & 0.925 & 0.495 & 0.450 & 1.640 & $* * *$ \\
\hline $03 / 04-05 / 07$ & $-0.226^{* * *}$ & 0.087 & 0.797 & $0.599 *$ & 0.325 & 1.820 & $* * *$ \\
\hline
\end{tabular}

Source: Author's analysis of data from RLMS-HSE.

Notes: ${ }^{* * *} \mathrm{p}<0.01,{ }^{* *} \mathrm{p}<0.05,{ }^{*} \mathrm{p}<0.1$.

The DID estimator in the negative binomial part is not statistically significant, with the exception of the pooled data (years 2003/04-2005/07), and the effect size is also rather small. In general, the DID estimator does not indicate any significant difference between the two groups in the amount of out-of-pocket expenditure on the prescribed or recommended pharmaceuticals. The significant DID estimator for pooled data can be interpreted as follows: belonging to the treatment group after the reform decreases the expected amounts of out-of-pocket payments for prescribed or recommended pharmaceuticals by a factor 0.79 , holding all other factors constant.

A statistically significant positive DID is observed in the inflated parts of two models in 2004/2005 and 2003/2005. The DID is 2.12-2.48, meaning that those belonging to a treatment group after the reform have a higher probability of having incurred a zero expenditure. In other words, the 
out-of-pocket expenditures of these beneficiaries is more likely to follow the negative binomial distribution, and, hence, these individuals are less likely to have additional expenditures than those in the control group after the reform. Based on the exponential of the coefficient $\operatorname{Exp}(\mathrm{b})$, being in the treatment group after the reform increases the odds of having zero expenditure by a factor of 8.33-11.98. The positive DID estimator observed for pooled data (DID being 0.59) can be interpreted analogously, with $\operatorname{Exp}(\mathrm{b})$ being 1.82. Re-estimated models for other years, that excluded the year of the reform did not produce a statistically significant DID estimator. The DID estimator for 2005/2006 was also statistically significant and negative (-1.76). Therefore, the odds to have only zero expenditure for a treatment group in 2006 were lower relative to other models and decreased by factor of 0.17 .

Based on the negative binominal regressions estimations, the year of the reform, belonging to the treatment group, lower education, working, having at least one chronic disease, as well as belonging to a highest income quintile were significantly associated with the amount of out-of-pocket expenditures on pharmaceuticals (Table 3.3). In particular, for respondents belonging to the fifth quintile the out-of-pocket expenditure was 1.84 times the expected out-of-pocket expenditure of a respondent from the lowest quintile (taken as a reference variable), while holding other variable constant. In the year 2005, as opposed to 2004, out-of-pocket expenditures increased by a factor of 1.60, while holding all other variables in the model constant.

The odds of incurring zero expenditure increased among those who belonged to a treatment group, lived in families with children or adults only, and belonged to third or fourth income quintiles (as compared to the lowest quintile). The odds decreased when respondents had a lower level of education (as compared to the middle, taken as a reference variable) and were working.

\subsection{Discussion}

In this chapter, we used a DID framework to see whether the 2005 social benefits reform had an impact on out-of-pocket expenditure on prescribed or recommended pharmaceuticals of eligible beneficiaries. Our treatment group included beneficiaries who were eligible for in-kind in 2005 (and/or in-cash in 2006-2007) provision of such pharmaceuticals, whilst the control group included those not eligible for such benefits. We applied zero-inflated negative binominal models to estimate DID estimators due to excess of zeroes in data. 
Table 3.3 Full model specification for 2004-2005

\begin{tabular}{|c|c|c|c|c|c|c|}
\hline \multirow[t]{2}{*}{ Variables } & \multicolumn{3}{|c|}{ Negative binomial regression } & \multicolumn{3}{|c|}{ Inflated part (logit) } \\
\hline & Coef & SE & $\operatorname{Exp}(b)$ & Coef & SE & $\operatorname{Exp}(b)$ \\
\hline DID & -0.084 & 0.137 & 0.919 & $2.120 * * *$ & 0.631 & 8.331 \\
\hline Year 2004-2005 & $0.471 * * *$ & 0.107 & 1.602 & -0.893 & 0.615 & 0.409 \\
\hline Treatment & $0.243^{* * *}$ & 0.094 & 1.275 & $1.926^{* * *}$ & 0.352 & 6.862 \\
\hline Age & 0.019 & 0.015 & 1.019 & -0.041 & 0.031 & 0.960 \\
\hline Age squared & -0.0001 & 0.0001 & 1.000 & 0.0004 & 0.0002 & 1.000 \\
\hline Gender, male & 0.068 & 0.079 & 1.070 & 0.226 & 0.154 & 1.253 \\
\hline Education, low & $0.175^{* *}$ & 0.081 & 0.839 & $-0.464 * * *$ & 0.167 & 0.629 \\
\hline Education, high & 0.078 & 0.090 & 1.081 & -0.059 & 0.188 & 0.942 \\
\hline Urban, yes & 0.114 & 0.076 & 1.120 & 0.216 & 0.163 & 1.241 \\
\hline $\begin{array}{l}\text { Family with adults only, } \\
\text { yes }\end{array}$ & 0.097 & 0.081 & 1.102 & $0.398^{* *}$ & 0.169 & 1.489 \\
\hline Family with children, yes & 0.136 & 0.117 & 1.146 & $0.640^{* * *}$ & 0.257 & 1.896 \\
\hline Work, yes & $-0.209 * *$ & 0.099 & 0.811 & $-0.632 * * *$ & 0.238 & 0.532 \\
\hline Pension, yes & -0.180 & 0.192 & 0.835 & 0.535 & 0.491 & 1.708 \\
\hline Disability, yes & $-1.21 \mathrm{E}-09$ & $3.37 \mathrm{E}-09$ & 1.000 & $-1.87 \mathrm{E}-08$ & $1.14 \mathrm{E}-08$ & 1.000 \\
\hline Chronic sickness, yes & $0.351 * * *$ & 0.122 & 1.420 & 0.222 & 0.329 & 1.248 \\
\hline Quintile 2 & -0.044 & 0.114 & 0.957 & 0.067 & 0.273 & 1.069 \\
\hline Quintile 3 & 0.024 & 0.114 & 1.024 & $0.515^{*}$ & 0.267 & 1.674 \\
\hline Quintile 4 & 0.140 & 0.119 & 1.150 & $0.500 *$ & 0.272 & 1.649 \\
\hline Quintile 5 & $0.609 * * *$ & 0.132 & 1.839 & 0.446 & 0.308 & 1.562 \\
\hline Const & $5.263^{* * *}$ & 0.398 & & $-3.150 * * *$ & 1.001 & \\
\hline
\end{tabular}

Model fit: LR $\chi 2-124.27$, Prob $>\chi^{2}-0.000$

Source: Author's analysis of data from RLMS-HSE.

Notes: ${ }^{* * *} \mathrm{p}<0.01,{ }^{* *} \mathrm{p}<0.05,{ }^{*} \mathrm{p}<0.1$. 


\subsubsection{Effect of the reform}

Our results, based on DID estimations for 2004-2005, suggest that changes brought by the 2005 social benefits reform had generally no statistically significant impact on the amount of the out-ofpocket expenditures on prescribed or recommended pharmaceuticals. It did have a positive impact on the likelihood of beneficiaries of incurring zero expenditure on these pharmaceuticals. There was also a statistically significant change associated with the year of the reform and some social economic characteristics. Overall, however, we find no strong evidence that belonging to a group of beneficiaries that received pharmaceuticals in-kind (2005) or/and in-cash (in 2006 or 2007) made one better or worse off after the 2005 social benefits reform.

This is not surprising, since the 2005 social benefits reform did not actually introduce a targeted categorical social assistance to low-income groups within the defined benefits. The targeted provision of in-kind benefits could potentially have worsened the condition of the non-poor (which is against Russian laws) and lead to possible charges by the Prosecutor General of Russia's office (Alexandrova \& Struyk, 2007). Also, following the analysis of the NOBUS data, collected in the pre-reform period (2003), the main users of the in-kind or discounted pharmaceuticals benefit program were middle-income groups, and not users from poor social economics strata (Ovcharova, 2005). The highest demand for benefits, therefore, was expected from middle-income groups, who pay more attention to their health and turned out to be the major users of the drug benefit programs. Users from low-income groups appeared to pay less attention to their health and demand treatment less often (Besstremyannaya, 2009b).

\subsubsection{Out-of-pocket expenditure on pharmaceuticals}

As indicated by our results, the majority of respondents were able to find and buy prescribed pharmaceuticals and this trend was consistent over the six-year period analyzed. Such findings are in line with the results reported earlier on the availability of pharmaceuticals in the general Russian population, also using RLMS-HSE data (Perlman \& Balabanova, 2011). Still, the recommended and prescribed pharmaceuticals were slightly less accessible for beneficiaries than for other consumers. Over the years, there was an overall increase in the out-of-pocket expenditure on pharmaceuticals among those who paid for pharmaceuticals in both groups. However, there was no significant difference in payments between the control and treatment group. 
We find support for our results in the analysis of the pharmaceutical market for the same period. In general, the reform and after-reform periods (2005-2008) were characterized by a tremendous growth in public expenditure on pharmaceuticals. The real monthly value of the per capita public expenditure on in-kind benefits in 2005 was considerably higher than the inflation adjusted prereform NOBUS estimations in 2003. In 2006, however, there was a decrease of public expenditure even below the 2003 level (Besstremyannaya, 2009b). Overall, an increase in public expenditure on pharmaceuticals encouraged drug consumption, which led to a considerable growth of this market (Zasimova, 2010), with a sharp increase in the production of drugs (Besstremyannaya, 2009b). At the same time, the dominant part of the economic burden of pharmaceutical treatment still fell on users. Moreover, the drug prescriptions for benefit groups were on average more costly than those on the pharmaceutical market (Besstremyannaya, 2009b).

In addition, we observed that beneficiaries paid for pharmaceuticals less frequently, but average payments were higher. In 2005, there was an obvious decrease in out-of-pocket expenditure among beneficiaries, which disappeared in 2006-2007. The reasons could be two-fold. First, there was an increase in the number of people who acquired pharmaceuticals but did not pay for them, thus, reducing the frequency of actual payments and lowering the average out-of-pocket expenditures. Such reasoning seems to be in agreement with an observation that some beneficiaries indeed tried to get as many free-of-charge pharmaceuticals as possible in 2005 before opting for in-cash provision in 2006 (Partiff, 2007). Second, since eligible beneficiaries gained the right to choose between in-kind or in-cash provision as of 2006, we speculate that beneficiaries adjusted their choice according to their expectations regarding their future needs. Therefore, we argue that possibly those who expected to incur significant expenditures related to pharmaceuticals most likely retained the in-kind provision, while those who expected to make less use of pharmaceuticals, opted for in-cash provision.

\subsubsection{A choice between in-cash and in-kind provision}

It is evident from our results that in the period of 2005-2007, the overall number of those who were eligible for benefits increased. Such observation is pursuant to the known fact that the total number of people eligible to receive in-kind (and in-cash) drug benefits in the Russian Federation increased from 14.8 million (2005) to 17 million (2007), mainly due to an increase in a demand for disability status and simplified medical procedure (Besstremyannaya, 2009b) - a phenomenon known as "invalidization" (Alexandrova \& Struyk, 2007). We also found that after two years, the 
share of beneficiaries who have opted for in-cash pharmaceutical provision increased by $9 \%$. Furthermore, beneficiaries started "switching" between different types of the provision more actively, choosing not only in-cash type of provision in place of in-kind, but also vice versa.

A preference for in-cash provision could have several rationales, besides those related to expectations regarding future health needs. For example, a physical absence of needed in-kind pharmaceuticals, as well as replacement of expensive pharmaceuticals with cheaper generic equivalents (in the revised list) could possibly stimulate additional purchases of more effective pharmaceuticals outside of the list, and, thus, beneficiaries paid out-of-pocket additionally. It is known, for instance, that the original brands of pharmaceuticals were obtained in less than $40 \%$ of cases when paid in-cash and in less than in 10\% of cases when received in-kind (Zasimova, 2010). There is also evidence that the choice between the two schemes led to an increased demand for drugs and adverse selection within the in-kind drug provision system. More specifically, in-kind benefits remained prevalent in regions with a relatively high economic potential, while in-cash benefits were more typical for less wealthy regions, where they had lower per capita revenues. Thus, those opting for in-kind provision in wealthier regions were given preferential treatment compared to in-cash compensations in less wealthy regions (Besstremyannaya, 2009b).

\subsubsection{Limitations}

When interpreting our results it is important to consider the limitations. Eligibility to in-kind or incash pharmaceutical provision was stated by the respondents, but was not verified otherwise. Thus, our analysis could potentially leave out those who were eligible for in-kind or in-cash pharmaceutical provision, but did not claim or receive it for one reason or another. Furthermore, the RLMS-HSE data provides only general information on the consumption of pharmaceuticals in the last 30 days recall period, without giving further details on which pharmaceuticals were purchased and exact quantities. Similarly, the income and expenditure questions also referred to the period of last 30 days, which could cause bias if respondents did not have a steady income, had expenditure/income during the year or consulted a doctor in the period prior to/after the interview. In addition, our analysis did not take into account expenditure on herbal and other home-made remedies, as well as unofficial under-the-table payments, which are present in the Russian healthcare sector (see Chapter 2). Another limitation is the lack of data enabling us to fully account for re-distributional transfers within households. In an attempt to do so, we included 
several types of family (single, families with children, with families without children as the base), but are aware that it could only partially account for such effects.

\subsection{Conclusions and policy implications}

The cashing-out of in-kind benefits was one of the most important steps towards a more liberal welfare regime and paved the way to a more market-based and targeted provision of subsidized public services (Wengle \& Rasell, 2008). Moreover, the reform brought more clarity to the financial and administrative aspects of welfare provision, and introduced some logic of cost-effectiveness, accountability and transparency in the system. The reform replaced the complex benefits system for eligible groups with a more simple and sustainable system of social support measures. However, it did not achieve as much in simplification, monetization, and targeting of in-kind benefits as some neighboring countries, like Moldova and Kazakhstan (see Alexandrova \& Struyk, 2007).

Based on our DID estimations, we confirmed our hypothesis that the social benefits reform of 2005 did not have a direct impact on beneficiaries' out-of-pocket expenditure on outpatient prescribed or recommended pharmaceuticals. We find no strong evidence that belonging to a group of beneficiaries that received pharmaceuticals in-kind (2005) or/and in-cash (in 2006 or 2007) made one better or worse off after the reform. The additional annual choice between in-kind and in-cash provision did not have a statistically significant impact either. Taking a policy perspective, this suggests that the implementation of the reform was successful. Since the reform did not make vulnerable groups better or worse off, most likely it did not have an adverse effect on equity in financing either. Future reforms should take into account pitfalls of this reform and focus on issues that were still not addressed - poverty alleviation, and implementation of a targeted and mean-testing social benefits provision. 
$60 \mid \mathrm{P}$ a g e 
Chapter 4

Informal payments for healthcare services in Russia: An old issue in new realities

This chapter draws upon:

Gordeev, V.S., Pavlova, M., Groot, W. (2014). Informal payments for healthcare services in Russia: old issue in new realities. Health Economics Policy and Law, 9(1), 25-48. 


\section{Abstract}

Informal payments can be found across Europe, Africa, Asia and South America. Due to their hidden nature, they pose an important policy issue. Reported as being widespread, the true scale and scope of informal payment are unknown, and estimations differ among studies.

This chapter looks at the Russian healthcare sector where the existence of informal payments has persisted for decades. It also presents the scale and scope of informal payments, as well as patterns of informal payments and their determinants.

Our results confirm that informal payments exist in all types of Russian healthcare services. The number of users who paid informally ranges from $1.4 \%$ to $17 \%$, depending on the type of healthcare service, averaging at ca. 7.3\% among all healthcare users. Informal payments occur more frequently for dental services in private settings than for any other type of services. Informal payments are initiated by healthcare users or are being suggested by medical staff. Healthcare users pay informally to gain access to healthcare service or treatment, receive care of a better quality, and as an expression of gratitude.

Overall, informal payments have proven to be self-sustainable and persisting over the years. With no appropriate governmental action taken, they will continue to exist. 


\subsection{Introduction}

Informal payments for healthcare services are reported in many countries in Europe, Africa, Asia and South America (Lewis, 2000; Gaal et al., 2006a; Stepurko et al., 2010; Cohen, 2011). In a broader context, informal payments are seen as a manifestation of corruption in the healthcare sector (Vian, 2008). Due to the hidden nature of informal payments, their presence can impose threats to the healthcare sector per se. They can impede efficiency and affect quality of care, jeopardize equality and equity in access to healthcare services, impose "cream-skimming", affect the solidarity principle of insurance-based healthcare systems, and even threaten democratic and inclusion values (Thompson \& Witter, 2000; Balabanova \& McKee, 2002; Ensor, 2004; Allin et al., 2006; Gaal et al., 2006a; Vian and Burak, 2006; Lewis, 2007; Cohen, 2011; Mæstad and Mwisongo, 2011). Therefore, informal payments are an important health-policy issue.

Given the unofficial and often illegal nature of informal payments, they remain unreported, hidden and unregistered (Lewis, 2000). Informal payments are a sensitive and a delicate issue; therefore, it is problematic to estimate the true level of informal payments and their exact burden. Nonetheless, studies from various countries have attempted to measure the scope and scale of informal payments, and to identify their determinants (Belli et al., 2004; Falkingham, 2004; Baschieri \& Falkingham, 2006; Gaal et al., 2006b; Liaropoulos et al., 2008; Lewis, 2000; Özgen et al., 2010; Tomini \& Maarse, 2011). Owing to ambiguities in terms of definitions and variations in representation techniques, it is often impossible to make cross-study comparisons of such estimations. However, regardless of these variations, evidence suggests that in some countries informal payments are widespread, representing an important source of healthcare financing that in some cases accounts for over a half of the national health expenditure (Lewis, 2000; Gaal et al., 2006a). This fact once again underlines the necessity to account for informal payments. An essential step in doing so would be the official recognition of the existence of informal payments and raising public awareness.

In Russia, the existence of informal payments has been documented in different studies (Boikov et al., 1997; Feeley et al., 1999; Saratov, 2001; Blam \& Kovalev, 2003; Shishkin et al., 2003; Besstremyannaya, 2007; Aarva et al., 2009; Fotaki, 2009). Informal payments made for medical services and drugs constituted 0.55\% of GDP (or 0.32\% for conservative estimations) in 1997 (Fotaki, 2009) and as much as 3.5\% of household spending (Feeley et al., 1999). Taking into account the current underfinancing of the Russian healthcare system (see Chapter 1), with the total 
expenditure on health (5.4\% of gross domestic product (GDP) in 2009) being lower than the average for the European and Central Asian region (9.8\% of GDP in 2009; The World Bank, 2011), informal payments represent an important source that currently bypasses the official channels of healthcare financing. Despite this, until now, informal payments are neither officially recognized, nor is there a clear policy agenda and response to informal payments. Therefore, a few questions arise: are informal payments still present in the Russian healthcare sector? If so, what are the present scale and scope of informal payments? Who is paying informally, why and how? Why are informal payments still present and continue to exit? Should the Russian policymakers address this issue and how?

This chapter aims to elaborate on these questions and to underline the importance of recognizing the existence of informal payments in the Russian healthcare sector. We draw attention to the possible implications of informal payments, which can be accounted for when adjusting and choosing the national strategy of further development of the Russian healthcare sector. Furthermore, findings in this chapter contribute to a better understanding of informal payments by providing more insight into the process of informal payments and by describing patterns of paying informally, which has not been done so far.

\subsection{Background}

Almost 20 years of continuous reform has not yet led to the Russian healthcare system's full recovery from the crisis and the sector remains a chronically ill "patient" of its own with a complex multi-morbidity for which a proper cure is yet to be found (see Chapter 2). The Russian government is still in search of optimal healthcare policies and strategies of further development and has not yet officially recognized the existence of informal payments in any way. Informal payments in the healthcare sector, which have existed since the Soviet era, have survived, despite numerous reforms, and have adapted to the new realities of modern Russia (Feeley et al., 1999).

The structural reasons that can explain informal payments, which are also found to be valid for other countries at a systematic level, are also applicable to the Russian healthcare sector and include: the lack of accountability, good governance and working regulations, as well as the presence of corruption in public administration; underfunding of the healthcare sector; personal avid interest and low salaries of medical staff; incoherence between officially set prices and personnel's perception of their true costs; and the lack of information about the range and quality services users 
are entitled to (Ensor \& Witter, 2001; Shishkin et al., 2003; Belli et al., 2004; Cohen, 2011). Moreover, it is believed that the nature of informal payments in Russia, as one of the ex-Soviet countries, is deeply rooted in the culture of gratitude and gift giving (Lewis, 2000; Thompson \& Witter, 2000; Lewis, 2002).

All previous studies that confirm the presence of informal payments in the Russian healthcare sector used individual-level data, but sources of data vary in the time of data collection and sample size. For instance, several studies used the all-Russia representative RLMS-HSE data (Boikov et al., 1997; Feeley et al.,1999; Blam \& Kovalev, 2003; Besstremyannaya, 2007), whereas others were based on region- or city-level data (Saratov, 2001; Aarva et al., 2009; Fotaki, 2009). Nonetheless, these studies provide insight into how the magnitude of the scale and scope of informal payments has changed over the last decade (1997-2006).

In 1997, according to Boikov et al. (1997) and Feeley et al. (1999), almost 7.4\% of Russian households that used healthcare services paid informally. The magnitude of informal payments was highest for public inpatient hospitals and outpatient clinics (34.4\% and $29 \%$ of all payments). In private settings, informal payments for similar services were lower $-4.5 \%$ and $18.3 \%$ of all payments. The share of informal payments for dental services and visits to private practitioners constituted $23.2 \%$ and $29 \%$ of all payments, respectively. Authors estimate the burden of informal payments made for medical services and drugs at $0.55 \%$ of GDP in 1997 (or $0.32 \%$ for conservative estimations), with ca. $15.4 \%$ of household expenditures on drugs and medical services made informally. In 1999-2000, between $67 \%$ and $86 \%$ of respondents had to pay for services they were entitled to use free of charge, averaging to $80.9 \%$ (Fotaki, 2009). Such payments included quasiformal payments officially charged by hospitals but not formally regulated by the government, as well as informal payments made to physicians and other health professionals.

In 2000, informal payments for public outpatient services were reported by $5 \%$ of the users and for state hospital services they were reported by 10\% of the users (Blam \& Kovalev, 2003). Based on Saratov (2001), estimates for the same year and types of services were higher, and constituted $22 \%$ for state polyclinics and $26 \%$ for state hospitals. Altogether, $36.1 \%$ of respondents had to pay with money or gifts to obtain medical help. However, one should note that these estimates were based on the responses of all respondents whose relatives had health problems during the year, whereas the RLMS-HSE data are based on responses of actual users of polyclinics in the (last 30 days) and hospitals (last three months). 
In 2003, users paid unofficially in polyclinics in 5.7-7.0\% of cases, for drugs in hospitals in 6.5$11.4 \%$ of cases, and for a stay in the hospitals - in 3.2-3.4\% of cases, where the two values refer to patients with good and bad health status, respectively (Besstremyannaya, 2007). In 2006, on average, $14.5 \%$ of those who visited health facilities in the past three years paid informally (Aarva et al., 2009). Altogether, $8.4 \%$ of respondents reported having paid informally for treatment and consultation services; $6.3 \%$ for receiving a medical statement or referral to other medical institutions; $5.3 \%$ for ensuring privacy and comfort; $3.2 \%$ for home visits of doctor/nurse; $2.3 \%$ for preventive services and additional medical information; and $1.5 \%$ for diagnostic procedures.

To summarize, over the last decade informal payments were reported in all types of Russian healthcare settings: inpatient and outpatient, private and public. A significant number of users had to pay for services they were actually entitled to use free of charge. Depending on the type of healthcare setting and year of the survey, the number of users who paid informally ranged from $3.2 \%$ to $36.1 \%$, and the share of informal payments constituted up to $34.4 \%$ of all healthcare payments.

In this chapter, we use the RLMS-HSE data collected in 2009. Given the inconsistent financial reforms in the Russian healthcare system (see Chapter 2), it is to be expected that informal patient payments are still present in Russia. The variation in the results of previously conducted studies also leads us to expect that the process of paying informally is very complex and that there are several patterns of paying informally, which can be described by a combination of several factors. These expectations are explored in our data analysis.

\subsection{Data and methods}

\subsubsection{Data and sample}

For this chapter, we use data from the 18th round (2009) of the RLMS-HSE survey (see Chapter 1, Section 1.6). The 18th round of the RLMS-HSE contains information on the utilization of healthcare services (outpatient non-dental, dental, check-up and inpatient), and on the scale and scope of the official and informal payments. In addition, it contains detailed information about the last incidence of paying informally in cash to a medical staff for outpatient non-dental and inpatient healthcare services (excluding dental services), which were not available in the preceding rounds. Those individuals who used at least one type of healthcare service in the last three months are referred to as "healthcare users". To compare our findings for 2009 with data for other years at 
least partly, we use data from rounds 17 (2007) and 19 (2010) of the RLMS-HSE, which did not include dental services. For 2008, no data about informal payments are available in the RLMSHSE. For the analysis, we aggregate data on hospital stay and materials used for hospitalization into one category - overall hospital stay. Similarly, the total amounts of informal payments for services are summed per user, and informal payments include both hand-to-hand monetary transactions and gift giving. Household income is calculated as the total household income divided by the square root of the number of household residents (Atkinson et al., 1995).

\subsubsection{Definitions: official and informal}

In the RLMS-HSE survey, payments for healthcare services are defined as 'official' if a user paid via the cashier's office in accordance with official regulations or in accordance with official prices set by the medical enterprise. The latter are also known as quasi-formal payments. "Informal" payments include hand-to-hand monetary transactions without any documents and gift giving. Both official and informal payments were given a monetary equivalent by the respondents.

\subsubsection{Analytical methods}

We use descriptive statistics to analyze the utilization of healthcare services and to measure the scale and scope of informal payments. A significant share of healthcare users report zero informal payments. Therefore, the related cost data are positively skewed and have an excess of zeroes. We present two types of models: (a) two-part model and (b) sample selection model. We use a twopart model to analyze individual expenditure on informal payments, assuming independence between decision to pay informally (probit) and a decision how much to pay informally (generalized linear model with gamma distribution and log link function). This implies that these decisions have different probability functions and, therefore, we estimate them separately. However, it is possible that these two decisions are interdependent, which implies joint normality of the error terms. In this case, to check for existence of potential bias with the selection of respondents (i.e. individuals that under given circumstance will not pay informally, but are still included in the analysis), we also estimate sample selection model using maximum likelihood (full-information maximumlikelihood).Owing to differences in the methods of estimation, we anticipate possible variations in the resulting models' estimations. More detailed reviews of two-part and sample selection models are available in studies by Cameron and Trivedi (2009) and Mihaylova et al. (2011), and examples of the models' use for healthcare expenditure can be found in studies by Powers et al. (2005) and Angulo et al. (2011). 
Both descriptive and regression analyses are performed using STATA 12. Whenever regressions per types of service are insignificant, pooled data is analyzed for all four services. The patterns of informal payments are assessed by means of cluster analysis using SPSS 20. Cluster analysis is based on automatic two-step clustering, which revealed two main types of patterns of behavior in making informal payments. The Silhouette measure of cohesion and separation are fair and clusters are nearly equal. Further on, the number of clusters is increased to four based on the results of a hierarchical cluster analysis using Ward's clustering method.

We use five characteristics to describe the clusters: who suggested the payment, who determined the amounts of the payment, when was the amount of the payment known, when did the payment occur and what were the reasons for paying informally? We define five common combinations of reasons for paying informally: access and gratitude; quality and gratitude; a combination of access, quality and gratitude; gratitude only; and other reasons. The "gratitude only" group should depict the cases of expression of "pure" gratitude. This separates them from cases when gratitude is expressed in combination with other reasoning, such as gaining access and/or quality, which by default should be provided free of charge.

\subsection{Results}

\subsubsection{Current healthcare utilization, scale and scope of informal payments}

In general, the majority of healthcare users visit a physician two to three times a year or less. Only few miss their work or study due to illness, and sick leave does not exceed on average more than a week (Table 4.1). Medical help is mainly sought in state-owned healthcare facilities (see Table 4.2). The descriptive statistics in Table 4.2 shows that the utilization of private healthcare is low (except for dental services) and is combined with visits to the public settings (referred to as "both" in Table 4.2). Almost every 10th polyclinic user pays for their visit officially. In the last three month-recall period, the highest frequency of official payments is reported by users of dental services $(52.2 \%)$, followed by payments related to hospitalizations (24.7\%). When hospitalized, the vast majority receives materials, medication and dressing materials necessary during hospitalization free of charge (78\%), fewer pay partially (17.6\%) and few have to pay fully (4\%; not presented in the table). Individuals who pay officially in most cases purchase necessary drugs and materials in the pharmacies located outside the hospital (not presented in the table). Overall, users are more prone to pay officially in private healthcare settings, in particular for outpatient non-dental and dental health services. 
Table 4.1 Respondents' socio-economic status and health characteristics

\begin{tabular}{|c|c|c|}
\hline $\begin{array}{l}\text { Socio-economic status and self-rated } \\
\text { health }\end{array}$ & $\begin{array}{l}\text { All respondents } \\
\quad[\mathrm{N}=9578]\end{array}$ & $\begin{array}{l}\text { Users of at least one service } \\
{[\mathrm{N}=3607]}\end{array}$ \\
\hline Characteristics & $\mathrm{N}(\%)$ of respondents & $\mathrm{N}(\%)$ of respondents \\
\hline \multicolumn{3}{|l|}{ Gender } \\
\hline Female & $5528(57.7)$ & $2254(62.5)$ \\
\hline Male & $4050(42.3)$ & $1353(37.5)$ \\
\hline Mean age (years), $\pm S D$ & $41.02 \pm 22.17$ & $38.51 \pm 24.30$ \\
\hline \multicolumn{3}{|l|}{ Age categories } \\
\hline Children $<18$ years old & $1624(17.0)$ & $921(25.5)$ \\
\hline Adults $\geq 18$ years old & $7954(83.0)$ & $2686(74.5)$ \\
\hline \multicolumn{3}{|l|}{ Education } \\
\hline Pre-school, primary/incomplete & $3282(34.3)$ & $1441(40.0)$ \\
\hline Complete secondary, technical & $4610(48.1)$ & $1516(42.0)$ \\
\hline Higher & 1681 (17.6) & $648(18.0)$ \\
\hline Household size mean, SD & $3.37 \pm 1.7$ & $3.23 \pm 1.56$ \\
\hline $\begin{array}{l}\text { Household income per capita in Rubles, } \\
\text { mean } \pm \text { SD }[N=8896 / 3607]\end{array}$ & $16443.93 \pm 23605.50$ & $17380.95 \pm 34171.64$ \\
\hline \multicolumn{3}{|l|}{ Family type } \\
\hline Single & $955(10.0)$ & $380(10.5)$ \\
\hline Family without children & $4026(42.0)$ & $1406(39.0)$ \\
\hline Family with children & $4597(48.0)$ & $1821(50.5)$ \\
\hline \multicolumn{3}{|l|}{ Place of residence } \\
\hline Urban & $6252(65.3)$ & $2604(72.2)$ \\
\hline Rural & $3326(34.7)$ & $1003(27.8)$ \\
\hline $\begin{array}{l}\text { Self-rated health, mean } \pm \text { SD } \\
{[N=9541 / 3593]}\end{array}$ & $2.77 \pm 0.76$ & $2.87 \pm 0.78$ \\
\hline Very good & $283(3.0)$ & $71(2.0)$ \\
\hline Good & 3114 (32.6) & $1056(29.4)$ \\
\hline Satisfactory & $4814(50.5)$ & $1797(50.0)$ \\
\hline Poor & $1168(12.2)$ & $582(16.2)$ \\
\hline Very poor & $163(1.7)$ & $87(2.4)$ \\
\hline At least one chronic disease, yes & $4491(47.0)$ & 1967 (54.6) \\
\hline Disability assigned, yes & $959(10.00)$ & $507(14.1)$ \\
\hline $\begin{array}{l}\text { Experienced some health problems ( } 30 \\
\text { days), yes }\end{array}$ & $3545(37.0)$ & $2046(56.8)$ \\
\hline Opted for self-treatment, yes & $2617(60.7)$ & $701(29.9)$ \\
\hline $\begin{array}{l}\text { Missed work/study due to illness ( } 30 \\
\text { days), } \\
\text { yes }\end{array}$ & $654(7.0)$ & $538(15.5)$ \\
\hline Days missed, mean \pm SD $[N=650 / 534]$ & $7.53 \pm 5.78$ & $8.27 \pm 5.96$ \\
\hline Visits doctor 2-3 times a year or less, yes & $8136(94.9)$ & $2572(72.1)$ \\
\hline
\end{tabular}

Source: Author's analysis of data from 2009 RLMS-HSE.

Notes: $€ 1=43.27$ Rubles (RR) in 2009. Valid percentages are rounded. 
Informal payments are reported by $1.4-4.3 \%$ of healthcare users of outpatient non-dental and check-up healthcare services. This share is higher among those who are hospitalized - ca. $12.7 \%$, with the highest prevalence among users of dental care services (17.0\%). On average, among all healthcare users, informal payments amount to ca. $7.3 \%$. If we exclude dental services, we find that informal payments total to 4.4\%, which is comparable with levels reported in 2007 and 2010 (5.7\% and $4.3 \%$, respectively), using the same RLMS-HSE survey data (results of our additional analysis). The absolute amounts of informal payments are highest among users of inpatient care and relate to the hospital stay itself. Informal payments for dental care are also high. The lowest rate and monetary value of informal payments are observed for check-up services. In general, healthcare users pay informally with money and less frequently with gifts, and on average the amounts paid in cash are higher than the estimated value of the gifts given.

\subsubsection{Informal payments: who is paying and how much?}

The regression analyses show that the education level of a healthcare user, the presence of chronic illness and overall self-rated health affect the probability of paying informally (see Table 4.3). More particularly, having a higher level of education (with the middle level as a reference), or bad selfrated health (as compared with an average health status) or at least one chronic disease increases the probability of paying informally (holding all other variables at zero). Having a low level of education, on the contrary, decreases such probability. A positive association of the amount paid informally is found with the level of the household income per capita. After correction for sample selection, the amount of informal payments is also positively associated with the patients' age and the presence of a disability. A low level of education (with the middle level as a reference), or a good self-rated health (average as a reference) or having at least one chronic sickness are negatively associated with the amounts paid informally. In the sample selection model, however, the association with the a low level of education becomes statistically insignificant. Overall, both models identify similar determinants of informal payments. In addition no difference in the statistical significance of the predictors of the informal payments is observed between the two models at the $\mathrm{p}=0.05$ significance level. 
Table 4.2 Payments for healthcare services by type of service

\begin{tabular}{|c|c|c|c|c|c|c|c|c|c|c|c|}
\hline & $\begin{array}{l}\text { Service } \\
\text { provider }\end{array}$ & $\begin{array}{l}\text { Total } \\
\text { users }\end{array}$ & $\begin{array}{c}\text { Users } \\
\text { who paid }\end{array}$ & $\begin{array}{l}\text { Users } \\
\text { who paid } \\
\text { officially }\end{array}$ & $\begin{array}{c}\text { Users } \\
\text { who paid } \\
\text { informally }\end{array}$ & $\begin{array}{l}\text { Users who } \\
\text { paid Informally: } \\
\text { cash }\end{array}$ & $\begin{array}{l}\text { Users who } \\
\text { paid Informally: } \\
\text { gifts }\end{array}$ & $\begin{array}{c}\text { Amount paid } \\
\text { officially }\end{array}$ & $\begin{array}{l}\text { Amount paid } \\
\text { informally }\end{array}$ & $\begin{array}{l}\text { Amount paid } \\
\text { Informally: } \\
\text { cash }\end{array}$ & $\begin{array}{l}\text { Amount paid } \\
\text { Informally: } \\
\text { gifts }\end{array}$ \\
\hline Type of services used & & & \multicolumn{5}{|c|}{ Observed frequency ( $\%$ of service users within category) } & \multicolumn{4}{|c|}{ Mean \pm SD (in Rubles) } \\
\hline \multicolumn{12}{|l|}{ Outpatient } \\
\hline Outpatient non-dental & public & 1424 & $142(9.97)$ & $91(6.39)$ & $55(3.86)$ & $41(2.88)$ & $16(1.12)$ & $1102.60 \pm 1353.06$ & $1360.59 \pm 1971.01$ & $1265.69 \pm 2006.84$ & $94.89 \pm 184.35$ \\
\hline \multirow[t]{3}{*}{ (last 30 days) } & private & 51 & $38(74.51)$ & $34(66.67)$ & $5(9.80)$ & $5(9.80)$ & 0 & $4553.52 \pm 7528.22$ & $2700.00 \pm 4210.30$ & $2700.00 \pm 4210.30$ & 0 \\
\hline & both & 46 & $41(89.13)$ & $37(80.43)$ & $6(13.04)$ & $6(13.04)$ & $2(4.35)$ & $2195.67 \pm 2172.52$ & $1420.00 \pm 1219.42$ & $1320.00 \pm 1008.46$ & $100.00 \pm 223.61$ \\
\hline & overall & 1521 & $222(14.60)$ & $163(10.72)$ & $66(4.34)$ & $52(3.42)$ & $18(1.18)$ & $2144.30 \pm 4007.93$ & $1458.08 \pm 2103.65$ & $1369.23 \pm 2128.27$ & $88.79 \pm 180.85$ \\
\hline Dental & public & 478 & $251(52.51)$ & $203(42.47)$ & $52(10.88)$ & $43(9.00)$ & $10(2.09)$ & $2569.44 \pm 8896.97$ & $2210.20 \pm 3701.18$ & $2032.20 \pm 3726.64$ & $178.00 \pm 737.69$ \\
\hline \multirow[t]{3}{*}{ (last 3 months) } & private & 250 & $238(95.20)$ & $172(68.80)$ & $69(27.60)$ & $65(26.00)$ & $6(2.40)$ & $4896.12 \pm 7842.54$ & $4035.56 \pm 7374.43$ & $3886.47 \pm 7120.93$ & $149.09 \pm 713.41$ \\
\hline & both & 20 & $18(90.00)$ & $14(70.00)$ & $7(35.00)$ & $7(35.00)$ & 0 & $6871.00 \pm 12414.28$ & $1614.28 \pm 1699.44$ & $1614.28 \pm 1699.44$ & 0 \\
\hline & overall & 751 & $510(67.91)$ & $392(52.20)$ & $128(17.04)$ & 115 (15.31) & $16(2.13)$ & $3753.37 \pm 8645.69$ & $3169.82 \pm 5987.97$ & $3017.52 \pm 5826.05$ & $152.30 \pm 701.16$ \\
\hline $\begin{array}{l}\text { Check-up } \\
\text { (last } 3 \text { months) } \\
\text { Inpatient }\end{array}$ & overall & 1942 & $290(14.93)$ & $266(13.70)$ & $27(1.39)$ & $20(1.03)$ & $9(0.46)$ & $809.55 \pm 1138.35$ & $540.00 \pm 426.61$ & $405.79 \pm 416.68$ & $134.21 \pm 206.37$ \\
\hline \multirow[t]{3}{*}{ (last 3 months) } & public & 445 & $147(33.03)$ & $108(24.27)$ & $56(12.58)$ & $-\mathrm{a}$ & $-\mathrm{a}$ & $9(0.46)$ & $5057.50 \pm 8439.86$ & $-\mathrm{a}$ & $-\mathrm{a}$ \\
\hline & private & 4 & $4(100.00)$ & $3(75.00)$ & $1(25.00)$ & $-\mathrm{a}$ & $-\mathrm{a}$ & $10000.00 \pm 2828.43$ & $22000.00 \pm 0$ & $-\mathrm{a}$ & $-\mathrm{a}$ \\
\hline & overall & 449 & $151(33.63)$ & $111(24.72)$ & $57(12.69)$ & $-\mathrm{a}$ & $-\mathrm{a}$ & $3114.61 \pm 4406.16$ & $5403.26 \pm 8695.14$ & $-a$ & $-\mathrm{a}$ \\
\hline \multirow[t]{3}{*}{ Inpatient: hospital stay } & public & 445 & $82(18.43)$ & $32(7.19)$ & $54(12.13)$ & $28(6.29)$ & $33(7.42)$ & $4742.59 \pm 6428.46$ & $4841.70 \pm 8040.19$ & $3992.55 \pm 8207.41$ & $849.15 \pm 1865.05$ \\
\hline & private & 4 & $4(100.00)$ & $3(75.00)$ & $1(25.00)$ & $1(25.00)$ & 0 & $5000.00 \pm 1414.21$ & $16000.00 \pm 0$ & $16000.00 \pm 0$ & 0 \\
\hline & overall & 449 & $86(19.15)$ & $35(7.80)$ & $55(12.25)$ & $29(6.46)$ & $33(7.35)$ & $4760.34 \pm 6200.74$ & $5074.16 \pm 8115.61$ & $4242.70 \pm 8302.54$ & $831.45 \pm 1849.17$ \\
\hline \multirow[t]{3}{*}{$\begin{array}{l}\text { Inpatient: materials, } \\
\text { pharmaceuticals-b }\end{array}$} & public & 445 & $92(20.67)$ & 87 (19.55) & $10(2.25)$ & $-\mathrm{a}$ & $-\mathrm{a}$ & $2015.15 \pm 2786.55$ & $2171.43 \pm 2062.94$ & $-\mathrm{a}$ & $-a$ \\
\hline & private & 4 & $4(100.00)$ & $3(75.00)$ & $1(25.00)$ & $-\mathrm{a}$ & $-\mathrm{a}$ & $5000.00 \pm 1414.21$ & $6000.00 \pm 0$ & $-a$ & $-\mathrm{a}$ \\
\hline & overall & 449 & $96(21.38)$ & $90(20.04)$ & $11(2.45)$ & $-\mathrm{a}$ & $-\mathrm{a}$ & $2089.77 \pm 2795.27$ & $2650.00 \pm 2340.94$ & $-\mathrm{a}$ & $-\mathrm{a}$ \\
\hline Total & & 3607 & $1069(29.64)$ & $861(23.87)$ & $263(7.29)$ & $-a$ & $-\mathrm{a}$ & $2782.66 \pm 6687.08$ & $3110.35 \pm 6057.08$ & $-\mathrm{a}$ & $-\mathrm{a}$ \\
\hline
\end{tabular}

Source: Author's analysis of data from 2009 RLMS-HSE.

Notes: $€ 1=43.27$ Rubles (RR) in 2009. Observed frequencies and mean values are calculated for valid responses, using number of service users per type of service and service provider as denominator. The total values of frequencies of payments may vary due to missing answers (lack of response, refusal to respond, or respondents did not know the answer). - $\mathrm{a}$ - following the formulation of the question, payments by cash and presents were estimated together; -b - accounts for purchases in pharmacies inside and outside of the hospital. 
Table 4.3 Informal payments for healthcare services - who pays and how much

\begin{tabular}{|c|c|c|c|c|c|c|}
\hline \multirow[b]{3}{*}{ Characteristics } & \multicolumn{3}{|c|}{ Model A - Two-part model } & \multicolumn{3}{|c|}{ Model B - Sample selection model } \\
\hline & \multicolumn{2}{|c|}{$\begin{array}{c}\text { Part 1 } \\
\text { Paying informally, yes/no } \\
\text { Yes }=1 \text { (Probit) }^{\mathrm{A}}\end{array}$} & \multirow{2}{*}{$\begin{array}{c}\text { Part } 2 \\
\begin{array}{c}\text { Amount paid informally, } \\
\text { Rubles }(\mathrm{GLM})^{\mathrm{B}}\end{array} \\
\text { Coef }(\mathrm{SE}) \\
\end{array}$} & \multicolumn{2}{|c|}{$\begin{array}{c}\text { Part 1 } \\
\text { Paying informally, yes/no } \\
\text { Yes =1 (MLE) }\end{array}$} & \multirow{2}{*}{$\begin{array}{c}\text { Part } 2 \\
\begin{array}{c}\text { Amount paid informally, } \\
\text { Rubles }(\mathrm{MLE})^{\mathrm{C}}\end{array} \\
\text { Coef }(\mathrm{SE}) \\
\end{array}$} \\
\hline & Coef (SE) & Marginal effects (SE) & & Coef (SE) & $\begin{array}{l}\text { Marginal effects after } \\
\text { selection (SE) }\end{array}$ & \\
\hline Gender, female & $-0.022(0.069)$ & $-0.003(0.009)$ & $0.003(0.194)$ & $0.006(0.072)$ & $0.008(0.008)$ & $32.820(797.190)$ \\
\hline Age & $0.011(0.007)$ & $0.001(0.001)$ & $0.032(0.021)$ & $0.010(0.007)$ & $0.001(0.001)$ & $149.700(86.620)^{*}$ \\
\hline Age squared / $* 1000$ & $-0.144(0.083)^{*}$ & $-0.019(0.011)^{*}$ & $-0.321(0.239)$ & $-0.120(0.085)$ & $-0.015(0.010)$ & $-1,687.00(938.00)^{*}$ \\
\hline Place of residence, urban & $-0.064(0.074)$ & $-0.008(0.010)$ & $-0.064(0.228)$ & $-0.038(0.076)$ & $-0.004(0.009)$ & $-269.572(905.204)$ \\
\hline Education, high & $0.197(0.083)^{* *}$ & $0.026(0.011)^{* *}$ & $-0.191(0.244)$ & $0.184(0.085)^{* *}$ & $0.025(0.012)^{* *}$ & $-d$ \\
\hline Education, low & $-0.193(0.098)^{* *}$ & $-0.026(0.013)^{* *}$ & $-0.523(0.293)^{*}$ & $-0.235(0.102)^{* *}$ & $-0.028(0.011)^{* *}$ & $-545.060(1252.627)$ \\
\hline Family type, single & $0.034(0.110)$ & $0.004(0.015)$ & $-0.253(0.326)$ & $0.028(0.112)$ & $0.003(0.014)$ & $-51.736(1270.414)$ \\
\hline $\begin{array}{l}\text { Household income per } \\
\text { capita } / * 1000000\end{array}$ & $0.408(0.004)$ & $0.055(0.110)$ & $2.58(0.738)^{* * *}$ & $0.425(0.807)$ & $0.053(0.000)$ & $97,000.00(25,000.000)^{* * *}$ \\
\hline Self-rated health, good & $0.090(0.093)$ & $0.012(0.012)$ & $-0.865(0.282)^{* * *}$ & $0.118(0.095)$ & $0.015(0.012)$ & $-3062.101(1084.137)^{* * *}$ \\
\hline Self-rated health, bad & $0.198(0.099)^{* *}$ & $0.027(0.013)^{* *}$ & $-0.216(0.286)$ & $0.203(0.102)^{* *}$ & $0.027(0.015)^{*}$ & $-d$ \\
\hline Disability, yes & $0.028(0.106)$ & $0.003(0.014)$ & $0.478(0.291)$ & $0.004(0.110)$ & $0.0005(0.013)$ & $2212.473(1176.622)^{*}$ \\
\hline Chronic disease, yes & $0.216(0.085)^{* * *}$ & $0.029(0.011)^{* * *}$ & $-0.469(0.242)^{* *}$ & $0.238(0.088)^{* * *}$ & $0.025(0.012)^{* * *}$ & $-2057.411(1126.508)^{*}$ \\
\hline Constant & $-1.694(0.191)^{* * *}$ & - & $7.413(0.581)^{* * *}$ & $-1.753(0.198)^{* * *}$ & - & $1675.122(5253.187)$ \\
\hline Number of respondents & $\begin{array}{l}\text { Prob } \\
\text { Pseu }\end{array}$ & $\begin{array}{l}=0.000 \\
=0.0269\end{array}$ & $\begin{array}{c}232 \\
\mathrm{AIC}=17.66 \\
\mathrm{BIC}=-825.78\end{array}$ & $\begin{array}{r}340 \\
\text { LR test of inde }\end{array}$ & $\begin{array}{l}\text { nsored observations }-3 \\
\text { ld chi } 2(10)=32.20 ; \text { Prol } \\
\text { lent equations }(\mathrm{Rho}=0)\end{array}$ & $\begin{array}{l}\text { ensored }-232) \\
=0.0004 \\
=0.04 \text { Prob }>\text { Chi2 }=0.84\end{array}$ \\
\hline
\end{tabular}

Source: Author's analysis of data from 2009 RLMS-HSE.

Notes: *- $\mathrm{p}<0.10 .{ }^{*}$ - $\mathrm{p}<0.05$. ${ }^{* * *}$ - $\mathrm{p}<0.01$; $€ 1=43.27$ Rubles $(\mathrm{RR})$ in 2009; a- probit regression; b-generalized linear model with gamma distribution and log link function; c-sample selection models are estimated using a full maximum-likelihood estimator; selection variables in Model B (Part 1) appear to affect the likelihood of paying informally and to be censored out of the sample, but models fail to reject rho $=0$ and cannot firmly reject the absence of the selection bias; $d-$ variables used for selection equation, but absent in the outcome equation. 


\subsubsection{Informal payments: how does the informal payment occur?}

To gain a better understanding of how informal payments occur in practice, we examine the latest incidents, recalled by users, of paying informally through a hand-to-hand monetary transaction (data are available for outpatient non-dental and inpatient healthcare settings only). The descriptive statistics in Table 4.4 show that healthcare users pay informally both for inpatient and outpatient healthcare services. For outpatient service, users pay informally more frequently at the request of healthcare staff, whereas users of inpatient services more frequently initiate informal payments themselves or make informal payments, following suggestions from other hospitalized users and/or friends. In both settings, informal payments occur more frequently after the service was provided and the exact amount is either not known before the service or known immediately before it. In the majority of cases, the exact amount of the informal payment is determined by the healthcare service user, while reasons for such payments vary. For outpatient users, the reasons for paying informally can be ranked as follows (from the most frequent to the least frequent): to gain access, to gain access and more attention or better quality care, to receive better quality care and to express gratitude. For users of inpatient settings, the reasons for informal payments are similar. However, such payments are more typical for receiving more attentive and better quality care, for expressing gratitude payments, gaining access to treatment and a combination of access- and quality-related reasons.

\subsubsection{Informal payments: patterns of payments}

To identify the possible patterns of paying informally, we use the data on the latest incidents of paying informally recalled by the users and apply cluster analysis. As suggested by our cluster analysis, each healthcare setting has two predominant patterns of informal payments, and two more patterns exist when no distinction is made between the types of settings (clusters 1 and 2 in Table 4.5).

The first pattern includes cases where healthcare users are suggested to pay informally by medical staff. In these cases, the exact amount to be paid informally is told by someone and is known only right before the service. In outpatient settings, users pay after the service is provided, whereas in inpatient settings such payments occur before the service. The second pattern depicts cases where informal payments are initiated by the users of healthcare services, where the exact amount of the informal payments is not known before the service, and therefore is determined by the users themselves. Both patterns share similar reasons for informal payments - to gain access to the 
provided service (for outpatient services) or to receive more attentive and better quality care (for inpatient services).

Similar patterns are evident when no distinction is made between the types of healthcare settings and all cases of paying informally are analyzed together. The only difference is found when the decision to pay informally is made by the user, where such payments serve as an expression of gratitude (Table 4.5; clusters 1 and 2 in Figure 4.1). In addition to the most dominant and frequently occurring patterns, we also identify two additional less frequent patterns, when we analyze all cases together (clusters 3 and 4 in Figure 4.2). For instance, the third pattern depicts users who decide to pay informally before the service and on their own initiative, in order to gain better quality and more attentive care. Similar to the predominant patterns, users determine the amount of payment themselves, as the amount of informal payment is unknown. The fourth pattern occurs following the recommendation of friends or other patients to gain access to the service, and users pay informally after the service. In these cases, the amount of informal payment is known before the service, but the exact amount is negotiated with the service provider.

In general, the exact amount of the payment depends on the initiator of the informal payment. Users are told how much they should pay, when the payments are requested; users determine the exact amount themselves should they themselves initiate the payment; and the amount was determined in the course of negotiations when paying informally was suggested by relatives, friends or other patients. Overall, informal payments, to gain access and as an expression of gratitude, are made after the service is provided. Payments for quality most often occur before the service provision.

The patterns of paying informally reveal how informal payments actually occur in the Russian healthcare facilities and confirm our expectations. Yet, it is important to mention that these core patterns are not uniquely characterized by attributes, but they rather represent the predominant characteristics within the pattern, which occurred more frequently among respondents. A more detailed overview of all characteristics within patterns and their frequency distribution can be found in Figure 4.2). 
Table 4.4 Characteristics of the cash informal payments during the last service use

\begin{tabular}{|c|c|c|c|}
\hline \multirow[t]{2}{*}{ At least one informal payment done } & $\begin{array}{c}\text { Outpatient } \\
\text { non-dental } \\
{[\mathrm{N}=50]}\end{array}$ & $\begin{array}{l}\text { Inpatient } \\
{[\mathrm{N}=26]}\end{array}$ & $\begin{array}{l}\text { Together } \\
{[\mathrm{N}=76]}\end{array}$ \\
\hline & \multicolumn{2}{|c|}{$\begin{array}{r}\text { Valid responses (yes)/No of obs. } \\
\text { within answer) }\end{array}$} & (valid \% \\
\hline \multicolumn{4}{|l|}{ Amount was known (when known): } \\
\hline Before the visit & $8 / 50(16.0)$ & $2 / 26(7.7)$ & $10 / 76(13.2)$ \\
\hline Right before the visit & $14 / 50(28.0)$ & $8 / 26(30.8)$ & $21 / 76(27.6)$ \\
\hline Was found out after the service & $7 / 50(14.0)$ & $2 / 26(7.7)$ & $9 / 76(11.8)$ \\
\hline Nobody told amount & $21 / 50(42.0)$ & $13 / 26(50.0)$ & $34 / 76(44.7)$ \\
\hline Other & $-a$ & $2 / 26(7.7)$ & $2 / 76(2.6)$ \\
\hline \multicolumn{4}{|c|}{ Informal payment was suggested by (who suggested): } \\
\hline Medical staff & $22 / 50(44.0)$ & $7 / 26(26.9)$ & $29 / 76(37.2)$ \\
\hline Self & $18 / 50(36.0)$ & $8 / 26(30.8)$ & $26 / 76(33.3)$ \\
\hline Others (patients, friends) & $7 / 50(14.0)$ & $8 / 26(30.8)$ & $15 / 76(19.2)$ \\
\hline Both (staff and others, self and others) & $3 / 50(6.0)$ & $5 / 26(19.2)$ & $8 / 76(10.3)$ \\
\hline \multicolumn{4}{|c|}{ Amount was determined by (who determined): } \\
\hline Agreed when told by someone & $18 / 50(36.0)$ & $8 / 26(30.8)$ & $26 / 76(33.8)$ \\
\hline Negotiated & $6 / 50(12.0)$ & $3 / 26(11.5)$ & $8 / 76(10.4)$ \\
\hline Him/herself & $23 / 50(46.0)$ & $16 / 26(51.5)$ & $39 / 76(50.6)$ \\
\hline Other way & $3 / 50(6.0)$ & $1 / 26(3.8)$ & $4 / 76(5.2)$ \\
\hline \multicolumn{4}{|l|}{ Reasons for informal payment (reason): } \\
\hline Quality and gratitude & $9 / 50(18.0)$ & $11 / 26(42.3)$ & $20 / 76(25.6)$ \\
\hline Access and gratitude, and other & $20 / 50(40.0)$ & $6 / 26(23.1)$ & $26 / 76(33.3)$ \\
\hline Access and quality, and gratitude & $11 / 50(22.0)$ & $3 / 26(11.5)$ & $14 / 76(17.9)$ \\
\hline Gratitude only and other & $6 / 50(12.0)$ & $7 / 26(26.9)$ & $13 / 76(16.7)$ \\
\hline Other & $4 / 50(8.0)$ & $1 / 26(3.9)$ & $5 / 76(6.4)$ \\
\hline \multicolumn{4}{|c|}{ Informal payment occurred (when occurred): } \\
\hline Before the service & $12 / 50(24.0)$ & $6 / 26(23.1)$ & $18 / 76(23.4)$ \\
\hline After the service & $35 / 50(70.0)$ & $13 / 26(50.0)$ & $48 / 76(62.3)$ \\
\hline Both before and after service & $3 / 50(6.0)$ & $8 / 26(30.8)$ & $11 / 76(14.3)$ \\
\hline
\end{tabular}

Source: Author's analysis of data from 2009 RLMS-HSE.

Notes: The group "medical staff” consists of physicians and other medical personnel; “others" friends or other patients; ${ }^{a}$ Not applicable 
Table 4.5 Description of the patterns of the informal payments

\begin{tabular}{|c|c|c|c|c|c|c|}
\hline \multirow[b]{2}{*}{ Characteristics of the cluster } & \multicolumn{2}{|c|}{ Outpatient non-dental } & \multicolumn{2}{|c|}{ Inpatient } & \multicolumn{2}{|c|}{ Both out- and inpatient } \\
\hline & Cluster 1 & Cluster 2 & Cluster 1 & Cluster 2 & Cluster 1 & Cluster 2 \\
\hline Cluster size & $\mathrm{n}=19(38.0 \%)$ & $\mathrm{N}=31(62.0 \%)$ & $\mathrm{N}=9(34.6 \%)$ & $\mathrm{N}=17(65.4 \%)$ & $\mathrm{N}=39(51.3 \%)$ & $\mathrm{N}=37(48.7 \%)$ \\
\hline \multicolumn{7}{|l|}{ When the amount was } \\
\hline known* & Right before & No one told & Right before & No one told & Right before & No one told \\
\hline Who suggested the payment* & Staff & Self & Staff & Self & Staff & Self \\
\hline \multicolumn{7}{|l|}{ Who determined the } \\
\hline amount* & Was told & Self & Was told & Self & Was told & Self \\
\hline Reason for payment* & Access & Access & Quality & Quality & Access & Gratitude \\
\hline \multicolumn{7}{|l|}{ When the payments } \\
\hline occurred* & After service & After service & Before service & After service & After service & After service \\
\hline
\end{tabular}

Source: Author's analysis of data from 2009 RLMS-HSE.

Notes: * - predominant characteristics of the cluster 
Figure 4.1 Overview of clusters when cases are analyzed together

\section{Cluster Comparison}
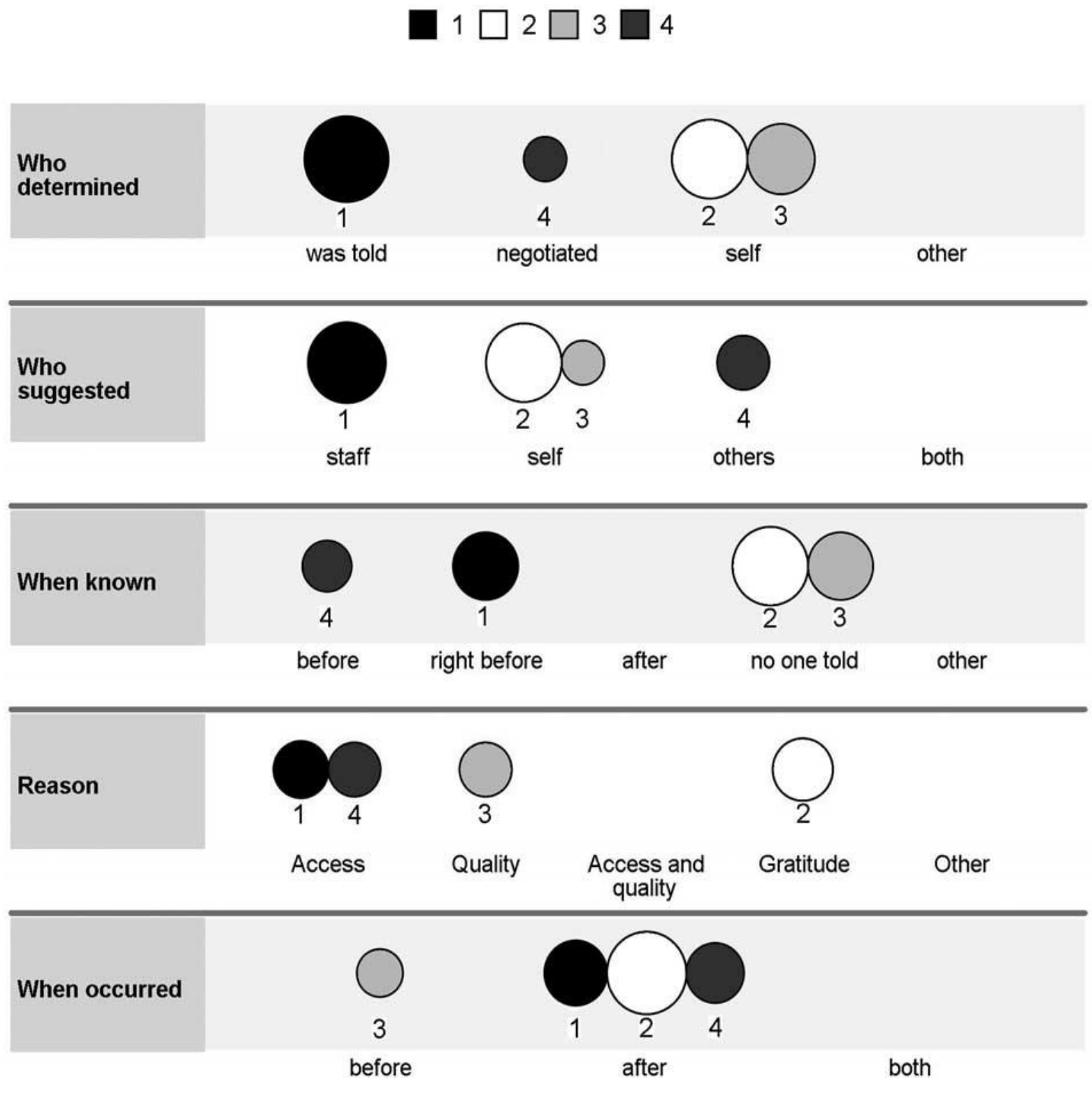

Source: Author's analysis of data from 2009 RLMS-HSE. 
Figure 4.2 Characteristics of clusters (distributional counts)

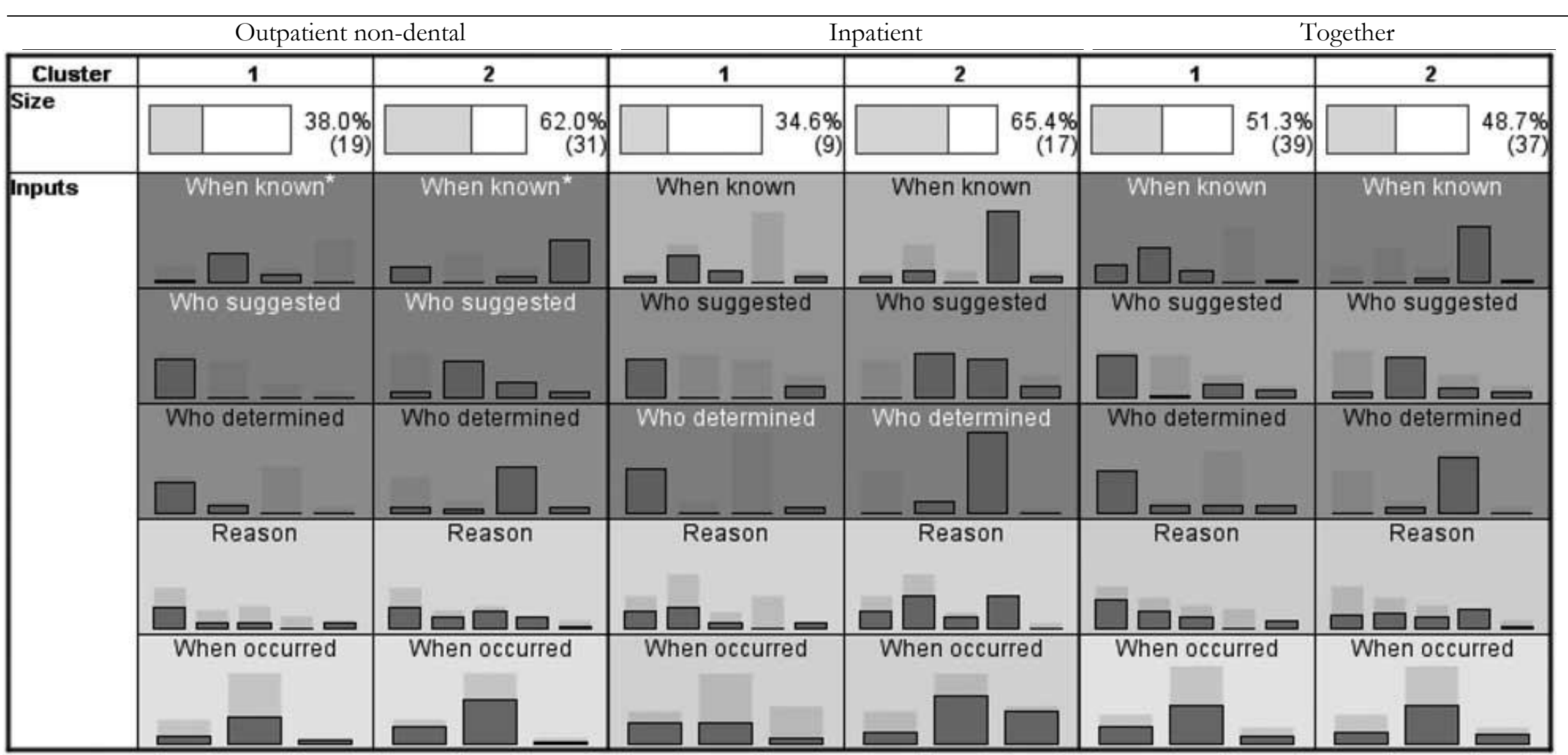

Source: Author's analysis of data from 2009 RLMS-HSE.

Notes: The automatic two-step clustering suggested two main clusters. The Silhouette measure of cohesion and separation was fair. Characteristics of rows as they appear from left to right: when known (before the visit, right before, after the service, nobody told the amount); who suggested to pay (medical staff, self, others, both); who determined (agreed when told by someone, negotiated, self, other way); reason for payment (access, quality, access and quality, gratitude, other); when the payment occurred (before, after service, both before and after service). The deeper shade of grey depicts predictor's importance that was determined automatically and used during cluster analysis. 


\subsection{Discussion}

\subsubsection{The scale and scope of informal payments in 2009}

The results confirm expectations that Russian healthcare users continue to pay informally for all types of healthcare services, both in public and private settings. Whenever users decide to pay informally, they tend to pay most frequently in cash. Gifts are also used for these purposes, but less frequently, and they have a lower monetary equivalent. We also find that the probability of informal payments and the amount paid are determined by socio-economic characteristics, such as the level of education, self-rated health, age, household income, and the presence of disability or at least one chronic sickness.

We find that, in 2009 , the number of users who paid informally ranged from $1.4 \%$ to $17.0 \%$, depending on the type of healthcare service, averaging to ca. $7.3 \%$ among all healthcare users. These figures are similar to those for the preceding and succeeding years, using the same data (as shown by our additional analysis not reported in this chapter). At the same time, it is worthwhile noting that the overall utilization rate of healthcare services by the general population is not high (users rely on self-treatment).

The highest incidence of informal payments (17\%) was reported by users of dental services. The informal payments for dental services are more frequently observed in private settings than in public settings $(27.6 \%$ vs $10.1 \%)$. These findings are interesting, as they indicate that shifting healthcare provision to a private market alone does not necessarily eradicate informal payments, despite a potentially higher quality of care and market-based prices. There are several possible explanations. For instance, the urge to bypass the official cashiers in dental services could be a result of patients' desire or need to avoid paying high tariffs. This could hold true whenever patients pay informally lower amounts (directly to medical personnel) than they would otherwise pay officially (via the cashier). By accepting/requesting informal payments, dentists may also increase their own income, as amounts received informally most likely exceed the official commission (when working on a salary-plus-commission plan). The management of the dental practices could also promote the practice of informal payments to hide income for the purposes of tax evasion. However, no data are currently available that could be used to test these explanations. Therefore, further research that could explain the reasons behind such payments is needed. 
Inpatient service users paid informally more frequently (12.7\% of users) than users of outpatient non-dental and check-up healthcare services ( $4.3 \%$ and $1.4 \%$ of users). Inpatient services normally deal with urgent health matters (when pain is acute and less tolerable), as opposed to outpatient non-dental services and check-up services, where care has a more planned or preventive nature. Therefore, a higher incidence of informal payments could be explained by the desire to avoid uncertainty when health risks are high and the time frame for decision making is constrained. Moreover, in such circumstances, patients and relatives could be more willing to pay informally to gain additional assurance that sufficient quality and attentive care is be provided to treat the health problem.

\subsubsection{Comparison with previous studies for Russia and other European countries}

As shown earlier in the background section, previous studies on the Russian healthcare sector reported a varying range of estimates of the incidence of informal payments in terms of the numbers of users who paid informally or the share of informal payments among all payments. Such variations make a cross-study comparison of the overall size of informal payments in Russia if not impossible, then at least problematic.

One reason for this is the lack of consensus on a universal definition of informal payments, despite previous attempts to formulate one (e.g. Gaal et al., 2006a; Stepurko et al., 2010). Depending on the chosen definition, studies capture different spectra of informal payments. For example, besides monetary hand-to-hand transactions and gift giving, informal payments can account for forced informal non-material contributions (e.g. bed linen and food brought from home, informal care). In addition to this, there are quasi-formal payments (e.g. additional purchases of medications and materials that should have been provided free of charge or "strongly suggested" purchases of certain drugs). The second source of differences are variations in sample sizes, region of data collection, data collection techniques (i.e. face-to-face interviews, self-administered questionnaires) and formulations of questions, all of which can lead to different estimation results. However, the main reason for misleading interpretations that makes cross-country comparisons almost impossible is using different data representation techniques. The most common practice, as shown in section 4.2, is presenting informal payments as a share of all payments and only among those who paid. 
However, we suggest reporting the frequency of incidents of informal payments among users of healthcare services and not among payers for healthcare services alone. This would give a more relevant and easier-to-interpret picture of the phenomenon for government and health policymakers, and help to avoid overestimation (the share of informal payments among payers) or underestimation (frequency of informal payments in the total sample) of the true scale and scope of informal payments. An example, based on findings in this chapter, serves as an illustration and is self-evident. Reporting informal payments among users gives an estimate of $7.3 \%$. If we present the same results as the share among payers, we obtain figures as high as $24.6 \%$, and if we present them as a share of the total sample, we obtain only $2.7 \%$.

When we apply the same scale of representation, we find our results regarding the average level of informal payments comparable with those in previously published reports. At the user and household levels, informal payments seem to remain within the 7\% range. The only difference we observe is the shift in the incidence of informal payments among services. Unlike findings for 2009, where the highest share of informal payments was reported for dental and inpatient services, previous studies for Russia reported the highest shares of informal payments among users of inpatient and outpatient non-dental services, followed by dental services.

Compared with other European countries, the level of informal payments in the Russian health sector (4.3\% users of outpatient non-dental services and $12.7 \%$ of users of inpatient services) seems to be lower. For instance, for the same services in 2010, in Bulgaria informal payments are reported by $9.6 \%$ and $19.8 \%$ of healthcare users, respectively; in Hungary, by $20.8 \%$ and $44.2 \%$, respectively; in Lithuania by $19.8 \%$ and $49.7 \%$; in Poland by $6.7 \%$ and $16.4 \%$; in Romania by $28.7 \%$ and $49.5 \%$; and in Ukraine by 36.1\% and 48.2\%, respectively (Stepurko et al., 2011; Atanasova et al., 2012; Baji et al., 2012; Pavlova et al., 2012). At the same time, the determinants of informal payments, found to be significant in this chapter for Russian healthcare settings, are similar to those reported for other European countries - education, income and health status (e.g. Balabanova \& McKee, 2002; Özgen et al., 2010; Tomini \& Maarse, 2011).

\subsubsection{Reasons for informal payments}

The scale and scope of informal payments estimated in empirical research can be used to approximate the burden that these payments pose on healthcare users. However, these data are not sufficient to explain why these payments exist and continue to exist over time. As the results given 
here confirm, informal patient payments in Russia are complex and can be described by several patterns of paying informally. The reasons for such informal payments are outlined below.

In line with the recent literature on informal payments that elaborates on the reasons of their existence, develops theories and behavioral models of informal payments (Hirschman, 1980; Ensor \& Witter, 2001; Ensor, 2004; Gaal \& McKee, 2004; Stepurko et al., 2010; Cohen, 2011), our results on the patterns of informal patient payments also suggest that on a micro-level (users' perspective), there are at least three dominating reasons for paying informally in the Russian healthcare sector. These reasons include: gaining access to the treatment/service (especially in outpatient non-dental settings), receiving care of a better quality (particularly in inpatient settings) and expressing gratitude to the healthcare professional (in both types of settings). Importantly, these reasons reflect the known problems of the Russian healthcare sector: the lack of satisfaction with the quality of healthcare services by users and providers themselves, equity and access problems and limited or no real users' choice of healthcare provides (Twigg, 2002; Fotaki, 2009; see also Chapter 2). Therefore, it is not surprising that Russian healthcare users have no other option but to search for alternative ways to obtain the healthcare services that they need and desire, via their social networks or informal payments.

Overall, it seems that informal payments in Russian healthcare not only indicate that there are existing problems (indicated above), but that they are also used as one of the compensation mechanisms developed over time. Such observation is in line with the theory of alternative politics for healthcare settings (Cohen, 2011), where in a context of poor governance, informal payments are seen as an alternative way for a user to obtain healthcare services with a quality and in a quantity that they need and desire. The fact that informal payments continue to exist at an almost unchanged $7 \%$ level is another proof of this observation.

Taking into account the patterns of paying informally, the persistent existence of informal payment in Russian healthcare can also be seen as one of the behavioral reactions described in the 'INXIT' theory (Gaal \& McKee, 2004). The theory suggests that when both patient and medical staff are dissatisfied with the declining performance of the healthcare system, both groups are motivated to change the situation. There are three possible options: leave the organization and satisfy wants elsewhere (EXIT), openly complain using available formal channels (VOICE) or try satisfying wants in the organization using informal channels (INXIT). The application of this theory to the Russian healthcare system shows that this system is still characterized by a blocked EXIT (not 
having an ability to leave and seek elsewhere) and a blocked VOICE (lack of complaint system). In particular, a real choice between healthcare providers is still lacking, the alternative market for healthcare services in terms of private sector is non-existent in the majority of Russian cities (with the exception of big capital cities), the spectrum of private healthcare sector services is very limited (with the exception of dental services) and an effective system of feedback within healthcare institutions or via healthcare insurers, which would have a real impact on the provider, is absent (Chapter 2).

\subsubsection{Main limitations}

The limitations in our analysis mainly concern the absence of data regarding other forms of informal payments, such as service-in-exchange, or other contributions (for instance, in the form of informal care, bed linen or food brought to the hospital). Another limitation is the inability to capture so-called "quasi-official" payments. This is because of a lack of objective data that would allow us to check whether users were fully aware of their entitlements and whether they paid for "true" chargeable service and not for services/drugs/materials that should have been provided free of charge. Therefore, our analysis only refers to pure informal payments. The data about the reasons for paying informally were only available for inpatient and outpatient non-dental services. Therefore, the reason behind such payment for dental services should be explored further, when such data becomes available. Lack of similar detailed longitudinal data does not make it possible to examine the relationship between occurred payments and future use of healthcare services in an attempt to identify "bribes for future care".

\subsection{Conclusions and policy implications}

Our results on the scale and scope of informal payments, and the process of paying informally (actors involved, settings, reasons and patterns), provide evidence for policy-makers about this phenomenon. Over time, the level of informal payments remained within the range of $7 \%$, and we believe they will continue to exist if no appropriate governmental actions are taken. And as informal payments impose threats and affect equity in access, as well as the overall efficiency and quality of the provided care, at any level of their existence (Thompson \& Witter, 2000; Balabanova \& McKee, 2002; Ensor, 2004; Allin et al., 2006; Gaal et al., 2006a; Vian \& Burak, 2006; Lewis, 2007; Cohen, 2011; Mæstad \& Mwisongo, 2011), a set of proper governmental actions is necessary to eliminate their existence. 
We believe that the first crucial step in dealing with informal payments should be their official recognition by the Russian government. A clear policy should be developed and implemented in consultation with the representatives of patients' safety organizations, insurers, associations of healthcare providers and medical ethical committees. However, policy-makers should not start a "witch hunt" to capture and punish "werewolves in white coats" (Masuk, 2010), which is how medical staff taking informal payments are sometimes being approached by the Russian media. This step can be rather fostered by conducting a nation-wide information campaign to raise awareness about healthcare users' rights, healthcare entitlements and the content of the ongoing healthcare reforms. Should such strategy be chosen, information campaigns should target both users and healthcare services providers, as both groups initiate informal payments (as shown by our results).

It is clear that official recognition and information awareness campaigns alone are not sufficient to eradicate informal payments. Tackling informal payments is challenging, as it requires implementing a number of conjugate measures. In general, reforms should address the main reasons why Russian healthcare users pay informally (i.e. access to healthcare services and more attentive and better quality care as suggested by our results), and aim at the development of a consumer- and market-oriented healthcare provision.

The basic package of healthcare services (Government of the Russian Federation, 1993) should be revised and exclude unaffordable State guarantees. Leaving fewer but affordable services would free sufficient funding necessary to increase the quality of the remaining services. Next, reforms should give more choice to healthcare consumers by improving the existing public healthcare sector services, but also possibly by creating more favorable conditions for the development of an alternative (private) market of healthcare services provision (e.g. relaxation of taxation). Competition between the public and private organizations in service provision (outside of the basic package of healthcare services) could improve cost-efficiency and lead to a significant quality improvement. However, an increase in the volume of services by including private sector providers alone would not eliminate informal payments. As shown in our results, patients pay informally also for services received in private settings.

Users should also have access to open channels of communication (both with service providers and insurance companies) to provide timely feedback on quality of received services and the possibility to file complaints regarding problems encountered (i.e. access, complications, waiting time and whether they had to pay informally). Health consumer empowerment should also be 
fostered and healthcare users should take more responsibility over their own health (something Russian citizens are still not used to). The introduction of co-payments for services outside the basic package and higher than standard quality of services via voluntary insurance or direct out-of pocket payments would leave less reason for informal payments to exist. To tackle the informal payments even further, we suggest that, in principle, all direct financial transactions between the healthcare user and the provider should be eliminated and be channeled solely via the insurer (e.g. via billing at home). Moreover, patients could express their gratitude (another identified reason for paying informally) not by means of presents or informal cash payments to the provider, but by staying loyal and choosing the same providers and insurers again.

Some of these proposed measures are possible for implementation as they gained additional legal bases as a result of the recent changes in the Russian legislation, i.e. Federal Law No. 326, 2010 and Federal Law No. 323, 2011 (Government of the Russian Federation, 2010, 2011). However, these legal acts were not specifically adopted for the purpose of eliminating informal payments. Therefore, we do not expect that they will affect the existence of informal payments in the short run (in 2014, none of the measures have been implemented). Nonetheless, considering the recent changes in legislation as a base for further actions, we call on Russian health policy-makers to put informal payments on their agenda as soon as possible. Once again, ignoring and avoiding the issue will not make informal payment disappear, as they had proven to be self-sustainable and persisting over the years. We believe that without active governmental measures, addressing informal payments will be doomed to fail. 
Chapter 5

Catastrophic and impoverishing effects of healthcare payments in Russia: Why forgo and why go below?

Gordeev, V.S., Pavlova, M., Groot, W.

Submitted for publication 


\begin{abstract}
In this chapter Russian households that had to forgo necessary healthcare services due to the lack of financial resources are examined. The catastrophic and impoverishing effects of incurred outof-pocket healthcare payments are examined, as is the association between spells of forgoing healthcare services and experiencing catastrophic healthcare payments with exiting or entering poverty the following year.
\end{abstract}

The results suggest that over the last decade (2001-2011), inequalities due to out-of-pocket healthcare payments decreased, but worse-off households are still affected the most by catastrophic and impoverishing out-of-pocket healthcare payments. A two-fold reduction in the incidence of forgoing healthcare services by households due to the lack of money followed by a three-fold reduction in overall poverty levels. Nonetheless, 10-12\% of Russian households still forgo necessary care. In 2011, 13\% of Russian households (using a 10\% total household expenditure threshold) or ca. $6 \%$ (using a $40 \%$ non-food threshold) incurred catastrophic out-of-pocket healthcare payments. The incidence of impoverishing out-of-pocket healthcare payments decreased and is now less than $1 \%$.

Forgoing necessary medical care due to a lack of money and experiencing catastrophic out-ofpocket healthcare payments are associated with the inability of poor households to exit poverty and with the probability of entering into poverty in the future for non-poor households. This finding is also relevant to policy-makers in countries, where out-of-pocket healthcare payments have considerable poverty effects. 


\subsection{Introduction}

To ensure the sustainability of healthcare financing, countries increasingly rely on out-of-pocket payments that complement government and insurance financing (Roberts et al., 2004). It is well known, however, that a heavy reliance on out-of-pocket healthcare payments results in a high financial burden for households and can have poverty effects (Amaya Lara \& Ruiz Gomez, 2011; Xu et al., 2003; Wagstaff \& Doorslaer, 2003). To depict such poverty effects, two complementary approaches are widely applied - estimation of the impoverishing and catastrophic effects of outof-pocket payments. Household out-of-pocket spending on healthcare is labelled as "impoverishing" when the financial burden caused by these payments either pushes non-poor household into poverty or pushes poor households even further into poverty (Wagstaff \& Doorslaer, 2003). Whenever out-of-pocket healthcare payments absorb a large fraction of a household's resources (exceeding a certain threshold) and, therefore, affect the household's standards of living, out-of-pocket payments are referred to as "catastrophic" (Berki, 1986; Russell, 2004; Wagstaff \& Doorslaer, 2003; Wyszewianski, 1986; Xu et al. 2003).

The Russian Federation has an upper-middle income economy (high income as of 2013), but the healthcare sector is still underfinanced (OECD, 2012; see also Chapter 2). As outlined in Chapter 1 , the share of out-of-pocket payments is $35 \%$ of total healthcare expenditure and $88 \%$ of private expenditure on healthcare (World Bank, 2013). It might be anticipated that such share of out-ofpocket healthcare payments may have substantial poverty effects and may affect the wealth of Russian households. Nonetheless, whilst a number of studies have addressed the changes in poverty levels, as well as issues of the transient and chronic poverty (for an overview see Denisova, 2012), none of them have actually examined the poverty effects of out-of-pocket healthcare payments or their relationship with existing poverty levels. Such empirical evidence could be essential for optimizing Russian social and healthcare policies aimed at fairness in both provision and financing of healthcare services. It would also be relevant for the development of appropriate strategies of mitigation and minimization of the incidence of payments that can push households into poverty; thus, helping to ensure the affordability of healthcare services.

In this chapter estimates of the catastrophic and impoverishing effects of out-of-pocket healthcare payments incurred by Russian households are provided. Such estimates have not been previously reported. We start by looking at Russian households that cannot afford to use healthcare services due to a lack of resources and which, therefore, completely or partially forgo healthcare use. This issue is quite often left out of the scope of studies on catastrophic and impoverishing effects of 
out-of-pocket healthcare payments, mainly due to the lack of data (Bhojani et al., 2012; Bonu et al., 2009; van Doorslaer et al., 2007). The chapter continues by estimating the possible poverty (catastrophic and impoverishing) effects of out-of-pocket healthcare payments, incurred by households, and reports related figures on their incidence and intensity. Furthermore, the association between spells of forgoing healthcare services and experiencing catastrophic healthcare payments with exiting or entering poverty the following year is examined. To our knowledge, none of the previous studies has examined such associations. Following the recommendations in the literature on catastrophic and impoverishing effects of out-of-pocket healthcare expenditure (Arsenijevic et al. 2013; Chuma and Maina, 2013; Gertler \& Gruber 2002; van Doorslaer et al., 2007; Wagstaff, 2007), a longitudinal approach for data analysis is used. Based on these results, we outline relevant policy implications for health policy-makers in countries with transitional economies and underfinanced healthcare sectors, in particular, for former-socialistic countries.

\subsection{Methods}

\subsubsection{Data}

This chapter utilizes the RLMS-HSE dataset (see Chapter 1, Section 1.6). The dataset provides data that allows for the precise measurement of household-level expenditures (out-of-pocket healthcare payments) and service utilization, including healthcare services. Data is used from rounds 10-20 (2001-2011).

The analysis focuses on household health-related out-of-pocket expenditure, which combines the payments for treatment and examination procedures in inpatient and outpatient clinics, dental treatment, and payments for pharmaceuticals, incurred by households over the last 30 days. We use household expenditure as an indicator of household wealth, which is a widely accepted and conventionally utilized wealth measure (Baeza \& Packard 2005; Xu et al. 2003; Xu et al., 2010). Total household expenditure in our dataset is an aggregate of various types of household expenditures, including health-related out-of-pocket payments. We included only households with complete expenditure information. Depending on the year (survey wave), the number of households that had incomplete expenditure records varied, but did not exceed 6-8\% of all households included in each survey wave. Household expenditure and household out-of-pocket healthcare payments are measured in Rubles. In order to account for the inflation over the years, 
for analysis, we use real rubble values, derived from the nominal values equivalent to June 1992 Rubles.

\subsubsection{Measurement of catastrophic and impoverishing effects of out-of-pocket payments}

We use several thresholds to estimate the catastrophic effects of the household's health-related out-of-pocket payments. Currently there seems to be no consensus regarding the value of the threshold, above which the payments should be labelled as "catastrophic". Therefore, for the analysis, the most frequently applied thresholds are set at 10\% of total household expenditure or 40\% of non-food expenditure (Arsenijevic et al. 2013; Pradhan \& Prescott 2002; Ranson 2002; Tomini et al. 2013; Wagstaff \& van Doorslaer 2003; Xu et al., 2003; Xu et al. 2007; Xu et al. 2010) is used. However, the cut-off points of $5 \%, 10 \%, 15 \%$, and $25 \%$ for total household expenditure, and $15 \%, 25 \%$, and $40 \%$ for non-food household expenditure are also applied.

The incidence and intensity of catastrophic payments by the catastrophic payment head count, catastrophic payment mean overshoot and catastrophic payment mean positive overshoot, as well as by distribution-sensitive measures (i.e. concentration indices of incidence and overshoot, rank weighted headcount and overshoot) are measured. The catastrophic payment headcount denotes the fraction of households whose out-of-pocket healthcare payments, as a share of total (or nonfood) expenditure, exceed the given threshold $(5 \%, 10 \%, 15 \%, 25 \%$, or $40 \%)$. The catastrophic payment mean overshoot captures the average degree by which household's out-of-pocket healthcare expenditure (as a share of total or non-food expenditure) exceeds the given threshold, thus, specifying the intensity of out-of-pocket healthcare payments. The catastrophic payment mean positive overshoot links the incidence and intensity indicators and is defined as the overshoot over the headcount (more details in O'Donnell et al., 2008; Wagstaff \& Doorslaer, 2003).

In order to estimate the impoverishing effects of the household's health-related out-of-pocket payments, we use the absolute poverty threshold (absolute poverty line) for the Russian Federation. Households' all-Russia poverty thresholds are based on the sum of each household member's individual-level poverty thresholds. More information about the construction of the absolute poverty can be found in Popkin et al. (1996). As with the measures of the catastrophic effects of out-of-pocket healthcare payments, the impoverishing effects are described by the poverty headcount and the poverty gap, as well as the normalized poverty gap and mean positive poverty gap. The poverty headcount depicts the fraction of households living in poverty. The depth of 
poverty, measured as the amount by which the poor households fall short of reaching the absolute poverty line, is captured by the poverty gap. The poverty gap can also be defined as the fraction of households who are poor, captured by the poverty headcount, multiplied by the average distance of the poor from the poverty line. The mean positive poverty gap is normalized on the poverty line (more details in O'Donnell et al., 2008).

\subsubsection{Regression analysis}

In addition to the above analyses, logistic regression to examine the association between spells of forgoing healthcare use (healthcare services and/or pharmaceuticals) or experiencing catastrophic healthcare payments with exiting or entering poverty in the following year is applied. The analysis is carried out for two separate groups of households: poor and non-poor households in the current year. Based on the panel structure of the data, we construct a dichotomous indicator that helps identify previously poor households that exited (or remained in) poverty the following year, and for the non-poor households - those that entered into poverty or remained non-poor compared to the previous year. In the analyses, we account for other variables found to have a significant impact in previous studies on poverty in the Russian Federation (e.g. Denisova, 2012). More specifically, characteristics that cushioned poverty spells include: households with pensioners; households headed by elderly members; extended families; households, where members had higher levels of education, and were residing in urban areas. Vulnerable households, on the contrary, typically have a larger number of children (especially single parents), the educational level of dwellers was low, and live in rural areas. We also include an additional set of variables that cover health-related household characteristics: the presence of any household member with at least one chronic illness or disability; the incidence of catastrophic out-of-pocket healthcare payments during the last 30 days; the incidence of forgoing healthcare service due to the lack of money in the last year by at least one household member. Both descriptive and regression analyses are performed using STATA 12.

\subsection{Results}

In general, households are headed by women below the official pension age and on average have 2-3 members living in the same household. The majority of households have at least one member that utilized at least one healthcare service, and most households had at least one member with a chronic illness (overview in Table 5.1). 


\subsubsection{Trends in the overall poverty levels, health utilization, and out-of-pocket healthcare payments}

During the last decade (2001-2011), the overall level of poverty in the Russian Federation has declined from 34\% to 12-13\% (Figure 5.1). Similarly, the number of households where at least one family member had to forgo healthcare use during the last 12 months (due to a lack of money) also decreased. The incidence of forgoing healthcare services almost halved from $21-22 \%$ in $2001-2002$ to a $10-12 \%$ level in 2010-2011. As depicted on Figure 5.2, a decline in forgoing healthcare services is comprised of a steep reduction in the incidence of forgoing the purchase of pharmaceuticals (from $15 \%$ to 6-7\% level) and a more gradual decline in forgoing dental care (from $11-12 \%$ to 9\%), followed by a moderate decline for outpatient and inpatient healthcare services (from $6 \%$ to 3\% and from $5 \%$ to $3 \%$, respectively).

Table 5.1 Overview of the pooled samples in 2005

\begin{tabular}{|c|c|c|}
\hline & Entered poverty & Exited poverty \\
\hline Characteristics & Pooled sample mean & Pooled sample mean \\
\hline \multicolumn{3}{|l|}{ Head of the household (HHH) } \\
\hline Gender of HHH (female), yes & 89.30 & 87 \\
\hline Age of $\mathrm{HHH}$, years & $49.65 \pm 16.69$ & $47.55 \pm 16.23$ \\
\hline Education level of HHH (high), yes & 24.30 & 9.40 \\
\hline Education level of $\mathrm{HHH}$ (low), yes & 18.20 & 27.20 \\
\hline \multicolumn{3}{|l|}{ Household (HH) } \\
\hline Number of adults & $2.27 \pm 1.08$ & $2.68 \pm 1.32$ \\
\hline Number of children & $0.40 \pm 0.66$ & $0.64 \pm 0.91$ \\
\hline $\mathrm{HH}$ resides in urban area, yes & 69.30 & 46.20 \\
\hline $\mathrm{HH}$ with pensioners, yes & 54.50 & 47.20 \\
\hline \multicolumn{3}{|l|}{ Healthcare utilization by $\mathbf{H H}$} \\
\hline HH used healthcare services, yes & 64.60 & 56.80 \\
\hline HH paid for healthcare, yes & 71.30 & 45.80 \\
\hline $\mathrm{HH}$ forwent service during last 12 months, yes & 15.90 & 21.20 \\
\hline At least $1 \mathrm{HH}$ member with disability, yes & 18.50 & 16.80 \\
\hline At least $1 \mathrm{HH}$ member with chronic disease, yes & 75.80 & 66.70 \\
\hline Catastrophic payment in the base year, yes & 12.70 & 11.00 \\
\hline
\end{tabular}

Source: Author's analysis of data from RLMS-HSE. 
The frequency of healthcare service utilization (inpatient, outpatient, dental and preventive) by Russian households has remained fairly constant (within 60-63\% range). Two-thirds of all Russian households have at least one (or more) household member who has used at least one healthcare service during the last three months (Figure 5.1). The incidence of out-of-pocket healthcare payments incurred by households also remains stable over time and fluctuates within the 30-33\% interval. Such out-of-pocket healthcare payments account both for official and informal payments. Additional analysis (not presented in Figure 5.1) shows that on average, the level of informal payments has remained within the $8-11 \%$ level among households where at least one (or more) household member has used healthcare services during the last 3 months, while the frequency of official payments ranges from $25 \%$ to $28 \%$.

Figure 5.1 Characteristics of households: poverty, healthcare utilization and out-of-pocket payments

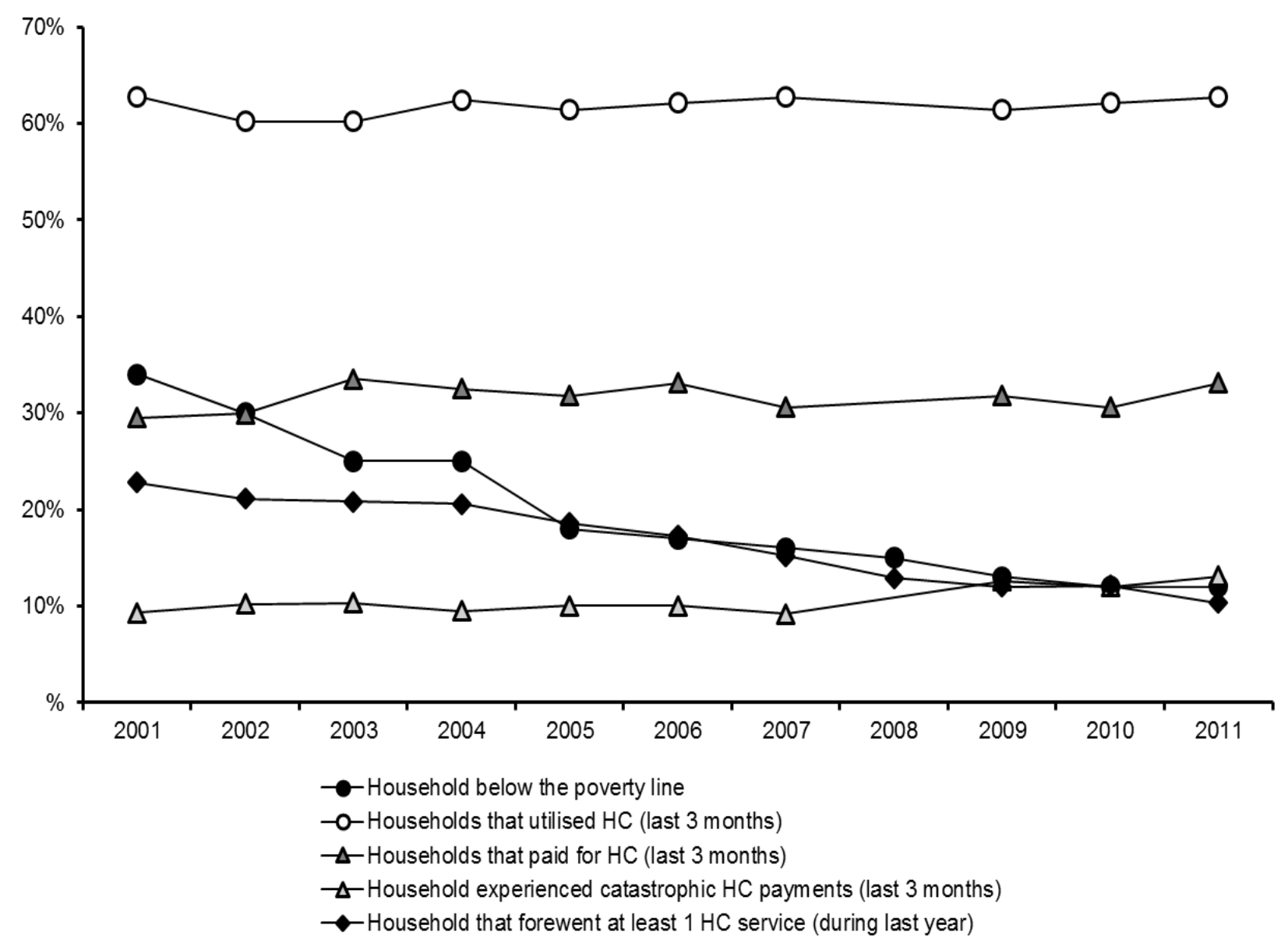

Source: Author's analysis of data from RLMS-HSE.

Notes: In 2008, no detailed data on healthcare expenditure was collected for individuals and households. 
The composition of healthcare expenditure varies by expenditure-based quintiles. Table 5.2 provides an overview of the out-of-pocket healthcare payments made by households, both as a share of non-food and total household expenditure. On average, $4-5 \%$ of the total and $9-11 \%$ of non-food household expenditure are out-of-pocket healthcare payments. The burden of out-ofpocket healthcare payments is higher for the first two lowest quintiles, and exceeds the mean share for all households, according to both total household expenditure and non-food expenditure approaches. In general, households belonging to the fourth expenditure quintile seem to have been spending consistently less on healthcare during the decade, followed by households belonging to the fifth and third quintile. Even though there is a slight increase in the overall share of out-ofpocket healthcare payments in total household expenditure, their proportion as a non-food expenditure varies, depending on the year.

Figure 5.2 Forgoing healthcare services

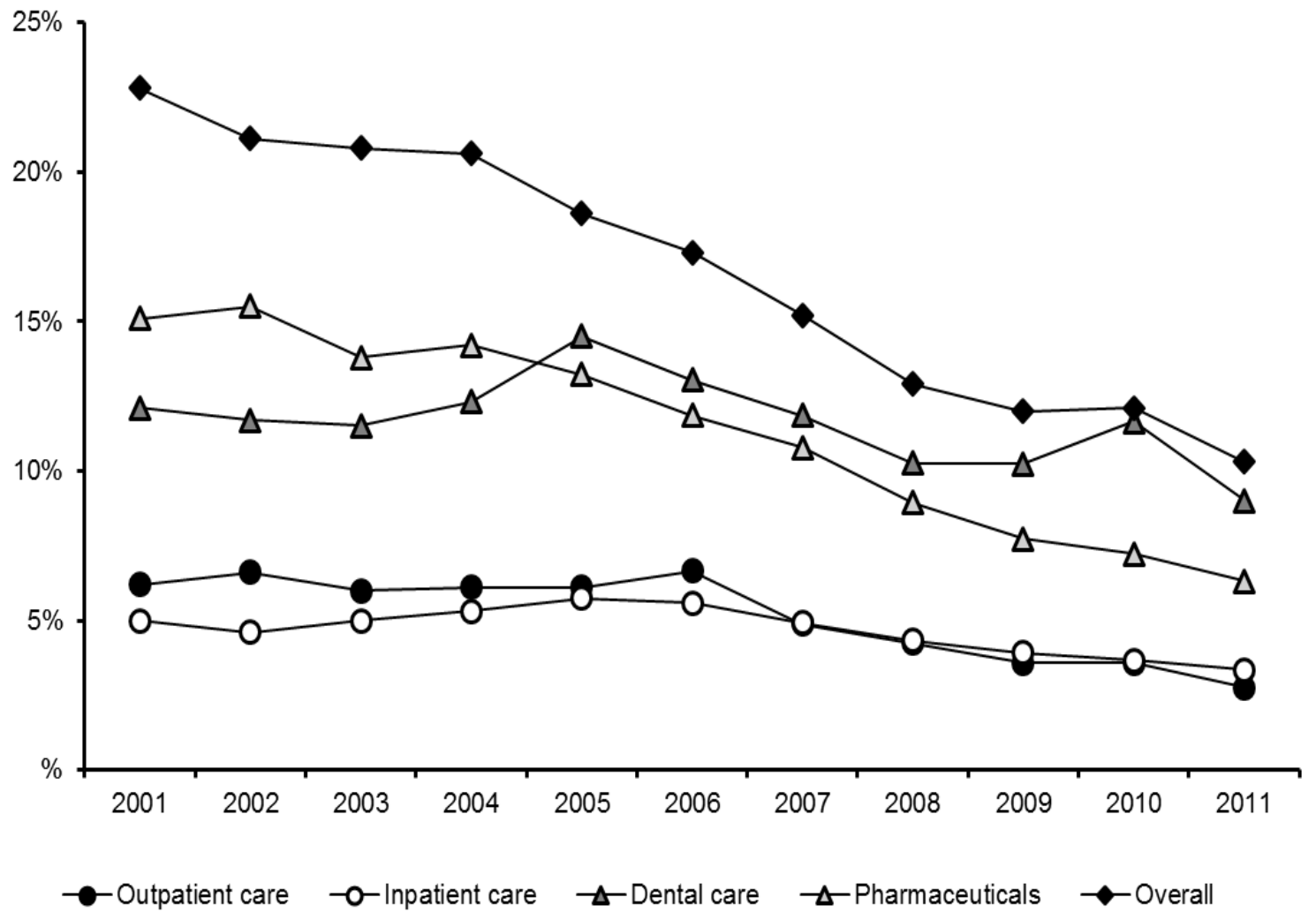

Source: Author's analysis of data from RLMS-HSE.

The rank weighted catastrophic payment headcount estimate values $\left(\mathrm{H}_{\mathrm{C}}{ }^{\mathrm{W}}\right.$ in Table 5.3) are more sensitive to the distribution of household expenditure. The values are similar to those of the headcount and have a similar tendency of increasing over the 11 years period and are higher than catastrophic payment headcount values, with the exception of 2004-2007. Since the rank weighted 
catastrophic headcount values are greater than catastrophic payment headcount, catastrophic payments occur more frequently among the poor.

During 2001-2003 and 2008-2011, those households that were worse-off had been most likely to exceed the $10 \%$ threshold (negative value of the concentration index of the incidence of catastrophic payments - $C_{E}$ - in Table 5.3), with the exception of four years in between (2004-2007), when the better-off households had been most likely to do so (as the positive value indicates). When health payments are assessed relative to non-food expenditure (40\% threshold), the incidence of catastrophic healthcare payments has slowly decreased from $8.3 \%$ in 2001 to $5.7 \%$ in $2011\left(\mathrm{H}_{\mathrm{C}}\right.$ in Table 5.3). The worse-off households were the ones who were likely to exceed the $40 \%$ non-food expenditure threshold persistently from 2002 onwards (negative $\mathrm{C}_{\mathrm{E}}$ - in Table 5.3). Rank weighted headcount estimates (denoted as $\mathrm{H}_{\mathrm{C}}{ }^{\mathrm{W}}$ in Table 5.3) also follow the catastrophic payment headcount estimates trend, with a steeper decline in 2004-2007. The rank weighted catastrophic headcount is greater than the catastrophic payment headcount; therefore, catastrophic payments occur more frequently among the poor.

The intensity of catastrophic payments (denoted as $\mathrm{O}$ in Table 5.4) decreases as the threshold is raised from 5 to $25 \%$, both for total and non-food household expenditure estimations. At the $10 \%$ threshold of total household expenditure, the concentration index (Co in Table 5.4) is mainly positive, which means that the overshoot tends to be greater among the better-off households. On the contrary, those households that are worse-off tend to experience the overshoot, but only following the non-food expenditure approach. The rank-weighted overshoot estimations $\left(\mathrm{O}^{\text {w }}\right.$ in Table 5.4) follow the respective trends of the mean overshoot for both total and non-food household expenditure approaches. Looking at the mean positive overshoot (MPO in Table 5.4), we observe that households that have been spending more than $10 \%$ of their total household healthcare expenditure, on average had spent $21.8 \%$ in out-of-pocket expenditure in 2001 . This is calculated by summing up the value of the threshold (10\%) and mean positive overshoot $(11.8 \%)$. In 2005 and 2011, households on average spent 21-22\% of the total household expenditure on healthcare, respectively. Following the non-food expenditure approach, households' expenditure had decreased slightly from $31.8 \%$ in 2001 to $28.3 \%$ in 2011 of the non-food expenditure. 


\subsubsection{The impoverishing out-of-pocket healthcare payments}

Table 5.5 gives the estimates of the impoverishing effects of out-of-pocket payments. Based on poverty headcount in Table 5.5, over the 11 years period, the number of households in extreme poverty has sharply decreased from $23.3 \%$ in 2001 to $3.4 \%$ in 2011 (third column in Table 5.5). However, the post-payment poverty headcounts (the fourth column in Table 5.5) are slightly higher. When out-of-pocket healthcare payments are netted out of household expenditure, the number of households in extreme poverty rises from $23.3 \%$ to $25 \%$ in 2001 , and similarly from 3.4 to $4.1 \%$ in 2011 . Thus, the percentage of Russian households that are not being counted as living in extreme poverty but would be considered poor if spending on healthcare is discounted from household resources, is $1.7 \%$ in 2001 and $0.7 \%$ in 2011 (fifth column in Table 5.5). Overall, this represents a $10-20 \%$ increase in the estimate of extreme poverty (sixth column in Table 5.5). The poverty gap after out-of-pocket healthcare payments is also consistently higher, although decreasing over the years.

The poverty impact, calculated as the difference in poverty gap values (pre- and post-payments), has decreased, showing that inequalities due to out-of-pocket healthcare payments have decreased over the 11 years period (fifth row in Table 5.5). On average, however, it increases by ca. 10\% when out-of-pocket payments are discounted (sixth column in Table 5.5). Expressed as the percentage of the poverty line (normalized poverty gap in Table 5.5), the poverty gap increases by $0.7 \%$ in 2001 and $0.2 \%$ in 2011 when health payments are netted out of household expenditure. 
Table 5.2 Out-of-pocket payments for healthcare services as a percentage of household expenditure

\begin{tabular}{|c|c|c|c|c|c|c|c|c|c|c|c|}
\hline Year & 2001 & 2002 & 2003 & 2004 & 2005 & 2006 & 2007 & 2008 & 2009 & 2010 & 2011 \\
\hline \multicolumn{12}{|c|}{ Out-of-pocket payments as percentage of total household expenditure } \\
\hline Mean & $4.01 \%$ & $4.29 \%$ & $4.47 \%$ & $4.38 \%$ & $4.29 \%$ & $4.25 \%$ & $4.27 \%$ & $4.57 \%$ & $5.00 \%$ & $4.94 \%$ & $5.35 \%$ \\
\hline \multicolumn{12}{|c|}{ Quintile means } \\
\hline Q1 & $5.17 \%$ & $6.31 \%$ & $5.77 \%$ & $5.84 \%$ & $5.27 \%$ & $4.95 \%$ & $5.51 \%$ & $6.40 \%$ & $6.89 \%$ & $6.46 \%$ & $6.73 \%$ \\
\hline Q2 & $4.19 \%$ & $4.23 \%$ & $5.01 \%$ & $4.51 \%$ & $4.32 \%$ & $4.29 \%$ & $4.84 \%$ & $4.82 \%$ & $5.24 \%$ & $5.45 \%$ & $5.97 \%$ \\
\hline Q3 & $3.56 \%$ & $3.64 \%$ & $4.25 \%$ & $4.29 \%$ & $3.69 \%$ & $3.93 \%$ & $3.83 \%$ & $4.10 \%$ & $4.81 \%$ & $4.68 \%$ & $4.69 \%$ \\
\hline Q4 & $3.19 \%$ & $3.45 \%$ & $3.83 \%$ & $3.70 \%$ & $3.45 \%$ & $4.06 \%$ & $3.81 \%$ & $3.84 \%$ & $4.46 \%$ & $3.89 \%$ & $4.91 \%$ \\
\hline Q5 & $3.94 \%$ & $3.81 \%$ & $3.48 \%$ & $3.54 \%$ & $4.75 \%$ & $3.99 \%$ & $3.34 \%$ & $3.71 \%$ & $3.62 \%$ & $4.32 \%$ & $4.45 \%$ \\
\hline \multicolumn{12}{|c|}{ Out-of-pocket payments as percentage of household non-food expenditure } \\
\hline Mean & $10.64 \%$ & $10.53 \%$ & $10.26 \%$ & $10.25 \%$ & $9.19 \%$ & $8.36 \%$ & $8.50 \%$ & $8.93 \%$ & $9.57 \%$ & $9.18 \%$ & $9.58 \%$ \\
\hline \multicolumn{12}{|c|}{ Quintile means } \\
\hline Q1 & $15.90 \%$ & $16.76 \%$ & $15.50 \%$ & $16.53 \%$ & $13.62 \%$ & $11.81 \%$ & $13.14 \%$ & $15.14 \%$ & $15.64 \%$ & $13.95 \%$ & $14.11 \%$ \\
\hline Q2 & $12.17 \%$ & $12.19 \%$ & $12.65 \%$ & $18.44 \%$ & $10.66 \%$ & $9.49 \%$ & $10.80 \%$ & $10.35 \%$ & $10.4 \%$ & $10.67 \%$ & $11.07 \%$ \\
\hline Q3 & $10.04 \%$ & $9.36 \%$ & $9.79 \%$ & $16.17 \%$ & $7.89 \%$ & $7.67 \%$ & $7.33 \%$ & $7.74 \%$ & $9.42 \%$ & $8.68 \%$ & $8.63 \%$ \\
\hline Q4 & $8.08 \%$ & $7.67 \%$ & $7.84 \%$ & $7.49 \%$ & $6.60 \%$ & $7.05 \%$ & $6.37 \%$ & $6.33 \%$ & $7.31 \%$ & $6.62 \%$ & $13.82 \%$ \\
\hline Q5 & $7.18 \%$ & $6.65 \%$ & $5.60 \%$ & $5.70 \%$ & $7.17 \%$ & $12.38 \%$ & $4.84 \%$ & $5.13 \%$ & $5.15 \%$ & $6.01 \%$ & $12.54 \%$ \\
\hline
\end{tabular}

Source: Author's analysis of data from RLMS-HSE. 
Table 5.3 Catastrophic out-of-pocket healthcare payments - headcount

\begin{tabular}{|c|c|c|c|c|c|c|c|c|}
\hline \multirow[b]{2}{*}{ Year } & \multirow[b]{2}{*}{ Threshold } & \multicolumn{4}{|c|}{$\begin{array}{l}\text { Out-of-pocket payments as share of } \\
\text { total household expenditure }\end{array}$} & \multicolumn{3}{|c|}{$\begin{array}{l}\text { Out-of-pocket payments as share } \\
\text { of non-food expenditure }\end{array}$} \\
\hline & & $5 \%$ & $10 \%$ & $15 \%$ & $25 \%$ & $15 \%$ & $25 \%$ & $40 \%$ \\
\hline \multirow[t]{3}{*}{2001} & Headcount $\left(\mathrm{H}_{\mathrm{C}}\right)$ & 18.60 & 9.30 & 5.60 & 2.40 & 21.60 & 14.20 & 8.30 \\
\hline & Concentration index $\left(\mathrm{C}_{\mathrm{E}}\right)$ & -0.022 & -0.010 & 0.019 & 0.064 & -0.172 & -0.114 & 0.022 \\
\hline & Rank weighted headcount $\left(\mathrm{H}_{\mathrm{C}}{ }^{\mathrm{W}}\right)$ & 19.00 & 9.43 & 5.46 & 2.26 & 25.31 & 15.82 & 8.48 \\
\hline \multirow[t]{3}{*}{2002} & Headcount $\left(\mathrm{H}_{\mathrm{C}}\right)$ & 20.90 & 10.20 & 5.90 & 2.70 & 22.10 & 14.20 & 7.80 \\
\hline & Concentration index $\left(\mathrm{C}_{\mathrm{E}}\right)$ & -0.044 & -0.062 & -0.088 & -0.036 & -0.230 & -0.294 & -0.345 \\
\hline & Rank weighted headcount $\left(\mathrm{H}_{\mathrm{C}}{ }^{\mathrm{W}}\right)$ & 21.81 & 10.78 & 6.39 & 2.76 & 27.23 & 18.33 & 10.50 \\
\hline \multirow[t]{3}{*}{2003} & Headcount $\left(\mathrm{H}_{\mathrm{C}}\right)$ & 21.10 & 10.30 & 6.00 & 2.70 & 21.4 & 13.60 & 7.10 \\
\hline & Concentration index $\left(\mathrm{C}_{\mathrm{E}}\right)$ & -0.054 & -0.044 & -0.011 & 0.037 & -0.255 & -0.289 & -0.316 \\
\hline & Rank weighted headcount $\left(\mathrm{H}_{\mathrm{C}}{ }^{\mathrm{W}}\right)$ & 22.23 & 10.79 & 6.03 & 2.60 & 26.83 & 17.49 & 9.29 \\
\hline \multirow[t]{3}{*}{2004} & Headcount $\left(\mathrm{H}_{\mathrm{C}}\right)$ & 19.6 & 9.50 & 6.00 & 2.40 & 21.5 & 13.6 & 7.70 \\
\hline & Concentration index $\left(C_{\mathrm{E}}\right)$ & -0.018 & 0.011 & 0.074 & 0.182 & -0.257 & -0.304 & -0.335 \\
\hline & Rank weighted headcount $\left(\mathrm{H}_{\mathrm{C}}{ }^{\mathrm{W}}\right)$ & 19.98 & 9.38 & 5.57 & 1.99 & 27.08 & 17.68 & 10.28 \\
\hline \multirow[t]{3}{*}{2005} & Headcount $\left(\mathrm{H}_{\mathrm{C}}\right)$ & 19.80 & 10.00 & 6.50 & 2.90 & 19.10 & 12.00 & 6.20 \\
\hline & Concentration index $\left(\mathrm{C}_{\mathrm{E}}\right)$ & 0.018 & 0.060 & 0.085 & 0.145 & -0.214 & -0.244 & -0.274 \\
\hline & Rank weighted headcount $\left(\mathrm{H}_{\mathrm{C}}{ }^{\mathrm{W}}\right)$ & 19.46 & 9.42 & 5.91 & 2.50 & 23.19 & 14.92 & 7.89 \\
\hline \multirow[t]{3}{*}{2006} & Headcount $\left(\mathrm{H}_{\mathrm{C}}\right)$ & 20.80 & 10.00 & 5.80 & 2.50 & 17.40 & 10.00 & 5.00 \\
\hline & Concentration index $\left(\mathrm{C}_{\mathrm{E}}\right)$ & -0.012 & 0.033 & 0.046 & 0.120 & -0.203 & -0.235 & -0.269 \\
\hline & Rank weighted headcount $\left(\mathrm{H}_{\mathrm{C}}{ }^{\mathrm{W}}\right)$ & 21.01 & 9.68 & 5.53 & 2.23 & 20.89 & 12.31 & 6.31 \\
\hline \multirow[t]{3}{*}{2007} & Headcount $\left(\mathrm{H}_{\mathrm{C}}\right)$ & 18.90 & 9.20 & 5.30 & 2.40 & 18.20 & 10.90 & 5.10 \\
\hline & Concentration index $\left(C_{E}\right)$ & -0.025 & 0.025 & 0.094 & 0.175 & -0.283 & -0.309 & -0.310 \\
\hline & Rank weighted headcount $\left(\mathrm{H}_{\mathrm{C}}{ }^{\mathrm{W}}\right)$ & 19.32 & 8.99 & 4.85 & 1.94 & 23.30 & 14.32 & 6.73 \\
\hline \multirow[t]{3}{*}{2008} & Headcount $\left(\mathrm{H}_{\mathrm{C}}\right)$ & 20.70 & 9.70 & 5.80 & 2.70 & 18.70 & 10.90 & 5.80 \\
\hline & Concentration index $\left(\mathrm{C}_{\mathrm{E}}\right)$ & -0.058 & -0.029 & 0.029 & 0.020 & -0.303 & -0.351 & -0.320 \\
\hline & Rank weighted headcount $\left(\mathrm{H}_{C}{ }^{\mathrm{W}}\right)$ & 21.88 & 9.95 & 5.65 & 2.61 & 24.31 & 14.68 & 7.72 \\
\hline \multirow[t]{3}{*}{2009} & Headcount $\left(\mathrm{H}_{\mathrm{C}}\right)$ & 24.60 & 12.60 & 6.80 & 2.70 & 20.40 & 12.00 & 5.50 \\
\hline & Concentration index $\left(C_{E}\right)$ & -0.036 & -0.036 & -0.011 & -0.002 & -0.264 & -0.312 & -0.343 \\
\hline & Rank weighted headcount $\left(\mathrm{H}_{\mathrm{C}}{ }^{\mathrm{W}}\right)$ & 25.48 & 13.04 & 6.92 & 2.74 & 25.78 & 15.74 & 7.39 \\
\hline \multirow[t]{3}{*}{2010} & Headcount $\left(\mathrm{H}_{\mathrm{C}}\right)$ & 24.30 & 12.00 & 6.70 & 2.90 & 19.20 & 11.30 & 5.40 \\
\hline & Concentration index $\left(\mathrm{C}_{\mathrm{E}}\right)$ & -0.044 & -0.032 & 0.025 & 0.150 & -0.246 & -0.284 & -0.313 \\
\hline & Rank weighted headcount $\left(\mathrm{H}_{\mathrm{C}}{ }^{\mathrm{W}}\right)$ & 25.34 & 12.40 & 6.51 & 2.43 & 23.98 & 14.51 & 7.14 \\
\hline \multirow[t]{3}{*}{2011} & Headcount $\left(\mathrm{H}_{\mathrm{C}}\right)$ & 26.60 & 13.10 & 7.70 & 3.50 & 20.50 & 11.80 & 5.70 \\
\hline & Concentration index $\left(C_{\mathrm{E}}\right)$ & -0.036 & -0.011 & 0.030 & 0.080 & -0.232 & -0.254 & -0.244 \\
\hline & Rank weighted headcount $\left(\mathrm{H}_{\mathrm{C}}{ }^{\mathrm{W}}\right)$ & 27.61 & 13.25 & 7.43 & 3.22 & 25.26 & 14.75 & 7.08 \\
\hline
\end{tabular}
Source: Author's analysis of data from RLMS-HSE. 
Table 5.4 Catastrophic out-of-pocket healthcare payments - overshoot

\begin{tabular}{|c|c|c|c|c|c|c|c|c|}
\hline \multirow[b]{2}{*}{ Year } & \multirow[b]{2}{*}{ Threshold } & \multicolumn{4}{|c|}{$\begin{array}{l}\text { Out-of-pocket payments as share of } \\
\text { total household expenditure }\end{array}$} & \multicolumn{3}{|c|}{$\begin{array}{c}\text { Out-of-pocket payments as share of } \\
\text { non-food expenditure }\end{array}$} \\
\hline & & $5 \%$ & $10 \%$ & $15 \%$ & $25 \%$ & $15 \%$ & $25 \%$ & $40 \%$ \\
\hline \multirow[t]{4}{*}{2001} & Mean overshoot $(\mathrm{O})$ & 1.80 & 1.10 & 0.70 & 0.40 & 5.20 & 3.40 & 1.80 \\
\hline & Concentration index $\left(\mathrm{C}_{\mathrm{o}}\right)$ & 0.063 & 0.112 & 0.163 & 0.279 & -0.258 & -0.272 & -0.286 \\
\hline & Rank weighted overshoot $\left(\mathrm{O}^{\mathrm{w}}\right)$ & 1.65 & 0.98 & 0.62 & 0.27 & 6.54 & 4.37 & 2.33 \\
\hline & Mean positive overshoot (MPO) & 9.5 & 11.8 & 13.40 & 15.70 & 24.10 & 24.30 & 21.80 \\
\hline \multirow[t]{4}{*}{2002} & Mean overshoot $(\mathrm{O})$ & 1.90 & 1.20 & 0.80 & 0.40 & 5.00 & 3.30 & 1.70 \\
\hline & Concentration index $\left(\mathrm{C}_{\mathrm{o}}\right)$ & -0.052 & -0.054 & -0.043 & -0.009 & -0.312 & -0.338 & -0.354 \\
\hline & Rank weighted overshoot $\left(\mathrm{O}^{\mathrm{w}}\right)$ & 2.01 & 1.24 & 0.82 & 0.40 & 6.61 & 4.39 & 2.33 \\
\hline & Mean positive overshoot (MPO) & 9.20 & 11.60 & 13.40 & 14.90 & 22.80 & 23.20 & 22.10 \\
\hline \multirow[t]{4}{*}{2003} & Mean overshoot $(\mathrm{O})$ & 1.90 & 1.20 & 0.80 & 0.40 & 4.80 & 3.00 & 1.50 \\
\hline & Concentration index $\left(\mathrm{C}_{\mathrm{o}}\right)$ & 0.007 & 0.036 & 0.068 & 0.117 & -0.317 & -0.340 & -0.371 \\
\hline & Rank weighted overshoot $\left(\mathrm{O}^{\mathrm{w}}\right)$ & 1.92 & 1.16 & 0.76 & 0.36 & 6.26 & 4.07 & 2.090 \\
\hline & Mean positive overshoot (MPO) & 9.20 & 11.60 & 13.60 & 15.30 & 22.20 & 22.40 & 21.70 \\
\hline \multirow[t]{4}{*}{2004} & Mean overshoot $(\mathrm{O})$ & 1.80 & 1.10 & 0.80 & 0.40 & 1.90 & 1.10 & 0.50 \\
\hline & Concentration index $\left(\mathrm{C}_{\mathrm{o}}\right)$ & 0.069 & 0.119 & 0.160 & 0.210 & -0.325 & -0.352 & -0.384 \\
\hline & Rank weighted overshoot $\left(\mathrm{O}^{w}\right)$ & 1.71 & 1.00 & 0.64 & 0.28 & 6.47 & 4.21 & 2.17 \\
\hline & Mean positive overshoot (MPO) & 9.30 & 12.00 & 12.60 & 14.60 & 22.50 & 22.90 & 20.30 \\
\hline \multirow[t]{3}{*}{2005} & Mean overshoot $(\mathrm{O})$ & 1.90 & 1.20 & 0.80 & 0.40 & 3.90 & 2.40 & 1.10 \\
\hline & Concentration index $\left(\mathrm{C}_{\mathrm{o}}\right)$ & 0.111 & 0.153 & 0.196 & 0.282 & -0.254 & -0.270 & -0.275 \\
\hline & Rank weighted overshoot $\left(\mathrm{O}^{\mathrm{w}}\right)$ & 1.73 & 1.05 & 0.67 & 0.29 & 4.94 & 3.09 & 1.43 \\
\hline \multirow{4}{*}{2006} & Mean positive overshoot (MPO) & 9.80 & 12.30 & 13.00 & 13.80 & 20.60 & 20.30 & 18.2 \\
\hline & Mean overshoot $(\mathrm{O})$ & 1.90 & 1.20 & 0.80 & 0.40 & 3.40 & 2.00 & 1.00 \\
\hline & Concentration index $\left(\mathrm{C}_{\mathrm{o}}\right)$ & 0.075 & 0.126 & 0.166 & 0.251 & -0.240 & -0.252 & -0.245 \\
\hline & Rank weighted overshoot $\left(\mathrm{O}^{\mathrm{w}}\right)$ & 1.75 & 1.02 & 0.66 & 0.30 & 4.16 & 2.56 & 1.21 \\
\hline \multirow{5}{*}{2007} & Mean positive overshoot (MPO) & 9.10 & 11.70 & 13.70 & 15.60 & 19.30 & 20.50 & 19.5 \\
\hline & Mean overshoot (O) & 1.70 & 1.00 & 0.70 & 0.30 & 3.40 & 2.00 & 0.90 \\
\hline & Concentration index $\left(\mathrm{C}_{\mathrm{o}}\right)$ & 0.087 & 0.147 & 0.204 & 0.285 & -0.310 & -0.312 & -0.289 \\
\hline & Rank weighted overshoot $\left(\mathrm{O}^{w}\right)$ & 1.55 & 0.89 & 0.54 & 0.23 & 4.49 & 2.65 & 1.14 \\
\hline & Mean positive overshoot (MPO) & 9.00 & 11.30 & 12.80 & 14.00 & 18.90 & 18.50 & 17.3 \\
\hline \multirow[t]{4}{*}{2008} & Mean overshoot $(\mathrm{O})$ & 1.90 & 1.20 & 0.80 & 0.40 & 3.60 & 2.20 & 1.00 \\
\hline & Concentration index $\left(\mathrm{C}_{\mathrm{o}}\right)$ & 0.051 & 0.105 & 0.156 & 0.276 & -0.313 & -0.301 & -0.245 \\
\hline & Rank weighted overshoot $\left(\mathrm{O}^{w}\right)$ & 1.77 & 1.04 & 0.66 & 0.29 & 4.74 & 2.84 & 1.24 \\
\hline & Mean positive overshoot (MPO) & 9.00 & 12.00 & 13.50 & 15.30 & 19.30 & 20.10 & 17.1 \\
\hline \multirow[t]{4}{*}{2009} & Mean overshoot $(\mathrm{O})$ & 2.20 & 1.30 & 0.80 & 0.40 & 3.90 & 2.30 & 1.00 \\
\hline & Concentration index $\left(\mathrm{C}_{\mathrm{o}}\right)$ & 0.008 & 0.035 & 0.068 & 0.153 & -0.319 & -0.337 & -0.351 \\
\hline & Rank weighted overshoot $\left(\mathrm{O}^{\mathrm{w}}\right)$ & 2.14 & 1.24 & 0.76 & 0.30 & 5.10 & 3.06 & 1.41 \\
\hline & Mean positive overshoot (MPO) & 8.80 & 10.20 & 11.90 & 13.00 & 19.00 & 19.10 & 19.00 \\
\hline \multirow[t]{4}{*}{2010} & Mean overshoot $(\mathrm{O})$ & 2.10 & 1.30 & 0.80 & 0.40 & 3.60 & 2.10 & 0.90 \\
\hline & Concentration index $\left(\mathrm{C}_{\mathrm{o}}\right)$ & 0.061 & 0.129 & 0.203 & 0.334 & -0.285 & -0.296 & -0.296 \\
\hline & Rank weighted overshoot $\left(\mathrm{O}^{\mathrm{w}}\right)$ & 2.00 & 1.11 & 0.66 & 0.25 & 4.64 & 2.75 & 1.22 \\
\hline & Mean positive overshoot (MPO) & 8.80 & 10.60 & 12.30 & 13.40 & 18.80 & 18.80 & 17.30 \\
\hline \multirow[t]{4}{*}{2011} & Mean overshoot $(\mathrm{O})$ & 2.50 & 1.50 & 1.00 & 0.50 & 3.90 & 2.30 & 1.00 \\
\hline & Concentration index $\left(\mathrm{C}_{\mathrm{o}}\right)$ & 0.042 & 0.086 & 0.129 & 0.202 & -0.244 & -0.241 & -0.220 \\
\hline & Rank weighted overshoot $\left(\mathrm{O}^{w}\right)$ & 2.35 & 1.38 & 0.88 & 0.39 & 4.80 & 2.85 & 1.27 \\
\hline & Mean positive overshoot (MPO) & 9.20 & 11.50 & 13.20 & 14.0 & 18.80 & 19.50 & 18.30 \\
\hline
\end{tabular}

Source: Author's analysis of data from RLMS-HSE. 
Table 5.5 Impoverishing out-of-pocket payments - poverty health count and gap

\begin{tabular}{|c|c|c|c|c|c|}
\hline Year & Indicators & $\begin{array}{l}\text { Gross of health } \\
\text { payments (1) }\end{array}$ & $\begin{array}{l}\text { Net of health } \\
\text { payments (2) }\end{array}$ & $\begin{array}{l}\text { Absolute } \\
(3)=(2)-(1)\end{array}$ & $\begin{array}{c}\text { Relative } \\
{[(3) /(1)] \%}\end{array}$ \\
\hline \multirow[t]{4}{*}{2001} & Poverty headcount & 23.3 & 25.0 & 1.7 & 0.1 \\
\hline & Poverty gap & 294.3 & 314.7 & 20.4 & 0.1 \\
\hline & Normalized poverty gap & 8.3 & 9.0 & 0.7 & 0.1 \\
\hline & Normalized mean positive poverty gap & 35.4 & 35.9 & 0.5 & 0.0 \\
\hline \multirow[t]{4}{*}{2002} & Poverty headcount & 20.1 & 21.7 & 1.6 & 0.1 \\
\hline & Poverty gap & 280 & 304.3 & 24.3 & 0.1 \\
\hline & Normalized poverty gap & 7.0 & 7.8 & 0.8 & 0.1 \\
\hline & Normalized mean positive poverty gap & 34.8 & 35.8 & 1.0 & 0.0 \\
\hline \multirow[t]{4}{*}{2003} & Poverty headcount & 17.1 & 18.8 & 1.7 & 0.1 \\
\hline & Poverty gap & 267.3 & 290.4 & 23.1 & 0.1 \\
\hline & Normalized poverty gap & 5.9 & 6.6 & 0.7 & 0.1 \\
\hline & Normalized mean positive poverty gap & 34.6 & 35.1 & 0.5 & 0.0 \\
\hline \multirow[t]{4}{*}{2004} & Poverty headcount & 16.5 & 17.9 & 1.4 & 0.1 \\
\hline & Poverty gap & 282.8 & 302.8 & 20.0 & 0.1 \\
\hline & Normalized poverty gap & 5.6 & 6.2 & 0.6 & 0.1 \\
\hline & Normalized mean positive poverty gap & 34.0 & 34.5 & 0.5 & 0.0 \\
\hline \multirow[t]{4}{*}{2005} & Poverty headcount & 14.3 & 15.6 & 1.3 & 0.1 \\
\hline & Poverty gap & 273.1 & 293.8 & 20.7 & 0.1 \\
\hline & Normalized poverty gap & 4.7 & 5.2 & 0.5 & 0.1 \\
\hline & Normalized mean positive poverty gap & 33.0 & 33.3 & 0.3 & 0.0 \\
\hline \multirow[t]{4}{*}{2006} & Poverty headcount & 11.1 & 12.4 & 1.3 & 0.1 \\
\hline & Poverty gap & 225.3 & 244.4 & 19.1 & 0.1 \\
\hline & Normalized poverty gap & 3.7 & 4.1 & 0.4 & 0.1 \\
\hline & Normalized mean positive poverty gap & 33.2 & 33.02 & -0.2 & 0.0 \\
\hline \multirow[t]{4}{*}{2007} & Poverty headcount & 7.9 & 8.9 & 1.0 & 0.1 \\
\hline & Poverty gap & 176.4 & 187.6 & 11.2 & 0.1 \\
\hline & Normalized poverty gap & 2.4 & 2.6 & 0.2 & 0.1 \\
\hline & Normalized mean positive poverty gap & 30.5 & 29.7 & -0.8 & 0.0 \\
\hline \multirow[t]{3}{*}{2008} & Poverty headcount & 6.3 & 7.2 & 0.9 & 0.1 \\
\hline & Poverty gap & 144.1 & 161.8 & 17.7 & 0.1 \\
\hline & Normalized poverty gap & 1.8 & 2.1 & 0.3 & 0.2 \\
\hline & $\begin{array}{l}\text { Normalized mean positive poverty gap } \\
\text { Poverty headcount }\end{array}$ & $\begin{array}{c}28.8 \\
6.1\end{array}$ & $\begin{array}{c}29.1 \\
7.2\end{array}$ & $\begin{array}{l}0.3 \\
1.1\end{array}$ & $\begin{array}{l}0.0 \\
0.2\end{array}$ \\
\hline \multirow{3}{*}{2009} & Poverty gap & 161.6 & 179.4 & 17.8 & 0.1 \\
\hline & Normalized poverty gap & 1.9 & 2.2 & 0.3 & 0.2 \\
\hline & Normalized mean positive poverty gap & 30.9 & 30.3 & -0.6 & 0.0 \\
\hline \multirow[t]{4}{*}{2010} & Poverty headcount & 5.8 & 6.4 & 0.6 & 0.1 \\
\hline & Poverty gap & 181.7 & 198.8 & 17.1 & 0.1 \\
\hline & Normalized poverty gap & 1.7 & 2.0 & 0.3 & 0.2 \\
\hline & Normalized mean positive poverty gap & 29.7 & 30.5 & 0.8 & 0.0 \\
\hline \multirow[t]{4}{*}{2011} & Poverty headcount & 3.4 & 4.1 & 0.7 & 0.2 \\
\hline & Poverty gap & 96.8 & 110.8 & 14.0 & 0.1 \\
\hline & Normalized poverty gap & 1.0 & 1.2 & 0.2 & 0.2 \\
\hline & Normalized mean positive poverty gap & 28.9 & 28.3 & -0.6 & 0.0 \\
\hline
\end{tabular}

Source: Author's analysis of data from RLMS-HSE. 


\subsubsection{The association between out-of-pocket healthcare payments and exiting/entering}

poverty

Based on the results of the regression analysis (Table 5.6), households headed by highly educated members (as compared to middle level educated heads of households), residing in an urban area, having used healthcare services, having at least one or more household members with a chronic disease, and including pensioners, are less likely to enter into poverty the following year. Larger households, especially with children, having at least one member with a disability, headed by a member with a lower level of education (as compared to the middle), and those who experience catastrophic out-of-pocket payments and had an incidence of forgoing healthcare services due to a lack of money, were more likely to enter into poverty the following year. The characteristics that protect against entering poverty also help to exit poverty during the following year, with an additional role of the female member heading the household added to these characteristics. Only the presence of a household member with a chronic disease is not statistically significant here. Having a larger household and number of children, a lower level of education of the household's head, as well as forgoing healthcare services during the last 12 months - those are the characteristics that most likely prevent households from exiting poverty the following year.

Overall, with every passing year, households were more likely to exit poverty and less likely to enter it compared to 2010/2011. Paying for healthcare services was also a statistically significant predictor of exiting poverty and prevented households from going below the poverty line. However, the interpretation of this result should be treated with caution. This result does not suggest that paying for healthcare itself is negatively related to poverty, but is rather an indicator of the household's ability to pay for healthcare services. Therefore, households that were able to pay for healthcare were most likely to exit and less likely to fall into poverty. A similar interpretation should be used for healthcare utilization indicator. 
Table 5.6 Regression results of entering and exiting the poverty next year after base year (20012011)

\begin{tabular}{|c|c|c|c|c|}
\hline \multirow[b]{2}{*}{ Characteristics } & \multicolumn{2}{|c|}{ Entered poverty } & \multicolumn{2}{|c|}{ Exited poverty } \\
\hline & Coef (SE) & OR & Coef(SE) & OR \\
\hline \multicolumn{5}{|l|}{ Head of the household (HHH) } \\
\hline Gender of $\mathrm{HHH}$ (female), yes & -0.063 & 0.939 & $0.399 * * *$ & 1.490 \\
\hline Age of $\mathrm{HHH}$, years & $0.006^{* * *}$ & 1.006 & 0.001 & 1.001 \\
\hline Education level of $\mathrm{HHH}$ (high), yes & $-0.790^{* * *}$ & 0.454 & $0.462^{* * *}$ & 1.587 \\
\hline Education level of $\mathrm{HHH}$ (low), yes & $0.315^{* * *}$ & 1.37 & $-0.204^{* * *}$ & 0.815 \\
\hline \multicolumn{5}{|l|}{ Household (HH) } \\
\hline Number of adults & $0.080^{* * *}$ & 1.083 & $-0.037 *$ & 0.963 \\
\hline Number of children & $0.214^{* * *}$ & 1.239 & $-0.079 * *$ & 0.923 \\
\hline $\mathrm{HH}$ resides in urban area, yes & $-0.688^{* * *}$ & 0.503 & $0.372^{* * *}$ & 1.451 \\
\hline HH with pensioners, yes & $-0.145^{* *}$ & 0.865 & $0.152^{* *}$ & 1.164 \\
\hline \multicolumn{5}{|l|}{ Healthcare utilization by $\mathbf{H H}$} \\
\hline HH used healthcare services, yes & $-0.238^{* * *}$ & 0.788 & $0.185^{* * *}$ & 1.204 \\
\hline HH paid for healthcare, yes & $-0.461 * * *$ & 0.631 & $0.281^{* * *}$ & 1.324 \\
\hline $\mathrm{HH}$ forwent service during last 12 months, yes & $0.235^{* * *}$ & 1.265 & $-0.198 * * *$ & 0.820 \\
\hline At least $1 \mathrm{HH}$ member with disability, yes & $0.326^{* * *}$ & 1.386 & -0.061 & 0.941 \\
\hline At least $1 \mathrm{HH}$ member with chronic disease, yes & $-0.279 * * *$ & 0.757 & 0.094 & 1.099 \\
\hline Catastrophic payment in the base year, yes & $0.390 * * *$ & 1.476 & -0.061 & 0.940 \\
\hline \multicolumn{5}{|l|}{ Period of observation $(2010 / 2011$ as a reference) } \\
\hline Period 2001/2002 & 0.079 & 1.082 & $-1.122^{* * *}$ & 0.325 \\
\hline Period 2002/2003 & $-0.140^{*}$ & 0.869 & $-1.052^{* * *}$ & 0.349 \\
\hline Period 2003/2004 & $-0.129 *$ & 0.879 & $-1.113^{* * *}$ & 0.328 \\
\hline Period 2004/2005 & $-0.384 * * *$ & 0.681 & $-1.008^{* * *}$ & 0.364 \\
\hline Period 2005/2006 & $-0.515^{* * *}$ & 0.597 & $-0.798 * * *$ & 0.450 \\
\hline Period 2006/2007 & $-0.952 * * *$ & 0.386 & $-0.547 * * *$ & 0.578 \\
\hline Period 2007/2008 & $-1.152^{* * *}$ & 0.316 & $-0.623^{* * *}$ & 0.536 \\
\hline Period 2008/2009 & $-1.103^{* * *}$ & 0.332 & $-0.590 * * *$ & 0.554 \\
\hline Period 2009/2010 & $-1.032^{* * *}$ & 0.356 & $-0.481 * * *$ & 0.617 \\
\hline Const & $-1.617 * * *$ & 0.198 & 0.285 & 1.33 \\
\hline
\end{tabular}

Source: Author's analysis of data from RLMS-HSE.

Notes: ${ }^{*}$-p $<0.1 ;{ }^{* *}$ - $\mathrm{p}<0.05 ;{ }^{* * *}{ }_{-} \mathrm{p}<0.01$. 


\subsection{Discussion}

Our analysis suggests that during the last decade, every third Russian household paid for healthcare services out of pocket. Even though the overall utilization of healthcare services remained consistent over the years, households started to pay for healthcare out of pocket more frequently. When constrained from diverting households resources to pay for healthcare services, Russian households forgo the necessary pharmaceuticals and medical treatment.

As shown in our analysis, despite the halving of the incidence of forgoing healthcare services and pharmaceuticals (along with the three-fold reduction in poverty levels), 10-12\% of Russian households are still compelled to forgo necessary care (medical care and/or pharmaceuticals) due to a lack of money. Both the incidence and intensity of catastrophic payments appear to be more concentrated amongst the worse-off households (irrespectively of which expenditure approach is used). The impoverishing results also show that health-related out-of-pocket payments can be held responsible for about $10 \%$ of the rise in the poverty gap, accounting for extreme poverty of ca. $1 \%$ of households that would not be considered as poor should they not have incurred out-of-pocket payments. Nonetheless, over the 11 years period, inequalities due to out-of-pocket payments have decreased.

\subsubsection{Forgoing healthcare services - comparison with previous studies for Russian and other ex-Soviet countries}

Due to a lack of studies on the poverty effects of out-of-pocket payments in Russia, we can only compare our findings on forgoing healthcare use to the results for Russia published in two previous studies (Balabanova et al., 2004; Balabanova et al., 2012). Following our results, in 2001, 21-22\% of the Russian households had to forgo healthcare services and pharmaceuticals. Using other data sources than ours, but also for 2001, Balabanova et al. (2004) report more detailed estimations. For instance, in 2001, $11.3 \%$ of households had to forgo medical services constantly and $16.8 \%$ of households had to forgo such services sometimes. For pharmaceuticals, this equaled 16.8\% (constantly) and 32.0\% (sometimes), respectively. And whilst our data allowed estimation of the incidence of forgoing necessary care due to the lack of money on the household level, Balabanova et al. (2004) report additional reasons for not seeking care among those reporting illness in Russia, specifically: self-treatment (46.9\%); purchasing pharmaceuticals without obtaining a doctor's 
prescription (26.8\%); long waiting times to see a health professional $(21.0 \%)$; no trust in staff qualification (17.2\%); and others (17.2\%).

If we use the results of the same study as a comparator, estimations for Russia in 2001 are lower than those for most of the other ex-Soviet countries. In particular, as Balabanova et al. (2004) report, the number of households that had to constantly do without medical services and pharmaceuticals was as follows: Armenia (38.0\% and 31.6\%), Ukraine (25.3\% and 27.4\%), Moldova (17.4\% and 17.5\%), Kyrgyzstan (17.4\% and 19.9\%), Kazakhstan (12.9 and 15.2), Russia (11.3 and 16.8\%); Georgia (10.9\% and 7.9\%), and Belarus (4.5\% and 7.4\%). The most important reason for not seeking care among those reporting illness among the eight ex-Soviet countries was once again a lack of money - 45.2\% (Balabanova et al., 2004); with highest prevalence in Armenia, Georgia, and Moldova (77.5\%, 70.0\%, and 53.6\%), Kazakhstan, Ukraine, and Kyrgyzstan (34.8\%, $33.9 \%$, and 26.4\%), Russia (11\%) and Belarus (0.7\%). According to another study (Falkingham, 2004), in Tajikistan in 1999, the lack of affordability was also one of the main reasons for not seeking medical attentionwith 33\% of respondents indicating that lack of financial resources acted as a barrier to access healthcare services. However, self-medication, using traditional or over-thecounter pharmaceuticals was the main reason for not seeking medical help.

Within a decade, as described earlier, the incidence of forgoing healthcare services in Russia reduced from $21-22 \%$ in 2001 , to $15-18 \%$ in $2005-2007$, to $10-12 \%$ in $2010-2011$. Despite this overall reduction, these estimations are still somewhat lower relative to other former socialistic countries. For example, for Latvia, evidence suggests that in 2005, 30\% of population did not access the health services they needed (WHO, 2009). As the main reason of forgoing healthcare services, $56 \%$ of non-users reported financial constraints, with over $70 \%$ of people in the poorest quintile, compared to $25 \%$ of people in the richest quintile. In $2007,12 \%$ of Georgian respondents had to forgo the purchase of pharmaceuticals as they were too expensive, while an equal share of Serbian households had to forgo healthcare use due to payments (Gotsadze et al., 2009; Arsenijevic et al. 2013). Even higher estimations are reported for six former socialist countries for both outpatient and inpatient care: in Bulgaria (30.6\% and 6\%), Hungary (24.8\% and 2.8\%), Lithuania (21.1\% and 3.2\%), Poland (21.5\% and 2.3\%), Romania (28.4\% and 9.4\%), and Ukraine (46.5\% and 16.5\%) (Atanasova et al. 2013; Murauskiene et al. 2012; Tambor et al. 2013). At the same time, selftreatment remained the main reason of not consulting a health professional in the last four weeks in Moldova (39.4\%), Belarus (52.9\%), Ukraine (51.2\%) and Kazakhstan (50.2), while the unaffordability of either services or drugs affected the most those residing in Georgia (69.7\%) and 
Azerbaijan (58.1\%) (Balabanova et al., 2012). Based on results from the same study, self-treatment remained to be the main reason of not consulting health professionals in Russia (45.1\%), while unaffordability of services reduced to $3.5 \%$, unaffordability of drugs to $2.5 \%$, and unaffordability of either services or drugs to $4.6 \%$ of respondents.

\subsubsection{Impoverishing and catastrophic effects of out-of-pocket healthcare payments - comparison with other countries}

In this chapter, we used widely accepted measures of catastrophic health expenditures (the share of discretionary non-food and total household expenditure), which allowed us to assess the reliability of our estimates and to compare them with findings from other studies. Our results for Russia during the last decade (ca. 6-8\% at the conservative $40 \%$ threshold of discretionary nonfood expenditure and $9-13 \%$ using the $10 \%$ threshold of total expenditure) appear to be similar or higher than in other upper-middle income countries reported for various years. For example, for the conservative $40 \%$ threshold of discretionary non-food expenditure, estimations range from less than 1\% (Romania, South Africa, Turkey, Malaysia, Thailand) up to 4-7\% level (Lebanon, Argentina, Azerbaijan, Tunisia, China), and 10\% in Brazil (Bredenkamp et al., 2011; van Doorslaer et al., 2007; Xu et al., 2003; Yardim et al., 2010). At a 10\% threshold of total household expenditure, estimations ranged from 1-6\% (Thailand, Montenegro, Bosnia and Herzegovina, Malaysia) to 712\% in Albania, Serbia, Tunisia, and China (Abu-Zaineh et al., 2013; Bredenkamp et al., 2011; van Doorslaer et al., 2007). Relative to other former socialist countries, the incidence of catastrophic out-of-pocket payments in Russia also seems to be higher. For example, at the $40 \%$ level of discretionary non-food expenditures, the estimates of the incidence are: Azerbaijan 7.1\%, Ukraine 3.9\%, Latvia 2.7\%, Lithuania 1.3\%, Kyrgyzstan 0.6\%, Estonia $0.3 \%$ (estimates for late 1990s) (Xu et al., 2003). More recent studies suggest that after 2000, the level of out-of-pocket catastrophic payments increased. For example, catastrophic healthcare expenditure affect 3.2\% of Latvians (2006) and 3.3\% of Estonians (2007), with 1.4\% of the Latvian population falling below the poverty line after paying for health services, with catastrophic expenditure mainly driven by spending on drugs (60\% of out-of-pocket payments in Latvia and 53\% in Estonia), especially for lower income households (Habicht et al., 2006). In Georgia, in 2007, catastrophic healthcare expenditure amounted to $11.7 \%$ and the poorest quintile had the highest share $-17.7 \%$ (Gotsadze et al., 2009). In Albania, as in Russia, the levels of catastrophic out-of-pocket healthcare payments also declined from $22.6 \%$ (2002) to $13.3 \%$ (2008), following the 10\% budget share threshold (Tomini et al. 2013). 
To summarize, the evidence suggests that forgoing healthcare services is an important issue not only in Russia, but also in the majority of the former socialist countries. Unaffordability and households' financial constraints remain the most important reasons of forgoing healthcare services, especially among poor households. Moreover, one can argue that the true burden of outof-pocket payments is still unknown, since many households cannot pay and forgo medical care that they perceive as necessary. There also seems to be a similar cultural trend across former socialistic countries of forgoing medical care following a habit (or strategy) of reliance on selftreatment and self-medication. To a lesser extent, reasons of forgoing healthcare relate to long waiting times and waiting lists. It is also clear that in most former socialistic countries, worse-off household are the ones that are burdened the most by catastrophic and impoverishing out-ofpocket healthcare payments.

\subsubsection{Association between out-of-pocket healthcare payments and existing/leaving poverty}

In this chapter, we also find that most characteristics of Russian households, previously found to be significant in shielding from poverty (both entering and exiting) (e.g. Denisova, 2012), were confirmed in this chapter. Moreover, evidence suggests that incidence of catastrophic out-ofpocket payments, as well as spells of forgoing healthcare services or purchasing of pharmaceuticals, are associated with entering into poverty the following year. Similar household characteristics prevented households from exiting the state of poverty. Interestingly, we found that those households that paid for healthcare services or pharmaceuticals, were most likely to exit and not fall into poverty. We argue that this attribute is related to the purchasing power of the household and the household's ability to pay, and identifies households with better financial coping strategies. Having at least one chronically ill household member had a similar protective effect. We believe this is due to the fact that in Russia, chronically ill members are receiving additional benefits and social support. However, we did not test this assumption. Interestingly enough, the presence of pensioners in households also protected households from entering into poverty. In studies on poverty determinants in other countries, the presence of pensioners, on the contrary, pushed households into the poverty (Bredenkamp et al. 2011; van Doorslaer et al. 2007).

\subsection{Conclusions and policy implications}

As indicated by our results and discussion on the findings, the poverty effects of out-of-pocket payments are obvious despite the overall reduction of the poverty level in the country. With 6-13\% of households experiencing catastrophic payments, we believe, this issue is relevant and should be 
placed on the agenda of Russian health policy-makers. Moreover, most of the ex-Soviet countries seem to experience similar problems, therefore the poverty effects of out-of-pocket payments, should be on the health policy agenda in these countries as well. To address this issue, the first necessary step is to recognize the problem. It is also necessary to keep in mind that for many households the burden of out-of-pocket payments is unbearable. Therefore, these households have to forgo care. Ensuring access to healthcare services should be implemented while coupled with shielding households from financial catastrophe due to high out-of-pocket payments. The issue of catastrophic and impoverishing out-of-pocket payments can be tackled following overall poverty reduction and alleviation, as shown in this chapter. However, poverty alleviation alone does not necessarily lead to a reduction of the burden of catastrophic payments. Even though, as we have shown in this chapter, mainly worse-off households in Russia are being affected by catastrophic payments. Primarily those households should be protected from the financial burden of out-ofpocket payments.

When designing policy interventions, health policy-makers can follow the policy recommendation by Xu et al. (K. Xu et al., 2007), who has suggested that moving away from out-of-pocket payments to prepayment mechanisms is one of the keys to reducing financial catastrophe due to healthcare use. Additionally, targeted financial risk-protection strategies can be put in practice. They argue that healthcare policy-makers can actively advocate complementary policies to reduce social inequalities and increase overall healthcare funding. We believe that this argument is particularly important in the former socialistic countries, where healthcare sectors are still generally underfinanced. Positive practical experience of dealing with catastrophic out-of-pocket payments from other countries should also be taken into account. For example, experiences in Mexico (Knaul et al., 2006) suggest the necessity to build local research capacity to stimulate links between research and policy. This suggests implementation and translation of the research findings into evidencebased policy-making. Another suggestion is to collect data and guarantee that these are comparable over time. In this respect, we believe that results presented in this chapter could serve as the starting point for future studies in Russia, but also in neighboring countries that share a similar history of economic and political development. Knaul et al. (2006) also call to invest in research and advocates international research initiatives. It is obvious, that well-timed collaboration with others could facilitate the necessary knowledge transfer and may facilitate finding creative solutions to longexisting problems. Micro-financing programs can also be seen as one of the tools that can mitigate the impact of the financial burden of the out-of-pocket payments and can be used as a means of targeted or addressed help to the most vulnerable households. 
Chapter 6

General discussion 


\subsection{Introduction}

This dissertation has provided empirical evidence about the effects of the financial reforms in the Russian healthcare sector, in the context of a healthcare system in transition. The main goal of this dissertation was to study the prevalence of changes in out-of-pocket payments in the Russian healthcare system, resulting from the financial reforms of the Russian healthcare sector.

Chapter 1 outlined the current model of the Russian healthcare provision and financing, described the content of healthcare reforms that occurred during the last two decades, and defined the scope of the dissertation. Chapter 2 appraised the financial reforms in the Russian public healthcare sector at the macro-level and assessed their impact on financial sustainability (system funding), efficiency, equity, and quality of provided care. Then Chapter 3 examined the monetization of the in-kind benefits and estimated its potential impact of related out-of-pocket expenditures on the prescribed or recommended pharmaceuticals. In Chapter 4the scale and scope of informal out-of-pocket payments paid by Russian users for outpatient non-dental, dental, check-up and inpatient healthcare services, their determinants and currently existing patterns of paying informally was examined. Chapter 5 looked at the relationship between households' out-of-pocket payments for healthcare services and households' poverty.

In this chapter the main findings of this dissertation are presented and discussed and are formulated in the form of five statements. Following the main aims of the dissertation (see Chapter 1), the first and the second statements relate to the content and implementation of the financial reforms in the Russian healthcare sector. The third and the fourth statements focus on the currently existing issues in the Russian healthcare sector that appear to have either direct or indirect consequences for the financial reforms implementation. The fifth statement is the overarching one for the whole dissertation. 


\subsection{Main findings}

\section{Statement 1: Whether or not Russian patients are better off after two decades of healthcare reform remains unclear.}

In this dissertation, we find that after two decades of financial reforms in the Russian healthcare sector, it is still not clear whether the reforms have been beneficial for Russian patients. We showed in Chapter 2 that despite the numerous financial reforms, the available empirical data on their outcomes are limited. Nonetheless, our review of the existing evidence sheds some light on both positive and negative consequences of the reforms that directly and indirectly affect healthcare users in Russia.

Starting from the system level, reforms had some positive impacts that are relevant to all Russian healthcare users. As mentioned in Chapter 2, the implementation of the health insurance system had a positive stabilizing effect during the economic crisis because it helped to maintain the financial sustainability (system financing) of the healthcare sector. One could argue that it helped to avoid the overall collapse of the Russian healthcare sector, which, in general, would have had a direct deteriorating effect on the health of the Russian population. The purchaser-provider separation, another significant change in the healthcare sector, was also a necessary building block for the future increase of the system's efficiency (even though the results of such change could not be seen immediately). Inarguably, the reforms had a positive result in that they safeguarded free universal access for the majority of the public healthcare services for every citizen and eventually provided an almost complete insurance coverage of the whole population (over 145 million people in 1990s).

Nevertheless, despite the reform efforts, the overall number of problems that directly and indirectly affected patients remained significant. For instance these might include high out-of-pocket payments; impeded equity in access to healthcare services as well as equity in financing; interregional inequalities and variations in access across the regions; inequalities among income groups; and the presence of informal payments. Moreover, the Russian healthcare sector remained underfinanced (Chapters 1 and 2), which could partially explain why most of the problems, such as poor quality of provided care, limited availability or lack of modern medical equipment and medication, or violations of patients' rights, continued to exist. Another explanation is more straightforward. Only a few of the issues received the attention of policy-makers (e.g. partial 
revision of State guarantees, as shown in Chapter 2), while others remained completely neglected (e.g. informal payments, forgoing healthcare services due to lack of money, and high burden of out-of-pocket healthcare payments in general, as discussed in Chapter 4 and 5).

It is also problematic to give a straightforward interpretation of how Russian healthcare users (endusers) perceived the results of the healthcare reforms. Even though there is evidence that users were not satisfied with the insurance system and perceived the quality of the provided services as poor (Chapter 2), one should remember that, in general, users were very poorly informed about the content of the ongoing reforms. And quite often, mass media served as the main and only source of information. Nevertheless, Russian patients generally supported the need for reform in the Russian healthcare sector, as did many healthcare providers.

To summarize, our findings show that many of the financial reform initiatives in the Russian healthcare sector were actually not directly related to already known and existing problems. Therefore, it is not possible to draw strong conclusions whether Russian patients are, after all, better off after two decades of financial reforms. We should also acknowledge the limitations of our analysis - we conducted a systematic literature review in Chapter 2 and performed an analysis of some aspects/reforms in Chapters 2 and Chapter 3, but we did not carry out a thorough impact evaluation of the financial reforms (mainly due to a limited number of studies presenting empirical evidence). We suggest, first, that future reforms should always be given a timely and thorough impact evaluation. Second, more studies are needed to provide empirical evidence about the impact of the reforms concerning the financing and healthcare provision in the Russian healthcare sectors.

\section{Statement 2: Replacing in-kind social benefits with in-cash provision by the Russian government did not affect the amounts of out-of-pocket payments paid by healthcare users.}

The results of our quantitative analysis in Chapter 3 suggest that the implementation of the monetization of the in-kind benefits (one of the reforms that affected the provision of prescribed or recommended pharmaceuticals) did not have a significant impact on the amount of out-ofpocket expenditure paid by affected beneficiaries. Our general observation was that over the observed period (2003-2007), there was an overall increase in out-of-pocket expenditure on pharmaceuticals among all healthcare users with and without benefits. We have also shown that 
the majority of healthcare users were able to find and buy the prescribed or recommended pharmaceuticals, and this trend was consistent over the 2003-2007 period. This observation was later confirmed in Chapter 5, where we have shown a steep reduction in the incidence of forgoing the purchase of pharmaceuticals from 15\% to 6-7\% (2001-2011).

Based on the results of our analysis, it is clear that the monetization reform did not make vulnerable groups better or worse off and most likely, did not have an adverse effect on equity in financing. As such, the reform efforts have been effective. And even though this particular reform was mainly facilitating the necessary revision of State obligations and not the patients directly, it still can be seen as to have had a positive effect on healthcare users, supporting arguments about a positive effect of some reform efforts declared in our Statement 1. At the same time, our findings are not surprising, as reform efforts did not actually include any targeted provision of in-kind benefits. This, in turn, has its own justification. Making one group better off at the expense of another contradicts current Russian legislation, which could potentially lead to possible charges by the Prosecutor General's office (Alexandrova \& Stryuk, 2007). Practically, this implies that any microfinancing program or targeted help for the most vulnerable groups is illegal and, therefore, unacceptable. However, targeted help is also suggested as a possible mitigation tool for the high burden of out-of-pocket healthcare payments (Chapter 5). This creates another gridlock, similar to the one related to the constitutional right of every Russian citizen to free access to the majority of healthcare services, when existing and available resources are not sufficient to adequately meet all declared State guarantees. As described in Chapter 2, the gridlock with free-of-charge healthcare provision was resolved by the creation of the Guaranteed Package, which did not only ensure the constitutional right of the citizens to free medical care, but also defined and limited the number of services included in the package.

As suggested in Chapter 4, the reform efforts should foster the empowerment of healthcare consumers. And since Russian citizens are not used to take responsibility over their own health, their engagement in an active choice between in-kind and in-cash provision of the benefits (addressed in Chapter 3) provided a valuable policy lesson. In particular, our analysis showed that given the possibility of an annual choice, almost half of the beneficiaries opted for in-cash provision in place of in-kind provision. Individuals adjust their choices according to their expectations regarding their future needs, while accounting for the economic conditions of the region where they live (i.e. in-kind benefits are prevailing in wealthier regions, as opposed to a preference of incash compensation in less wealthy ones (Bestremyannaya, 2009). This confirms the great potential of currently passive patient engagement, which, if enhanced, could become a valuable consumer- 
driven force in the future development of Russian health policy. The active choice between in-cash and in-kind provision, could also be seen as an opportunity for healthcare users to develop their own strategies of coping with problems they might face in healthcare provision (alike coping strategies in the form of informal payments, addressed in Chapter 4).

As shown in Chapter 3, replacing in-kind benefits with in-cash provision by the Russian government has had little effect on out-of-pocket payments. However, an interpretation of such results is challenging. It comprises both expected and unforeseen results on the system level due to its rapid implementation (e.g. mismatch between demand and supply of pharmaceuticals, underestimation of the total number of beneficiaries), as well as changes in the individual behavior of those affected by the reform.

Nonetheless, the experience of Russian policy-making with replacing in-kind benefits with in-cash provision might be interesting for other neighboring countries with broad social and healthcare State guarantees. This particularly applies to most of the ex-socialist countries that inherited many features of the "Semashko" model of healthcare provision. Our analysis was limited only to the Russian social and healthcare settings; however, we acknowledge that future studies should take advantage of inter-country comparisons.

\section{Statement 3: The common belief that the incidence and prevalence of informal payments in the Russian healthcare sector are very high is a myth.}

In line with previous studies (Boikov et al., 1997; Feeley et al., 1999; Blam \& Kovalev, 2003; Besstremyannaya, 2007; Saratov, 2001; Aarva et al., 2009; Fotaki, 2009), we have shown in this dissertation that informal payments for healthcare services in Russia continue to exist in both private and public healthcare sectors (Chapters 1, 4, and 5). Based on our estimations (Chapters 4 and 5), the share of healthcare users who made informal payments, remained at an almost unchanged 7\% level over the last 15 years; and our findings are similar to those reported for the 1990s by others. We argue that although informal patient payments are persistent, the common belief that informal payments are widely spread in the Russian healthcare sector is actually misleading and does not reflect the reality when compared to other Eastern European countries. For example, as shown in Chapter 4 for 2010, the incidence of informal payments in the Russian healthcare sector seems to be lower than in Bulgaria, Hungary, Lithuania, Poland, Romania, and Ukraine (Stepurko et al., 2011; Atanasova et al., 2012; Baji et al., 2012; Pavlova et al., 2012). The reasons for the informal payments that we found to be significant (Chapter 4), are similar to those 
reported in studies for other European countries (e.g. Balabanova and McKee, 2002; Özgen et al., 2010; Tomini and Maarse, 2011).

A more detailed analysis of the published literature on informal payments for Russia and other European countries (see Chapter 4) indicated potential difficulties with the comparison of the scale and scope of informal payments across studies. These difficulties are related to the lack of an universal definition of informal payments (Gaal et al., 2006; Stepurko et al., 2010; Cherecheş et al., 2013), the use of different data representation techniques (presenting informal payments among all respondents, only users, or all payers), and more trivial reasons - i.e. differences in data collection techniques, sample sizes, recall period, region of data collections. Based on our results and our comparison with other studies, in Chapter 4, we suggest to report the frequency of informal payments among users of healthcare services and not among payers for healthcare services alone. Most likely, due to the use of the latter scale of representation (based on payers), informal payments for healthcare are perceived to be widely spread. Once adjusted to another denominator (based on users), the frequency of informal payments seems to be much lower. For example, if we use our results, the impressive figure for informal payments (i.e. $24.6 \%$ of payers) deflates to the estimate that we have reported ( $7.3 \%$ of users). Nevertheless, the existence of informal payments in the Russian healthcare sector should not be ignored. We believe that several factors explain the existence of the common perception of a very high level in the incidence and prevalence of informal payments in the Russian healthcare sector. The most important factors include: the sensitivity of the issue of informal payments; existing discrepancies in data representation; a lack of detailed studies on informal payments in the Russian healthcare sector; and the absence of an official acknowledgement of their existence and a clear healthcare policy agenda and set of actions regarding such type of payments.

Based on our findings in Chapter 4, we conclude that numerous factors in multiple combinations explain the existence of informal payments. Such factors include: a complex interaction between service providers and users (as well as their expectations, demands, and needs), and healthcare users clashing between the necessity to gain the needed access to and quality of healthcare services. This provides the healthcare staff with the power of gate-keeping the access for those who need services or treatment. Other factors include: a culture of gift-giving and a need to express gratitude, as well achieving a sense of security by making payments or giving gifts; national cultural heritage; and overall healthcare system functioning and malfunctioning. Even though it seems that the complex issue of informal payments is hard to tackle, we believe that informal payments can and should be 
addressed by Russian health policy-makers. This is particularly important as informal payments can have adverse effect on the healthcare sector and on healthcare users in general, and they can represent an important financial source that currently bypasses the official channels of healthcare financing (as discussed in Chapter 4). Furthermore, we acknowledge the concern that with no action, informal payments will continue to exist in the Russian healthcare sector, just as they have had successfully done during the last decades.

Chapter 4 focused on the scale and scope of informal payments, as well as the reasoning behind such payments and patterns of paying informally. We presented our results, based on the responses from users of the Russian healthcare sector and, therefore, we limited our findings only to the user perspective. Future studies should focus on the reason behind informal payments taking into account the perspective of healthcare providers, as this would shed more light on the complex phenomenon of the informal payments. Currently, such data are lacking.

\section{Statement 4: Over the past decade (2001-2011), poverty in Russia has decreased and fewer households have to forgo healthcare use due to the lack of financial resources.}

The problem of forgoing healthcare services is still relevant for the Russian healthcare sector even though the overall poverty level in the country has decreased. As shown in Chapter 5, approximately $10-12 \%$ of Russian households are still compelled to forgo pharmaceuticals and medical treatment due to a lack of money. Moreover, health-related out-of-pocket payments pose catastrophic and impoverishing effects with the highest burden for the worse-off households. In addition, we confirmed in Chapter 5 that catastrophic out-of-pocket healthcare payments and the incidence of forgoing medical care are associated with the entry into poverty and the inability to exit poverty the following year. Nonetheless, the overall situation is improving and trends are positive. More specifically, we showed that during the last decade (2001-2011), the overall threefold reduction in poverty was accompanied by a two-fold decline in the incidence of forgoing healthcare services. Overall, inequalities due to catastrophic and impoverishing out-of-pocket healthcare payments also decreased.

When compared to other former-Soviet republics (like Armenia, Ukraine, Kazakhstan, Moldova, Kyrgyzstan, Georgia and Belarus), the incidence of forgoing healthcare services in the Russian Federation seems to be lower. This observation is similar to the overall lower incidence of informal 
payment in the Russian healthcare sector, when compared to selected European countries (see Chapter 4 and Statement 3). At the same time, the incidence of both catastrophic and impoverishing healthcare out-of-pocket payments in the Russian Federation is similar or higher than in other upper-middle income countries. This once again indicates the relevance of this issue for policy-makers. Another interesting observation based on Chapter 5 is a steep reduction in the incidence of forgoing the purchase of pharmaceuticals for the overall population. This relates to our findings in Chapter 3, where the analysis showed that the majority of the healthcare users were able to find and buy the prescribed or recommended pharmaceuticals with the trend being consistent over the years.

In general, both issues of forgoing healthcare services and the impoverishing effects of out-ofpocket healthcare payments cannot be tackled without the active involvement of policy-makers. Ideally, all households should be shielded from the financial burden caused by out-of-pocket healthcare payments. A correct estimation of forgone healthcare services can be important to draw a complete picture of healthcare utilization, correct estimation of existing ratios between demand and supply for healthcare services, as well as the planning of activities aimed at improving equity in the access and financing to these services and treatments. However, such data are often unavailable, and potential healthcare users, who needed healthcare services but had to forgo healthcare utilization due to financial hurdles, are not included in the analysis. An adequate and effective protection of households that mitigates the impact of the financial burden of the out-ofpocket might require a targeted help or social assistance and means-tested benefits provision. This could specifically relate to the most vulnerable households. And while the overall poverty alleviation has already been shown to be effective, more specific measures that would assist specific vulnerable groups, might contradict the currently existing Russian legislation, as it was previously discussed in Chapter 3 and Statement 2.

While household level data on the incidence of forgoing healthcare services due to the lack of money were available, no such data were available for individuals. To address the problem of forgoing healthcare services even further, future studies should explore in mode depth all possible reasons of forgoing necessary healthcare services (e.g. self-treatment, long waiting times, distance, lack of access, others). 


\section{Statement 5: The right to access public medical care completely free-of-charge remains an illusion.}

Free-of-charge medical care is a constitutional right of Russian citizens (the Russian Constitution, 1993). This constitutional right is assured by the Guarantee Package Program, described in Chapter 1 and Chapter 2. Access to other healthcare services can be gained by means of additional out-ofpocket payments in public or private settings (i.e. official chargeable fees; quasi-formal payments; informal payments; non-monetary contributions, such as bed linen or food during hospitalization) or if services are covered by the supplementary voluntary insurance (as shown in Chapters 1 and 4). Importantly, contribution in the form of co-payments is not among available options for the Russian healthcare users. Whenever the individuals and their households are confronted with high healthcare costs, they need to decide whether they can reallocate resources internally or get more resources (i.e. by borrowing/lending/selling assets), or perhaps forgo the treatment completely (as shown and discussed in Chapter 5 and Statement 4).

In principle, the State guarantees only access to services that are included in the Guarantee Package Program and all other services healthcare users obtain by means of out-of-pocket payments. Therefore, in practice, Russian healthcare users actually will not receive all services that they need free of charge. Moreover, healthcare users can face challenges even with access to healthcare services that are guaranteed by the State. Access can be impeded due to existing inter-regional inequalities and variations in access across the regions (Chapters 1 and 2) and presence of informal payments (Chapter 4). For example, our analysis in Chapter 4 confirmed that there are several reasons for paying informally (i.e. quality, access, gratitude, as well as possible combination of these reasons). Even though, almost a third of the healthcare users in our analysis initiated informal payments following their own initiative, an even higher share of patients paid informally upon the request of medical staff. When patients decide to pay themselves, such payment could serve as an "entrance ticket" to gain access to a needed service or treatment, or as an "insurance" to guarantee (though not always objectively) receiving a more attentive and better quality care. This confirms that patients' access to healthcare services can be restricted depending on their willingness and ability to pay informally for care.

Based on our cluster analysis (Chapter 4), several patterns of paying informally to gain access to healthcare services exist in the Russian healthcare sector. In particular, informal payments for gaining access to necessary services were more common in outpatient non-dental healthcare 
settings and most frequently occurred after the service was provided. Depending on who initiated (healthcare user) or requested (healthcare provider) the informal payment for access for outpatient non-dental services, the amount was either self-determined or was told right before the service by the medical staff. When no distinction was made between the in- and outpatient services, we identified an additional pattern of paying informally for access. This pattern includes informal payment that were suggested by others (patients or friends). In such cases, the amounts of informal payments were negotiated with medical staff before the service and paid alike other patterns - after the service.

\subsection{Concluding remarks}

As described in Chapters 1-5, the Russian healthcare and social sectors face numerous problems and challenges, including those inherited from the Soviet era. The healthcare reforms coupled with the overall improvement of the economic situation in the country, brought some positive changes but still there is more to be done to adequately address the healthcare problems (including those not being officially recognized). This requires a substantial revision of the existing legislative documents, which would inevitably lead to substantial changes in daily provision of affected healthcare and social services. In doing so, healthcare and social policy-makers should not rely on chance when implementing reforms. A clear strategy for planning and managing the implementation of change is essential, especially, when estimating the number of those who can be potentially affected by the reforms.

The twenty years of the reforms in the Russian healthcare and social sectors provide valuable lessons that should not be overlooked. Policy-makers should learn from previous mistakes, especially when the scope and inter-relation between reform measures and initiatives are not comparable with the time allotted to their implementation. Moreover, the reform implementation should be logical, consequent and account for previous reform initiatives, leading to continuity one of the essential elements in achieving stability.

Healthcare and social policy-makers in Russia should take into account another essential element, which was previously missing during almost all financial healthcare financial reforms - informing both healthcare providers and consumers about ongoing or planned reform initiatives. Mass media should not be the only source of information (as it is now), but should rather be used as an aiding tool while conducting nation-wide information campaigns to raise awareness about healthcare 
users' rights, healthcare entitlements and the content of the past/ongoing/future healthcare reforms. 


\section{References}

Aarva, P., Ilchenko, I., Gorobets, P., \& Rogacheva, A. (2009). Formal and Informal Payments in Health Care Facilities in Two Russian Cities, Tyumen and Lipetsk. Health Policy and Planning, 24(5), 395-405.

Abu-Zaineh, M., Romdhane, H. B., Ventelou, B., Moatti, J. P., \& Chokri, A. (2013). Appraising financial protection in health: the case of Tunisia. International Journal of Health Care Finance and Economics, 13, 73-93.

Akopian, A. S, Goluhov, G. N, \& Shilenko, Y. V. (1999). Aktual'nye problemy reformirovanija Rossijskogo Zdravoohranenija. Problemy social'noj gigieny zdravoohranenija i istorii mediciny, 6, 20-1. (in Russian).

Alexandrova, A., \& Struyk, R. (2007). Reform of in-kind benefits in Russia: high cost for a small gain. Journal of European Social Policy, 17(2), 153-166.

Allin, S., Davaki, K., \& Mossialos, E. (2006). Paying for 'Free' Health Care. The Conundrum of Informal Payments in Post-Communist Europe, in Global Corruption Report 2006. Special focus on corruption and health. Transparency International: London, 62-71.

Amaya Lara, J. L., \& Ruiz Gomez, F. (2011). Determining factors of catastrophic health spending in Bogota, Colombia. International Journal of Health Care Finance and Economics, 11, 83100 .

Angulo, A. M., Barberán, R., Pilar Egea, P., \& Mur, J. (2011). An analysis of health expenditure on a microdata population basis, Economic Modelling, 28(1-2), 169-180.

Arsenijevic, J., Pavlova, M., \& Groot, W. (2013). Measuring the catastrophic and impoverishing effect of household health care spending in Serbia. Social Science and Medicine, 78, 17-25.

Ashenfelter, O. (1978). Estimating the effect of training programs on earnings. Review of Economics and Statistics, 60, 47-57.

Atanasova, E., Pavlova, M., Moutafova, E., Rechel, B., \& Groot, W. (2013). Out-of-pocket payments for health care services in Bulgaria: financial burden and barrier to access. Eur J Public Health, 23(6), 916-22.

Atkinson, A., Rainwater, L., \& Smeeding, T. M. (1995). Income distribution in OECD countries. The evidence from the Luxembourg Income Study (LIS). OECD, Paris.

Baji, P., Pavlova, M., Gulácsi, L., \& Groot W. (2012). Informal payments for health care services and short-term effects of the introduction of visit fee on these payments in Hungary. Int J Health Plann Manage, 27(1), 63-79. 
Balabanova, D., McKee, M., Pomerleau, J., Rose, R., \& Haerpfer, C. (2004). Health service utilization in the former Soviet Union, evidence from eight countries. Health Services Research, 39(6 pt 2),1927-50.

Balabanova, D. C, Falkingham, J., \& McKee, M. (2003). Winners and losers, expansion of insurance coverage in Russia in the 1990s. American Journal of Public Health, 93(12), 2124-30.

Balabanova, D., \& McKee, M. (2002). Understanding Informal Payments for Health Care. The Example of Bulgaria. Health Policy, 62(3), 243-73.

Balabanova, D., Roberts, B., Richardson, E., Haerpfer, C., \& McKee, M. (2012). Health care reform in the former Soviet Union: beyond the transition. Health Serv Res, 47(2), 840-64.

Baschieri, A., \& Falkingham, J. (2006), Formalizing Informal Payments. The Progress of Health Reform in Kyrgyzstan. Central Asian Survey, 25, 1-20.

Belli, P., Gotsadze, G., \& Shahriari, H. (2004), Out-of-Pocket and Informal Payments in Health Sector Evidence from Georgia. Health Policy, 70(1), 109-23.

Berki, S.E. (1986). A look at catastrophic medical expenses and the poor. Health Affairs, 5, 13845.

Bertrand, M., Duflo, E., \& Mullainathan, S. (2004). How Much Should We Trust Differences-InDifferences Estimates? Quarterly Journal of Economics, 119(1), 249-275.

Besstremyannaya, G. E. (2007). Out-of-pocket health care expenditures by Russian consumers with different health status. Transition Studies Review, 14(2), 331-338.

Besstremyannaya, G. E. (2009a). Increased public financing and health care outcomes in Russia. Transition Studies Review 2009, 16, 723-34.

Besstremyannaya, G. E. (2009b). Micro data assessment of Russian drug benefit monetization. J Health Organ Manag, 23(5), 465-476.

Bhojani, U., Thriveni, B., Devadasan, R., et al. (2012). Out-of-pocket healthcare payments on chronic conditions impoverish urban poor in Bangalore, India. BMC Public Health, 12, 990.

Blam, I., \& Kovalev, S. (2003). Commercialization of medical care and household behavior in transitional Russia. Geneva United Nations Research Institute for Social Development (UNRISD).

Blam, I., \& Kovalev, S. (2006). Spontaneous commercialisation, inequality and the contradictions of compulsory medical insurance in transitional Russia. Journal of International Development, 18(3), 407-23. 
Blundell, R., \& Costa Dias, M. (2000). Evaluation methods for non-experimental data. Fiscal Studies, 21, 427-68.

Blundell, R., \& Dias, M.C. (2009). Alternative Approaches to Evaluation in Empirical Microeconomics. Journal of Human Resources, 44(3), 565-640.

Boikov, V. E., Feeley, F. G., Sheiman, I. M, \& Shishkin, S. V. (unpublished). Russian household expenditures on drugs and medical care, results of a December 1997 survey of 3000 households

(unpublished) http://dcc2.bumc.bu.edu/russianlegalhealthreform/ProjectDocuments/n640.IIIB6.Artic le.pdf

Bonu, S., Bhushan, I., Rani, M., \& Anderson I. (2009). Incidence and correlates of 'catastrophic' maternal health care expenditure in India. Health Policy and Planning, 24, 445-456.

Bredenkamp, C., Mendola, M., \& Gragnolati, M. (2011). Catastrophic and impoverishing effects of health expenditure: new evidence from the Western Balkans. Health Policy and Planning, 26, 349-356.

Brown, J. V., \& Rusinova, N. L. (1997). Russian medical care in the 1990s, a user's perspective. Social Science and Medicine, 45(8), 1265-76.

Cameron, A. C., \& Trivedi, P. K. (2009). Microeconometrics Using Stata. College Station Texas Stata Press.

Campbell, S., Siobhan, B., Coates, E., Davies, P., \& Penn, G. (2007). Analysis for policy, evidencebased policy in practice. Government Social Research. London, HM Treasury.

Cherecheş, R. M., Ungureanu M. I., Sandu P., Rus I.A. (2013). Defining informal payments in healthcare: a systematic review. Health Policy, 110(2-3),105-14.

Chernichovsky, D., Barnum, H., \& Potapchik, E. (1996a). Health system reform in Russia, the finance and organization perspectives. Economics of Transition, 4(1), 113-34.

Chernichovsky, D., Ofer, G., \& Potapchik, E. (1996b). Health sector reform in Russia, the heritage and the private/public mix. MOCT-MOST, Economic Policy in Transitional Economies, 6(3), 125-52.

Chuma, J., \& Maina, T. (2012). Catastrophic health care spending and impoverishment in Kenya. BMC Health Services Research, 12, 413.

Cockx, B., \& Brasseur, C. (2003). The demand for physician services Evidence from a natural experiment. Journal of Health Economics, 22(6), 881-913.

Cohen, N. (2011). Informal Payments for Health Care - the Phenomenon and Its Context. Health economics, policy, and law, 5 1-24. 
Currie, J., \& Gahvari, F. (2008). Transfers in Cash and In-Kind Theory Meets the Data. Journal of Economic Literature, 46(2), 333-383.

Danishevski, K., Balabanova, D., Mckee, M., \& Atkinson, S. (2006). The fragmentary federation, experiences with the decentralized health system in Russia. Health Policy and Planning, 21(3), 183-94.

Denisova, I. Income distribution and poverty in Russia. (2012). OECD Social, Employment and Migration Working Papers, No. 132, OECD Publishing.

Diukareva, A. M., Grigor'eva, T. A., Il'chenko, O., \& Kuznetsova, T. N. (1997). Vrachi i naselenie o reformirovanii zdravoohranenija. Problemy social'noj gigieny zdravoohranenija $i$ istorii mediciny, 2, 36-9. (in Russian).

Duke, T., Keshishiyan, E., Kuttumuratova, A., Ostergren, M., Ryumina, I., Stasii, E., et al. (2006). Quality of hospital care for children in Kazakhstan, Republic of Moldova, and Russia, systematic observational assessment. Lancet, 367, 919-25.

Ensor, T. (2004). Informal Payments for Health Care in Transition Economies. Social Science and Medicine, 58(2), 237-46.

Ensor, T., \& Witter, S. (2001). Health Economics in Low Income Countries Adapting to the Reality of the Unofficial Economy. Health Policy, 57(1), 1-13.

Falkingham, J. (2004). Poverty, out-of-Pocket Payments and Access to Health Care Evidence from Tajikistan. Social Science \& Medicine, 58(2), 247-58.

Farrar, S., Yi, D., Sutton, M., Chalkley, M., Sussex, J., \& Scott, A. (2009). Has payment by results affected the way that English hospitals provide care? Difference-in-differences analysis. BMJ, 339.

Feeley, F. G, Sheiman, I. M, \& Shiskin, SV. (unpublished). Health sector informal payments in Russia. Boston Boston University Department of International Health. Moscow; 1999.

FFOMS. (2010). Federal Compulsory Health Insurance Fund. http://www.ffoms.ru

Filatov, V. B. (2003). Politicheskie faktory i Rossijskoe zdravoohranenie. Vestnik Rossijskoj Akademii Medicinskih Nauk, 4, 46-9. (in Russian).

Fotaki, M. (2006). Users' perceptions of health care reforms, quality of care and patient rights in four regions in the Russian Federation. Social Science and Medicine, 63(6),1637-47.

Fotaki, M. (2009). Informal payments, a side effect of transition or a mechanism for sustaining the illusion of 'free' health care? The experience of four regions in the Russian Federation. Journal of Social Policy, 38(04), 649-70.

Gaal, P., \& McKee, M. (2004), Informal Payment for Health Care and the Theory of "Inxit". The International Journal of Health Planning and Management, 19(2), 163-78. 
Gaal, P., Belli, P. C., McKee, M., \& Szócska, M. (2006a). Informal Payments for Health Care Definitions, Distinctions, and Dilemmas. Journal of Health Politics, Policy and Law, 31(2), 251-93.

Gaal, P., Evetovits, T., \& McKee, M. (2006b). Informal Payment for Health Care Evidence from Hungary. Health Policy, 77(1), 86-102.

Gertler, P., \& Gruber, J. (2002). Insuring consumption against illness. American Economic Review, 92(1), 51-70.

Global rates. (2012). http //www.global-rates.com. Accessed 1 June 2012.

Gordeev, V. S., Pavlova, M., \& Groot, W. (2011), Two Decades of Reforms. Appraisal of the Financial Reforms in the Russian Public Healthcare Sector, Health Policy, 102(2-3) 270-77.

Gordeev, V. S., Pavlova, M., \& Groot, W. (2014). Informal payments for health care services in Russia, old issue in new realities. Health Econ Policy Law, 9(1), 25-48.

Gotsadze, G., Zoidze, A., \& Rukhadze, N. (2009). Household catastrophic health expenditure Evidence from georgia and its policy implications. BMC Health Services Research, 9.

Government of the Russian Federation. (1993). Constitution of the Russian Federation. Ratified $\begin{array}{llll}\text { December } & 12, & \text { (in } & \text { Russian). }\end{array}$ http:/ /www.consultant.ru/online/base/?req=doc;base=LAW;n=2875

Government of the Russian Federation. Zakon RF No 1499-1. (1991). "O medicinskom strahovanii grazhdan v Rossijskoj Federacii". Adopted 28 June 1991. (in Russian). http://www.consultant.ru/online/base/?req=doc;base $=\mathrm{LAW} ; \mathrm{n}=89957$

Government of the Russian Federation. Zakon RF No 212. (2009). "O strahovyh vznosah v pensionnyj fond Rossijskoj Federacii, fond social'nogo strahovanija rossijskoj federacii, federal'nyj fond objazatel'nogo medicinskogo strahovanija". Adopted 18 July, 2009. (in Russian). http://www.consultant.ru/document/cons_doc_LAW_149063

Government of the Russian Federation. Zakon RFNo. 122. (2004). "O vnesenii izmenenij v zakonodatel'nye akty Rossijskoj Federacii i priznanii utrativshimi silu nekotoryh zakonodatel'nyh aktov Rossijskoj Federacii v svjazi s prinjatiem federal'nyh zakonov "O vnesenii izmenenij i dopolnenij v Federal'nyj zakon "Ob obshhih principah organizacii zakonodatel'nyh (predstavitel'nyh) i ispolnitel'nyh organov gosudarstvennoj vlasti sub"ektov Rossijskoj Federacii" i "Ob obshhih principah organizacii mestnogo samoupravlenija v Rossijskoj Federacii". (in Russian). http://www.consultant.ru/online/base/?req=doc;base=LAW;n=110231 
Government of the Russian Federation. Zakon RF No. 178. (1999). "O gosudarstvennoj social'noj pomoshi". Adopted 17 July $1999 . \quad$ (in Russian). http:/ /www.consultant.ru/online/base/?req=doc;base=LAW;n=107708

Government of the Russian Federation. Zakon RF No. 323. (2011). "Ob osnovah ohrany zdorov'ja grazhdan v rossijskoj federacii". Adopted 21 November 2011. (in Russian). http://base.consultant.ru/cons/cgi/online.cgi?req=doc;base=LAW;n=131658

Government of the Russian Federation. Zakon RF No. 326. (2010). “Ob objazatel'nom medicinskom strahovanii v rossijskoj federacii”. Adopted 29 November 2010. (in Russian). http:/ / base.consultant.ru/cons/cgi/online.cgi?req=doc;base=LAW;n=133398

Government of the Russian Federation. Federal Law No. 5487-1. (1993). "Osnovy zakonodatel'stva Rossijskoj Federacii ob ohrane zdorov'ja grazhdan”. Adopted 22 July 1993. (in Russian).

http://www. consultant.ru/online/base/?req=doc;base=LAW;n=90012.

Government of the Russian Federation. Government resolution no. 1096. (1998). "Ob utverzhdenii programmy gosudarstvennyh garantij okazanija grazhdanam Rossijskoj Federacii besplatnoj medicinskoj pomoshhi”. Adopted 11 September, 1998. (in Russian). http://base.consultant.ru/cons/cgi/online.cgi?req=doc;base=LAW;n=32659

Government of the Russian Federation. Government resolution no. 27. (1996). "Ob utverzhdenii pravil predostavlenija platnyh medicinskih uslug naseleniju medicinskimi uchrezhdenijami”. Adopted 13 January 1996. (in Russian). http://www.consultant.ru/online/base/?req=doc;base=LAW;n=8832

Government of the Russian Federation. Government resolution no. 296. (2007) "Ob utverzhdenii Pravil finansirovanija v 2007 godu rashodov na realizaciju v sub"ektah Rossijskoj Federacii pilotnogo proekta, napravlennogo na povyshenie kachestva uslug v sfere zdravoohranenija, i perechnja sub"ektov Rossijskoj Federacii, uchastvujushhih v ego realizacii". Adopted 19 May 2007. (in Russian). http:/ /www.consultant.ru/ online/base/?req=doc;base=LAW;n=68415.

Habicht, J., Xu, K., Couffinhal, A., \& Kutzin J. (2006). Detecting changes in financial protection creating evidence for policy in Estonia. Health Policy and Planning, 21, 421-431.

Hahulina, L. A. (2005). Monetizacija l'got v zerkale obshhestvennogo mnenija. SPERO 3, 51-61. (in Russian)

Hirschman, A. O. (1980). Exit, Voice, and Loyalty. Further Reflections and a Survey of Recent Contributions. Milbank Mem Fund Q Health Soc, 58(3), 430-53. 
Hurst, J. (1992). The reform of health care, a comparative analysis of seven OECD countries. Paris, OECD.

Isakova, L. E., Zelckovich, R. M., \& Frid, E. M. (1995). Health insurance in Russia - the Kuzbass experience. Health Policy, 31(3), 157-69.

Khisamutdinov, R. A., \& Husnutdinova, Z. A. (2003). Otnoshenie medicinskih rabotnikov k reformam $\mathrm{v}$ zdravoohraneniiю Problemy social'noj gigieny zdravoohranenija i istorii mediciny, 3, 26-8. (in Russian).

Knaul, F. M., Arreola-Ornelas, H., Méndez-Carniado, O., et al. (2006). Evidence is good for your health system policy reform to remedy catastrophic and impoverishing health spending in Mexico. Lancet, 368, 1828-1841.

Kringos, D., Boerma, W., Spaan, E., Pellny, M., Son, I., \& Korotkova, A. (2009). Evaluation of the organizational model of primary care in the Russian Federation. A survey based pilot project in two rayons in Moscow oblast. Copenhagen, WHO Regional Office for Europe.

Lewis, M. (2000). Who is Paying for Health Care in Eastern Europe and Central Asia? Washington, DC. Human Development Sector Unit, Europe and Central Asia Region, The World Bank.

Lewis, M. (2002). Informal health payments in central and eastern Europe and the former Soviet Union issues, trends and policy implications, in E. Mossialos, A. Dixon, J. Figueras, and J. Kutzin (Eds), Funding Health Care Option for Europe. Buckingham, U.K. Open University Press, 184-205.

Lewis, M. (2007). Informal payments and the financing of health care in developing and transition countries. Health Affairs, 26(4), 984-997.

Liaropoulos, L., Siskou, O., Kaitelidou, D., Theodorou, M., \& Katostaras, T. (2008). Informal Payments in Public Hospitals in Greece. Health Policy, 87(1), 72-81.

Liu, Y., Rao, K., \& Fei, J. (1998). Economic transition and health transition, comparing China and Russia. Health Policy 1998; 44(2), 103-22.

Lohlein D., Jütting J., Wehrheim P. (2003). Rural Russia in transition, what determines access to health-care services? Post-Soviet Affairs, 19(1), 80-94.

Long, F., \& Freese, J. (2006). Regression models for categoriacal dependent variables using STATA. Stata Press Publications, Texas.

Mæstad, O., \& Mwisongo, A. (2011). Informal Payments and the Quality of Health Care Mechanisms Revealed by Tanzanian Health Workers. Health Policy, 99(2), 107-15.

Masuk, E. (2010). Oborotni v belih halatah, Moskovskij komsomolec, no. 25419, http://www.mk.ru/social/article/2010/08/05/521320-oborotni-v-belyih-halatah.html. 
Mihaylova B., Briggs, A., O’Hagan, A., \& Thompson, S. G. (2011). Review of statistical methods for analyzing healthcare resources and costs. Health Econ, 20, 897-916.

Ministry of Finances of the Russian Federation. (2012). http //www.minfin.ru (in Russian).

Murauskiene, L., Pavlova, M., Veniute, M., \& Groot, W. (2012). Towards a more comprehensive view on patient payments in lithuania new findings from a population survey. Society and Economy, 34(2), 241-251.

NOBUS. (2003). http //www.hse.ru/jesda/mathbase/databases/db_32

O'Donnell, O., van Doorslaer, E., Wagstaff, A., \& Lindelow, M. (2008). Analyzing health equity using household survey data. A guide to techniques and their implementation. Washington, D.C, The World Bank.

OECD. (2006). Organization for Economic Cooperation and Development. Reforming healthcare. In, Economic survey of the Russian Federation. Paris, Organisation for Economic Co-operation and Development, p.187-221.

OECD. (2012). Organization for Economic Cooperation and Development. OECD Reviews of Health Systems Russian Federation.

Ovcharova, L. N. (2005). Sotzialnie l'goti chto poluchilos v rezultate monetizazii? SPERO 3, 5-24 (in Russian)

Özgen, H., Sahin, B., Belli, P., Tatar, M., \& Berman, P. (2010). Predictors of Informal Health Payments. The Example from Turkey. J Med Syst, 34(3), 387-96.

Parfitt, T. (2007). Russia's prescription drugs crisis. The Lancet 369(9575), 1779-1780.

Pavlova, M., Tambor, M., Stepurko, T., van Merode, G.G., \& Groot, W. (2012). Assessment of patient payment policy in CEE countries from a conceptual framework to policy indicators. Society and Economy in Central and Eastern Europe, 34(2), 193-220.

Perlman, F., \& Balabanova, D. (2011). Prescription for change accessing medication in transitional Russia. Health Policy Plan, 26(6), 453-63.

Petrova, N. G, Balohina, S. A, Martirosjan, M. M, Petrov, M. V, Temirova, L. H, \& Shatkovskaja, O. V. (2009). Patient's opinion as an important criteria of quality of medical aid. Problemi upravlenija zdravoohraneniem,1, 59-61. (in Russian).

Pickard, L., Comas-Herrera, A., Costa-Font, J., Gori, C., di Maio, A., Patxot, C., Pozzi, A., Rothgang, H., \& Wittenberg, R. (2007).Modelling an entitlement to long-term care services for older people in Europe projections for long-term care expenditure to 2050. Journal of European Social Policy, 17(1), 33-48. 
Popkin, B. M., Baturin, A. K., Mozhina M., \& Mroz, T. (1996). The Russian Federation Subsistence Income Level The Development of Regional Food Baskets and Other Methodological Improvements. World Bank mimeo.

Powers, C. A., Meyer, C. M., Roebuck, M. C., \& Vaziri, B. (2005). Predictive modeling of total healthcare costs using pharmacy claims data a comparison of alternative econometric cost modeling techniques, Med Care,.43(11) 1065-72.

Pradhan, M., \& Prescott, N. (2002). Social risk management options for medical care in Indonesia. Health Economics, 11, 431-446.

Ranson, M. K. (2002). Reduction of catastrophic health care expenditures by a community-based health insurance scheme in Gujarat, India current experiences and challenges. Bulletin of the World Health Organisation, 80(8), 613-21.

Rechel, B., \& McKee, M. (2009) Health reform in central and eastern Europe and the former Soviet Union. Lancet 2009;374,1186-95.

Rekhter, N, \& Togunov, I. A. (2006). Needs assessment for health care management education in Russia. Journal of Continuing Education in the Health Professions, 26(4), 314-26.

RLMS-HSE. (2013). Russia Longitudinal Monitoring Survey - Higher School of Economics. www.cpc.unc.edu/projects/rlms-hse; www.hse.ru/en/rlms/

Roberts, M. J., Hsiao, W., Berman, P., \& Reich, M. R. (2004). Getting Health Reform Right. A Guide to Improving Performance and Equity. Oxford University Press Oxford.

Russell, S. (2004). The economic burden of illness for households in developing countries a review of studies focusing on malaria, tuberculosis, and human immunodeficiency virus/acquired immunodeficiency syndrome. Am J Trop Med Hyg, 71(Supp. 2), 147-155.

Saratov, G. (2001). Diagnosing Russian Corruption A Sociological Analysis, Moscow. The INDEM Foundation Report. http //www.anti-corr.ru/awbreport/index.htm.

Schreyögg, J., \& Grabka, M. (2010). Copayments for ambulatory care in Germany a natural experiment using a difference-in-difference approach. The European Journal of Health Economics, 11(3), 331-341.

Sheaff, R. (2005). Governance in gridlock in the Russian health system; the case of Sverdlovsk oblast. Social Science and Medicine, 60(10), 2359-69.

Shenberg, M. (2005). Gorkie "uroki" monetizazii l'got. Uluchshitsja li polozhenie rossijan. Agency of Social Information.

http://www.asi.org.ru/ASI3/main.nsf/0/702E418285403167C3257015002EFB93

(in Russian). Accessed 1 June 2012 
Shishkin, S. (1998). Priorities of the Russia health care reform. Croatian Medical Journal, 39, 298 307

Shishkin, S. V., Bogatova, T. V., Potapchik, Y. G., Chernets, V. A., Chirikova, A. Y., \& Shilova, L.S. (2003). Informal out-of-Pocket Payments for Health Care in Russia, Moscow. Moscow Public Scientific Foundation, Independent Institute for Social Policy.

Sinitsina, I. (2009). Experience in implementation social benefits monetization reform in Russia. Literature review. No. 381/2009. Case Network studies and analyses. Center for Social and Economic Research, Warsaw.

Starodubov, V. I., \& Flek, V. O. (2007). Problems and perspectives of funding Russian healthcare. Healthcare Economy, 1(111), 5-16. (in Russian).

Stepurko, T., Pavlova, M., Gryga, I., \& Groot, W. (2010). Empirical Studies on Informal Patient Payments for Health Care Services. A Systematic and Critical Review of Research Methods and Instruments. BMC Health Services Research, 10(1), 273.

Stepurko, T., Pavlova, M., Gryga, I., \& Groot, W. (2011). Informal patient payments and public attitudes towards these payments evidence from six CEE countries, Scripta Scientifica Medica, 43(7), 143-146.

Struyk, R., Grishina, E., \& Kovalenko, E. (2007). Effects on Beneficiaries of the "Monetization" of Privileges in Russia Initial Experience in Saratov Oblast. Problems of Economic Transition, 50(2), 6-32.

TACIS. (2000). Governance of health insurance. Report submitted to the Ministry of Labor and Social Security of the Russian Federations Moscow,TACIS.

Tambor, M., Pavlova, M., Rechel, B., Golinowska, S., Sowada, C., \& Groot, W. (2013). The inability to pay for health services in Central and Eastern Europe evidence from six countries. Eur J Public Health. [Epub ahead of print]

Tax code of the Russian Federation (2010). Adopted 31 July, 1998. http://base.consultant.ru/cons/cgi/online.cgi?req=doc;base=LAW;n=148796

The Ministry of Healthcare of the Russian Federation, 2013. http://www.rosminzdrav.ru

The World Bank. (2013). http://www.worldbank.org/.

Thompson, R., \& Witter, S. (2000). Informal Payments in Transitional Economies Implications for Health Sector Reform. The International Journal of Health Planning and Management, 15(3), 169-87.

Tkatchenko, E., McKee, M., \& Tsouros, A. D. (2000). Public health in Russia, the view from the inside. Health Policy and Planning, 15(2),164-9. 
Tomini, S. M., Packard, T. G., \& Tomini, F. (2013). Catastrophic and impoverishing effects of outof-pocket payments for health care in Albania evidence from Albania Living Standards Measurement Surveys 2002, 2005 and 2008. Health Policy Plan, 28(4), 419-28.

Tomini, S., \& Maarse, H. (2011). How Do Patient Characteristics Influence Informal Payments for Inpatient and Outpatient Health Care in Albania Results of Logit and Ols Models Using Albanian LSMS 2005. BMC Public Health, 11(1), 375.

Tompson, W. (2007). Healthcare reform in Russia, problems and prospects. Economics department working paper no 538. ECO/WKP(2006)66. Organisation for Economic Cooperation and Development. OECD Publishing, Paris

Tragakes, E., Lessof, S., editors. (2003). Health care systems in transition, Russian Federation. Copenhagen, European Observatory on Health Systems and Policies.

Twigg, J. L. (1998). Balancing the state and the market, Russia's adoption of obligatory medical insurance. Europe-Asia Studies, 50(4), 583.

Twigg, J. L. (1999). Obligatory medical insurance in Russia, the participants' perspective. Social Science and Medicine 1999, 49(3), 371-82.

Twigg, J. L. (2001). Russian health care reform at the regional level, status and impact. Post-Soviet Geography and Economics, 42(3), 202-19.

Twigg, J. L. (2002). Health care reform in Russia, a survey of head doctors and insurance administrators. Social Science and Medicine, 55(12), 2253-65.

USAID. (1999). Analysis of structural/functional reform of the health care system in Russia. Research Institute of Social Hygiene, Health Organization and Economics; 2010. http://dcc2.bumc.bu.edu/ RussianLegalHealthReform/ProjectDocuments/n970.IIIE1. Analysis.pdf.

van Doorslaer, E., O'Donnell, O., Rannan-Eliya, R., et al. (2007). Catastrophic payments for health care in Asia. Health Econ, 16, 1159-1184.

Vian, T. (2008). Review of Corruption in the Health Sector Theory, Methods and Interventions. Health Policy and Planning, 23(2), 83-94.

Vian, T., \& Burak, L.J. (2006). Beliefs About Informal Payments in Albania. Health Policy and Planning, 21(5), 392-401.

Volchkova, N., Gorshkova, E., Lobanov, S., Makrushin, A., Tundyeva, N., \& Haleeva, Y. (2006). Ocenka posledstvij reformirovanija sistemy social'nyh garantij: monetizacija l'got i reforma ZhKH. http:/ / www.cefir.ru/download.php?id=469 (in Russian).

Wagstaff, A. (2007). The economic consequences of health shocks. Evidence from Vietnam. J Health Econ, 6(1), 82-100. 
Wagstaff, A., \& Moreno-Serra, R. (2009). Europe and central Asia's great post-communist social health insurance experiment, aggregate impacts on health sector outcomes. Journal of Health Economics, 28,322-40.

Wagstaff, A., van Doorslaer, E. (2003). Catastrophe and impoverishment in paying for health care with applications to Vietnam 1993-1998. Health Economics, 12, 921-933.

Wengle, S., \& Rasell, M. (2008). The monetisation of l'goty.Changing patterns of welfare politics and provision in Russia. Europe-Asia Stud, 60(5), 739-756.

WHO. (2009). Access to health care and the financial burden of out-of-pocket health payments in Latvia. http://www.who.int/health_financing/documents/pb_e_09_1-oopslat.pdf

Winkelmann, R. (2004) Co-payments for prescription drugs and the demand for doctor visits Evidence from a natural experiment. Health Economics, 13(11), 1081-1089.

World Bank. (2004). Russian Federation Poverty Assessment. Report No. 28923-RU. World Bank, Washington, DC.

World Bank. (2008). Better outcomes through health care reforms in the Russian Federations, the challenge in 2008 and beyond. Washington, DC, World Bank.

World Bank. http://www.worldbank.org/

World Health Organization. (1999). Methods for evaluating effects of health reforms.

World Health Organization. (2010). http://apps.who.int/whosis/ database/core/core select process.cfm.

World Health organization. (2013). http://www.who.int

Wyszewianski, L. (1986). Families with catastrophic health care expenditures. Health Serv Res, 21(5), 617-34.

Xu, K., Evans, D. B., Carrin, G., et al. (2007). Protecting households from catastrophic health spending. Health Affairs, 26, 972-983.

Xu, K., Evans, D. B., Kawabata, K., et al. (2003). Household catastrophic health expenditure a multicountry analysis. The Lancet, 362, 111-117.

Xu, K., Saksena, P., Jowett, M., Indikadahena, C., Kutzin, J., \& Evans, D. (2010). Exploring the thresholds of health expenditure for protection against financial risk. Background Paper 19, World Health Report. World Health Organization Geneva.

Yardim, M. S., Cilingiroglu, N., \& Yardim, N. (2010). Catastrophic health expenditure and impoverishment in Turkey. Health Policy, 94, 26-33.

Zasimova, L. (2010). Public policy and access to new drugs evidence from Russian pharmaceutical market. 
Zhang, J. (2007). A DID analysis of the impact of health insurance reform in the city of Hangzhou. Health Economics, 16(12), 1389-1402

Zhang, J. (2010). The impact of a diagnosis-related group-based prospective payment experiment the experience of Shanghai. Applied Economics Letters, 17(18), 1797-1803. 


\section{Appendix A}

English wording of the selected questions from the questionnaires used in the dissertation.

The full version of questionnaires for all rounds can be found at: http://www.cpc.unc.edu/projects/rlms-hse/data/questionnaires and

http://www.hse.ru/rlms/question

\section{- HEALTH CARE UTILIZATION AND OUT-OF-POCKET PAYMENTS}

In the last 30 days did you apply for out-patient/ambulatory care? Please, don't take into account dental care or dental prosthetics. You will tell about it later.

Did you go to:

A regional, city, state, or village polyclinic

A commercial polyclinic

A regional, city, state, or village hospital

A commercial hospital

A private physician

Possible answers: Yes No Don't know Refuses to answer

To whom, how, and how much did you or your family pay for out-patient/ ambulatory non-dental care in the last 30 days? Did you pay? How much in rubles?

Paid officially at a cashier's office in accordance with official rules or with the medical enterprise's official prices

Paid unofficially through hand-to-hand monetary transactions without any documents

Paid unofficially through gift-giving

Possible answers: Yes No Don't know Refuses to answer

If Yes, then How much? 
Let's talk about the latest case in which you unofficially paid a health worker money for out-patient non-dental care. Who suggested that you pay unofficially, straight to the hands of the health worker?

A health worker, whom you then paid

Another worker of this enterprise

Other patients suggested

Your friends suggested

Nobody advised, you suggested it to a health worker on your own initiative

Other

Possible answers: Yes No Don't know Refuses to answer

Why did you pay unofficially for out-patient/ambulatory non-dental care this time?

It was difficult or impossible to get to this medical enterprise by another way

It was difficult or impossible to get to the doctor who was recommended to you by another way

Can't get necessary service by another way at all

Would need to wait a long time for the necessary service in any other way

You expected more attentive and better quality treatment

You wanted to thank the health worker for successful treatment and attention

Other reason

Possible answers: Yes No Don't know Refuses to answer

Remember, that we are asking only about unofficial payments with money. Last time you paid:

Possible answers:

Before service

After service

Both before and after service

Don't know

Refuses to answer 
When did you find out about the amount of money to be paid?

Possible answers:

You knew before the visit to the medical enterprise

You found out just before the medical service

You found out after the medical service

Nobody told you the amount of payment

Other

Don't know

Refuses to answer

Who determined the amount of payment?

Possible answers:

Somebody told you the amount of payment and you agreed

The amount of payment was negotiated

You determined how much to pay

Other way

Don't know

Refuses to answer

Did you or your family incur any expenses on medicines or dressing materials for your home treatment in the last $\mathbf{3 0}$ days? Do not count any expenditures on medicines for treatment in hospital, expenditures on vitamins or probiotics.

Possible answers: Yes No Don't know Refuses to answer

How much did you pay for them?

RUBLES

Don't know

Refuses to answer

Have you been in the hospital in the last three months?

Possible answers: Yes No Don't know Refuses to answer 
How many days in total in the last three months did you spend in the hospital? DAYS

Don't know

Refuses to answer

In which of the following facilities were you hospitalized in the last three months?

In state, municipal hospital

In an institutional hospital

In a commercial hospital

Possible answers: Yes No Don't know Refuses to answer

Did you receive medicine, syringes, and dressing materials that were necessary for your treatment in a hospital, for free or did you pay for them with money or gifts?

Possible answers:

All medicines, syringes, and dressing materials were received free

Some medicines, syringes, and dressing materials were received free of charge, and some we paid for

We paid for all medicines, syringes, and dressing materials

Don't know

Refuses to answer

To whom, how, and how much did you or your family pay for medicines, syringes and dressing materials in the last 3 months when you were in the hospital or hospitals? Did you pay? How much in rubles?

Paid officially at the cashier's office of the hospital you were in according to official rules or the medical enterprise's official prices

You paid unofficially by giving money or gifts directly to a doctor or medical staff of the hospital you were

Somebody bought medicine, syringes and dressing materials for treatment in the hospital in pharmacies outside of hospital

Possible answers: Yes No Don't know Refuses to answer

If Yes, then How much? 
Did you pay for a stay in hospital, medical services and treatment, not including payments for medicine, syringes and dressing materials it doesn ' $t$ matter whether it was money or presents?

Possible answers: Yes No Don't know Refuses to answer

To whom, how, and how much did you or your family pay in the last three months for a stay in the hospital, medical services, and treatment, not including payments for medicine, syringes and dressing materials? Did you pay? How much in rubles? You paid officially in a cashier's office in accordance with the official rules or the medical enterprise's official prices

You paid unofficially through hand-to-hand monetary transactions without any

You paid unofficially through gift-giving

Possible answers: Yes No Don't know Refuses to answer

If Yes, then How much?

Let's talk about the latest case in which you unofficially paid a health worker money in the hospital. Who suggested that you pay unofficially?

A health worker, whom you then paid

Another worker of this enterpise

Other patients suggested it

Your friends suggested it

Nobody advised, you suggested it to a health worker on your own initiative

Other

Possible answers: Yes No Don't know Refuses to answer

Why did you pay unofficially for care in the hospital this time?

It was difficult or impossible to get access to this medical enterprise by any other way or you would need to wait for hospitalization for a long time

It was difficult or impossible to get treatment or an operation from the doctor that was recommended to you by any other way

Can't get necessary treatment or get an operation by any other way at all 
You expected to receive more attentive and better quality treatment

You wanted to thank the health worker for successful treatment and attention

Other reason

Possible answers: Yes No Don't know Refuses to answer

Remember, that we are asking only about unofficial payments with money. Last time you paid:

Possible answers:

Before service

After service

Both before and after service

Don't know

Refuses to answer

When did you find out about the amount of money to be paid?

Possible answers:

You knew before the visit to the medical enterprise

You found out just before the medical service

You found out after the medical service

Nobody told you the amount of payment

Other

Don't know

Refuses to answer

\section{Who determined the amount of payment?}

Possible answers:

Somebody told you the amount of payment and you agreed

The amount of payment was determined during negotiation

You determined how much to pay

Other way

Don't know

Refuses to answer 
Did you apply for dental care, including dental prosthetics, in the past three months?

Possible answers: Yes No Don't know Refuses to answer

In what kind of facility did you apply for dental care in the last three months?

In state, municipal hospital

In institutional hospital

In a commercial hospital, commercial room

Possible answers: Yes No Don't know Refuses to answer

To whom, how, and how much did you or your family pay for dental services in the last three months? Did you pay? How much in rubles?

You paid officially in the cashier's office in accordance with official rules or the medical enterprise's official prices

You paid unofficially through hand-to-hand monetary transactions without any documents You paid unofficially through gift-giving

Possible answers: Yes No Don't know Refuses to answer If Yes, then How much?

Tell me, please: In the last three months have you seen a doctor for a medical checkup, not because you were sick?

Possible answers: Yes No Don't know Refuses to answer

To whom, how, and how much did you or your family pay for this medical checkup in the last three months? Did you pay? How much in rubles?

You paid officially in the cashier's office in accordance with official rules or the medical enterprise's official prices

You paid unofficially through hand-to-hand monetary transactions without any documents You paid unofficially through gift-giving

Possible answers: Yes No Don't know Refuses to answer If Yes, then How much? 
Tell me, please, do you have a regular physician, whom you consult about all your health issues?

Possible answers: Yes No Don't know Refuses to answer

\section{- INDIVIDUAL'S HEALTH CARE AND SOCIAL CARE BENEFITS}

Please recall which social benefits you personally are entitled to. For each of them tell me whether you have used it in 2005 or not. You are entitled to free or discounted medicines provision?

Possible answers: Yes No

Have you used this benefit in 2005?

Possible answers: Yes No

And in 2006, do you want to have this benefit in natural form or receive money instead?

Possible answers: Natural benefits Money

Were you entitled to social benefits or money compensation for free or discounted medicines provision in 2005 ?

Possible answers: Yes No

Have you had natural benefits or money?

Possible answers: Natural benefits Money

Were you entitled to social benefits or money compensation for free or discounted medicines provision in 2006 ?

Possible answers: Yes No 
Have you had natural benefits or money?

Possible answers: Natural benefits Money

Were you entitled to social benefits or money compensation for free or discounted medicines provision in 2007 ?

Possible answers: Yes No

Have you had natural benefits or money?

Possible answers: Natural benefits Money

\section{- HOUSEHOLD'S HEALTH CARE UTILIZATION (INCLUDING FORGOING HEALTH CARE SERVICES) AND RELATED OUT-OF-POCKET PAYMENTS}

Did your family spend money in the last 30 days, and, if so, how much?

Family spend money

For treatment or examination in inpatient hospitals, military hospitals, or clinics, not including medicine

For treatment or examination in polyclinics, not including medicine

For dental treatment, dentures, false teeth, not including medicine

For medicines, including vitamins and other drugs

Possible answers: Yes No Don't know Refuses to answer If Yes, then How much?

Tell me, please: During the last 12 months has there been a situation in which a member of your family needed some form of medical help and could not get it only because he or she did not have enough money

Could not receive outpatient clinic or polyclinic treatment

Could not receive inpatient treatment in a hospital, military hospital, or clinic

Could not receive dental care

Could not buy necessary medicine

Possible answers: Yes No Don't know Refuses to answer 


\section{Appendix B}

The list of publications included in the systematic literature review.

1. Organization for Economic Cooperation and Development. Reforming healthcare. In: Economic survey of the Russian Federation. Paris: Organisation for Economic Co-operation and Development; 2006. p.187-221.

2. Rechel B, McKee M. Health reform in central and eastern Europe and the former Soviet Union. Lancet 2009;374:1186-95.

6. Blam I, Kovalev S. Spontaneous commercialisation, inequality and the contradictions of compulsory medical insurance in transitional Russia. Journal of International Development 2006;18(3):407-23.

16. Twigg JL. Russian health care reform at the regional level: status and impact. Post-Soviet Geography and Economics 2001;42(3):202-19.

17. Tkatchenko E, McKee M, Tsouros AD. Public health in Russia: the view from the inside. Health Policy and Planning 2000;15(2):164-9.

18. Liu Y, Rao K, Fei J. Economic transition and health transition: comparing China and Russia. Health Policy 1998;44(2):103-22.

19. Diukareva, A. M., Grigor'eva, T. A., Il'chenko, O., \& Kuznetsova, T. N. Vrachi i naselenie o reformirovanii zdravoohranenija. Problemy social'noj gigieny zdravoohranenija i istorii mediciny 1997; 2, 36-9. (in Russian).

20. Fotaki M. Users' perceptions of health care reforms: quality of care and patient rights in four regions in the Russian Federation. Social Science and Medicine 2006;63(6):1637-47.

21. Twigg JL. Health care reform in Russia: a survey of head doctors and insurance administrators. Social Science and Medicine 2002;55(12):2253-65.

22. Chernichovsky D, Barnum H, Potapchik E. Health system reform in Russia: the finance and organization perspectives. Economics of Transition 1996;4(1):113-34.

24. Shishkin S. Priorities of the Russia health care reform. Croatian Medical Journal 1998;39:298307.

26. Tompson W. Healthcare reform in Russia: problems and prospects. Economics department working paper no 538. ECO/WKP (2006) 66, Organisation for Economic Co-operation and Development; 2007.

27. World Bank. Better outcomes through health care reforms in the Russian Federations: the challenge in 2008 and beyond. Washington, DC: World Bank; 2008. 
28. Besstremyannaya GE. Increased public financing and health care outcomes in Russia. Transition Studies Review 2009;16:723-34.

29. Tragakes E, Lessof S, editors. Health care systems in transition: Russian Federation. Copenhagen: European Observatory on Health Systems and Policies; 2003.

30. Starodubov, V. I., \& Flek, V. O. Problems and perspectives of funding Russian healthcare. Healthcare Economy 2007; 1(111), 5-16. (in Russian).

32. Boikov VE, Feeley FG, Sheiman IM, Shishkin SV. Russian household expenditures on drugs and medical care: results of a December 1997 survey of 3000 households (unpublished); 2010. http://dcc2.bumc.bu.edu/RussianLegalHealthReform/ProjectDocuments/n640.

IIIB6.Article.pdf.

33. Isakova LE, Zelckovich RM, Frid EM. Health insurance in Russia - the Kuzbass experience. Health Policy 1995;31(3):157-69.

34. Sheaff R. Governance in gridlock in the Russian health system; the case of Sverdlovsk oblast. Social Science and Medicine 2005;60(10):2359-69.

35. 'Twigg JL. Obligatory medical insurance in Russia: the participants' perspective. Social Science and Medicine 1999;49(3):371-82.

36. Balabanova DC, Falkingham J, McKee M. Winners and losers: expansion of insurance coverage in Russia in the 1990s. American Journal of Public Health 2003;93(12):2124-30.

37. Lohlein D, Jütting J, Wehrheim P. Rural Russia in transition: what determines access to healthcare services? Post-Soviet Affairs 2003;19(1):80-94.

38. Fotaki M. Informal payments: a side effect of transition or a mechanism for sustaining the illusion of 'free' health care? The experience of four regions in the Russian Federation. Journal of Social Policy 2009;38(04):649-70.

39. Balabanova D, McKee M, Pomerleau J, Rose R, Haerpfer C. Health service utilization in the former Soviet Union: evidence from eight countries. Health Services Research 2004;39(6 pt 2):1927-50.

40. TACIS. Governance of health insurance. Report submitted to the Ministry of Labor and Social Security of the Russian Federations Moscow: TACIS; 2000.

41. Aarva P, Ilchenko I, Gorobets P, Rogacheva A. Formal and informal payments in health care facilities in two Russian cities, Tyumen and Lipetsk. Health Policy and Planning 2009;24(5):395405.

42. Feeley FG, Sheiman IM, Shiskin SV. Health sector informal payments in Russia. Moscow; 1999 unpublished. 
43. Kringos D, Boerma W, Spaan E, Pellny M, Son I, Korotkova A. Evaluation of the organizational model of primary care in the Russian Federation. A survey based pilot project in two rayons in Moscow oblast. Copenhagen: WHO Regional Office for Europe; 2009.

44. Brown JV, Rusinova NL. Russian medical care in the 1990s: a user's perspective. Social Science and Medicine 1997;45(8):1265-76.

45. Danishevski K, Balabanova D, Mckee M, Atkinson S. The fragmentary federation: experiences with the decentralized health system in Russia. Health Policy and Planning 2006;21(3):183-94.

46. USAID 1999. Analysis of structural/functional reform of the health care system in Russia. Research Institute of Social Hygiene, Health Organization and Economics; 2010. http://dcc2.bumc.bu.edu/RussianLegalHealthReform/ProjectDocuments/n970.IIIE1.

Analysis.pdf.

47. Petrova NG, Balohina SA, Martirosjan MM, Petrov MV, Temirova LH, Shatkovskaja OV. Patient's opinion as an important criteria of quality of medical aid. Problemi upravlenija zdravoohraneniem 2009; 1, 59-61. (in Russian).

48. Filatov VB. Politicheskie faktory i Rossijskoe zdravoohranenie. Vestnik Rossijskoj Akademii Medicinskih Nauk 2003; 4, 46-9. (in Russian).

49. Duke T, Keshishiyan E, Kuttumuratova A, Ostergren M, Ryumina I, Stasii E, et al. Quality of hospital care for children in Kazakhstan, Republic of Moldova, and Russia: systematic observational assessment. Lancet 2006;367:919-25.

50. Akopian AS, Goluhov GN, Shilenko YV. Aktualnie problemi reformirovania Rossijskogo Zdravoohranenija. Problemi sotsial'noi gigieni zdravoohranenia i istorii mediciny 1999;6:20-1. (in Russian).

51. Rekhter N, Togunov IA. Needs assessment for health care management education in Russia. Journal of Continuing Education in the Health Professions 2006;26(4):314-26.

52. Khisamutdinov RA, Husnutdinova ZA. Otnoshenie medicinskih rabotnikov k reformam v zdravoohranenii. Problemi sotsial'noi gigieni zdravoohranenija i istorii mediciny 2003;3:26-8. (in Russian). 


\section{Summary}

This dissertation is focused on the financial reforms of the Russian healthcare sector and the outof-pocket payments incurred by users of healthcare services during the transition period (19912011). In the Russian Federation, the financial reform of the healthcare sector started in the early 1990s by opting for a transition to an insurance-based system - a common trend in the transitional economies of Central and Eastern Europe. The Russian government had to face many challenges inherited from the previous Soviet healthcare system: an absence of effective mechanisms to equalize medical care across regions; inter-regional inequalities across income groups both in terms of financing and access to healthcare services; overall underfunding of the healthcare sector; lack of working mechanisms to ensure adequate quality of healthcare services, as well as efficiency and equity problems; significant obligations in terms of the provision of numerous in-kind healthcare and social benefits; and the existence of the informal payments. Facing obligations to provide unaffordable State guarantees, defined by the legislation, the Russian government implemented a number of financial reforms, which consequently introduced numerous changes in the provision of social and healthcare services.

Finding an optimal model of financing was a challenging task for the Russian government in the 1990s, taking into account previously existing problems that remained as a legacy from the Soviet period. According to the Russian legislation, Russian citizens have the right to free-of-charge medical care and are guaranteed equal access to it. In reality, however, despite the existing insurance-based model and social security based on a solidarity principle, a large share of the healthcare financing falls directly on the shoulders of households. During the transition period of the 1990s and 2000s, government expenditure on healthcare was declining and has increased in real terms only since 2006. Overall, the share of household income spent on healthcare services and medication increased in the period from 1994 to 2005 and only slightly decreased from 2006 onwards. The gaps in public funding were filled by private out-of-pocket payments and questionable quasi-formal payments. They were also complemented by substantial informal payments.

As outlined in Chapter 1, the two decades of continuous financial healthcare reforms are characterized by a shifting between multi- and single-channel financing of the healthcare sector and revision of the entitlements to social benefits. Coupled with the changes in the provision of social and healthcare services, considerable out-of-pocket expenditures for healthcare services have placed an additional burden on the budgets of many Russian households, and have potentially 
affected efficiency, equity and quality of the provided care. Since the style of implementation of the reforms was not continuous, but rather chaotic, a study of the effects of the reforms on outof-pocket payments is timely and necessary. Moreover, despite the numerous changes in the financing of the Russian healthcare sector as well as the provision of social benefits, the empirical evidence on the effects of the financial reforms is still scarce or lacking.

This dissertation attempts to contribute to filling this research gap. Therefore, the goal of this dissertation is to study the prevalence of changes in out-of-pocket payments in the Russian healthcare system against the background of the financial reforms of the Russian healthcare sector.

This dissertation is based on a series of studies that examined the effects of the financial reforms in the Russian public healthcare sector. It uses a wide spectrum of quantitative techniques to provide empirical evidence on the prevalence of changes in out-of-pocket payments for Russian healthcare services. Chapter 2 is based on a systematic literature review of empirical evidence on the effects of the financial reforms in the Russian public healthcare sector. The obtained list of publications was refined by a set of limitations and relevance criteria. The language of publications was limited to Russian and English. The next three chapters (Chapters 3, 4, 5) are based on the all-Russia representative survey data - the Russia Longitudinal Monitoring Survey - Higher School of Economics (RLMS-HSE, 2013). The RLMS-HSE survey is carried out by face-to-face interviews, with data for the children's questionnaires obtained from adults in the household. The survey contains data on the utilization and out-of-pocket payments for all types of healthcare services (outpatient non-dental, dental, check-up, and inpatient), as well as prescribed and recommended pharmaceuticals. The following statistical methods are used: descriptive statistics, parametric and non-parametric regression analysis, and cluster analysis.

Chapter 2 provides the appraisal of the financial reforms in the Russian public healthcare sector. It gives background information and outlines key milestones of the Russian healthcare sector reforms, as well as changes in healthcare financing over the last two decades. It reviews the empirical evidence on the effects of the financial reforms in the Russian public healthcare sector on financial sustainability (system funding), efficiency, equity, and quality of provided care.

We analyze the existing empirical evidence with the aim to outline the influence of the financial reforms in the Russian public healthcare sector on macro- and micro-efficiency, cost-containment mechanisms, equity in healthcare services delivery and quality of care. Only 31 articles and reports 
in English and 6 articles in Russian met the relevance criteria and presented evidence-based data. Overall, the evidence presented in the studies reviewed, was not enough to conduct a thorough impact evaluation of the financial reforms of the Russian healthcare sector. This is due to the limited number of studies and the limitations of each study. However, our analysis outlines several conclusions relevant to policy and research.

Our results suggest that the initial goal to generate additional non-budget revenues (i.e. via the collection of insurance premiums) was achieved and helped to maintain the sustainability of the system financing. This had a positive stabilizing influence during the economic crisis in the country. Local government spending as a percentage of GDP varies considerably across regions, which indicates large efficiency differences among regions and difference in access to healthcare services. Sometimes, redistribution of health insurance funds reflects a region's relationship with the center. Inter-regional variations in financing, payment and reimbursement mechanisms, as well as in volumes of financing continue to be reported. Currently, social-economic status remains one of the reasons for the unaffordability of some drugs and services.

Universal access and equity in financing and access to healthcare services are still impeded by inequalities among income groups (social-economic status) and regions (geographical location), as well as by the presence of informal and out-of-pocket payments. Patients may receive medical services either free-of-charge or by paying an official formal payment (service fee), or by making a shadow payment (gift or money). Out-of-pocket payments are made to gain quicker access or better quality, while some users of chargeable services had no other choice but to pay for the service, or had to pay for services that were declared as free.

Recipients of healthcare services perceive quality of care as "poor" and are "rather dissatisfied" with the quality of care received, due to several factors: long waiting time and queues; limited availability of modern medical equipment and medication, dissatisfaction with the quality of medical personnel, concern about physicians' competence and qualification; high costs of medicine, lack of necessary medicines and equipment, bad nutrition, insufficient skills of physicians, bad sanitary conditions and others; expensive drug treatment, violation of patients' rights, existence of under-the-table payments, and poor conditions of healthcare facilities; the necessity to pay for more convenient and better quality of care. Overall, patients are poorly informed about the reforms and the mass media are the main source of information. The majority of patients express that they accept the necessity of the reforms, but satisfaction with the insurance 
system is not high. Providers are also badly informed about healthcare documents, some peculiarities of work in the new health insurance system and patients' rights and express a general interest in the legal aspects of the healthcare system and issues of quality of healthcare provision. Still, the vast majority of providers is in favor of the ongoing economic reforms in the healthcare sector, but lack personal interest to participate in the reforms.

Chapter 3 evaluates the monetization of the social benefits reform of 2005, which cashed-out most of the in-kind benefits and affected the provision of prescribed and recommended outpatient pharmaceuticals. In particular, we evaluate the impact of the 2005 social benefits reform on outof-pocket expenditure on prescribed or recommended pharmaceuticals, based on a difference-indifferences method, using zero-inflated models. Additionally, we examine whether the annual choice between in-kind and in-cash provision of prescribed and recommended outpatient pharmaceuticals (possible as of 2006) had any significant impact as well.

As outlined in Chapter 3, modern Russia has inherited the system of privileges in healthcare and social systems introduced during the Soviet era. With almost $70 \%$ of the population being entitled to some sort of privilege and over a quarter of the Russian population being eligible for in-kind benefits resulting from the privileges, the system of privileges was very complex. Numerous problems with provision (including pharmaceuticals), effectiveness, equity in access to privileges, and transparency of the financial flows pointed to the necessity of a reform, which took place in 2005.

The social benefits reform of 2005 by the Russian government cashed-out (monetized) most of the in-kind benefits. However, a provision of prescribed outpatient pharmaceuticals to eligible beneficiaries remained in-kind. The reform affected the eligible beneficiaries, mainly by abolishing the existing discounts, and by limiting and annually revising the list of pharmaceuticals available for in-kind outpatient provision (also by replacing the more expensive pharmaceuticals with cheaper generics). Additionally, as of 2006, beneficiaries were given the right to opt for in-cash in place of in-kind pharmaceutical provision. The reform could potentially affect beneficiaries' consumption of prescribed outpatient pharmaceuticals and related out-of-pocket expenditure. Therefore, we took a retrospective look at changes in the provision of pharmaceuticals. We treated the reform as an exogenous factor and looked at its possible effect on beneficiaries' ability to find and buy prescribed or recommended pharmaceuticals and related out-of-pocket expenditure, using a difference-in-differences method, using zero-inflated models. 
Based on our analysis, we observe that the majority of respondents are able to buy and find prescribed pharmaceuticals and this trend is consistent over the six years period. The number of respondents, who opted for the in-cash pharmaceutical provision in place of in-kind, is $43.7 \%$ and $47.3 \%$ in 2006 and 2007 respectively. In 2008, this proportion is higher, namely $58.7 \%$, with ca. $16.4 \%$ of respondents who opted for in-cash in place of in-kind pharmaceutical provision. Overall, based on our difference-in-differences estimations, we find that the reform itself did not have a direct impact on beneficiaries out-of-pocket expenditure on outpatient prescribed or recommended pharmaceuticals. However, it did have a positive impact on the likelihood of incurring zero expenditure on these pharmaceuticals. The additional annual choice between in-kind and in-cash provision did not have a statistically significant impact either. Therefore, we find no evidence that the reform made one better or worse off, mainly because the reform did not introduce targeting of categorical social assistance. Taking a policy perspective, this suggests that the implementation of the reform was successful and did not make vulnerable groups better or worse off, and most likely did not have an adverse effect on equity in financing.

In general, one can argue that cashing-out in-kind benefits was one of the steps towards a more liberal welfare regime and paved the way to a more market-based and targeted provision of subsidized public services. The reform replaced the complex benefits system for eligible groups with a more simple and sustainable system of social support measures. Moreover, the reform brought more clarity to the financial and administrative aspects of welfare provision, and introduced some logic of cost-effectiveness, accountability and transparency in the system. However, a top-down and short-notice implementation of the reform led to the underestimation of the overall number of beneficiaries and related budgetary deficits, as well as a demand-supply imbalance. Hence, problems with the provision of outpatient prescribed pharmaceuticals still raise the questions regarding equity.

Chapter 4 examines the issue of informal payments for healthcare services in Russia. This chapter contains the results on the magnitude of the scale and scope of informal payments in the Russian healthcare sector and their determinants in 2009. The results are compared to previous studies about informal payments in Russia and other Central and Eastern European countries. We also give a detailed description of the process of paying informally (actors involved, settings, and reasons), including identified patterns of paying informally, assessed by the means of cluster analysis. This chapter also elaborates on the reasons for the persistent existence of informal 
payments in the Russian healthcare sector and its possible implications for Russian health policymakers.

As outlined in Chapter 4, informal payments that exist since the Soviet period have survived despite numerous reforms and have adapted to the new realities of modern Russia. Based on previous studies over the past decade, informal payments in the Russian healthcare sector were reported in all types of healthcare settings: inpatient and outpatient, private and public. A significant number of users have to pay for services they were actually entitled to free of charge. Depending on the type of healthcare setting and year of the survey, the number of users who paid informally ranges from $3.2 \%$ to $36.1 \%$, and the share of informal payments constitutes up to $34.4 \%$ of all healthcare payments.

We find that in 2009 , the number of users who pay informally ranges from $1.4 \%-17.0 \%$, depending on the type of healthcare service, averaging to ca. $7.3 \%$ among all healthcare users. The highest incidence of informal payments $(17 \%)$ is reported by users of dental services, particularly in private settings ( $27.6 \%$ vs. $10.1 \%$ in public settings). Inpatient service users pay informally more frequently (12.7 \% of users) than users of outpatient non-dental and check-up healthcare services $(4.3 \%$ and $1.4 \%$ of users). Compared to other European countries, the level of informal payments in the Russian health sector seems to be lower.

Based on cluster analysis, we find several patterns of paying informally. The first pattern includes cases where healthcare users are suggested to pay informally by medical staff: the exact amount to be paid informally is told by someone and is known only right before the service, and users pay after the service is provided (outpatient settings) or before the service (inpatient settings). The second pattern depicts cases where users of healthcare services initiate informal payments themselves: the exact amount of the informal payments is not known before the service and, therefore, is being determined by the users themselves. Both patterns share similar reasons for informal payments - gaining access to the provided service (for outpatient services) or receiving better quality care (for inpatient services). Similar patterns emerge when all cases of paying informally are analyzed together, depicting gratitude as an additional reason for paying informally.

Overall, our results confirm that healthcare users in Russia continue to pay informally for all types of healthcare services, both in public and private settings. Whenever users decide to pay informally, they tend to pay more frequently in cash. Gifts are also used for these purposes, but less frequently and they have a lower monetary equivalent. We also find that the probability of informal payments 
and the amount paid are determined by socio-economic characteristics, such as the level of education, self-rated health, age, and household income, presence of disability or at least one chronic sickness.

Chapter 5 analyzes how exposure of Russian healthcare users to catastrophic payments of healthcare services has changed during the last decade (2001-2011). The incidence and intensity of catastrophic payments are characterized by headcount, overshoot, and mean positive overshoot. The impoverishing impact of out-of-pocket expenditure are assessed by distribution-sensitive measures (concentration index), while measures of poverty are based on poverty headcounts, poverty gap, normalized poverty gap and normalized mean positive poverty gap.

In Russia, fairness in access and financing is one of the problems that is yet to be tackled. Therefore, background information on the exposure to catastrophic and impoverishing out-of-pocket health payments is needed. And whilst there are a number of studies addressing the changes in poverty levels in the Russian populations, none of them actually mentions the exposure of Russian healthcare users to catastrophic or impoverishing payments for healthcare services. At the same time, such studies could be potentially used by the policy-makers to optimize policies aimed at fairness in both provision and financing of the Russian healthcare sector.

Over the last 11 years health-related payments as a share of total household consumption grew from $4 \%$ to $5.3 \%$, with the highest share among households belonging to the first and second income quintiles. At the same time, the overall number of households where at least one member had to forgo healthcare service use (due to a lack of financial resources) declined. A similar trend is observed for the utilization of pharmaceuticals. Dental care is the least affordable type of service, and the number of households that forewent these services remained steady within a $9 \%-12 \%$ interval. Poorer households have a greater tendency to fall into catastrophic payments and the overall incidence of catastrophic payments increased over the decade for all households. However, the incidence of impoverishing healthcare payments declined. Households residing in a rural area, households with a larger number of children (especially with a single parent) are more vulnerable to the impoverishing effects of healthcare-related expenditure. Residing in an urban area, living as an extended household with highly-educated family members, as well as having pensioners in the household, on the contrary, cushions healthcare expenditure-related poverty spells.

Forgoing healthcare services remains an important issue in Russia, mainly due to unaffordability and households' financial constraints, especially among poor households. Our results confirm that 
the increase of healthcare expenditures affects all households and policy measures require addressing poverty alleviation and implementation of targeted and means-tested healthcare provision.

Chapter 6 outlines the main findings of the dissertation, followed by the general conclusions and policy implications of the dissertation.

As discussed in this chapter, almost two decades of experimenting did not yield the optimal model of healthcare financing in Russia. There is still a lack of continuity in the reforms. The system of financing lacks transparency. Unfortunately, cost control is still not at the center of the ongoing reforms. The Russian healthcare sector opted once again for a single-channel model of financing, mainly via compulsory social health insurance. The question whether one-channel financing will eliminate the old and newly created problems is still unanswered. Moreover, the full transition of the Russian healthcare sector to a purely insurance-based model is not completed, and insurance premiums are still collected in the form of a tax.

Two decades of financial healthcare reforms aided to move towards a market-based healthcare provision. The reforms have introduced the healthcare insurance mechanism, which established the purchaser-provider separation. However, the priorities of the reforms still seem to depend on the Heads of the Ministry of Healthcare and corroborate a principle that was and still is put into practice - "new lords, new laws". As a result, reform initiatives affected equity in access and financing, as well as the quality of the provided healthcare services. Some reforms (i.e. monetization of social benefits) had very limited effect, compared to what it could have achieved. With no obvious substantial benefits, such reform could turn out to be only an expensive policy-changing exercise.

Most financial reforms had a top-down and short-notice implementation, which led to an underestimation of the overall number of beneficiaries and related budgetary deficits, as well as a demand-supply imbalance. Hence, these problems once again raised the question about equity. Both providers and healthcare users are poorly informed about the ongoing reforms and acquire information mainly through mass media. Therefore, future reforms and actions (i.e. addressing informal payments) should include nation-wide information campaigns to raise awareness about healthcare users' rights, healthcare entitlements, and the content of the on-going healthcare reforms. Should such strategy be chosen, information campaigns should target both users and 
healthcare services providers, since both groups initiate informal payments (as shown by our results).

Our results on informal payments indicate that users of healthcare services in Russia pay informally to gain access to the treatment/service (especially in outpatient non-dental settings), receive care of a better quality (particularly in inpatient settings), and to express gratitude to the healthcare professional (in both types of settings). Importantly, these reasons are a signal about the existing problems of the Russian healthcare sector, which require immediate attention of policy-makers. Based on our findings, we believe that Russian users of healthcare might be ready for the introduction of co-payments for services outside the basic package via voluntary insurance or direct out-of pocket payments. To tackle the informal payments even further, we suggest that, in principle, all direct financial transactions between the healthcare users and providers should be eliminated and be channeled solely via the insurer (e.g. via billing at home).

Overall, the problems of the Russian healthcare sector urge for altering the structure of spending while stimulating the enhancement of efficiency and the implementation of cost-containment, and creating incentives for a better allocation and distribution. Insurance companies and funds should become more active players on the compulsory social health insurance market and protect users' interests ex-ante and not post-ante. Also, users should have access to open channels of communication (both with service providers and insurance companies) to provide timely feedback on quality of received services and the possibility to file complaints regarding problems encountered (i.e. access, complications, waiting time, necessity to pay informally). The empowerment of healthcare consumers should also be fostered and healthcare users should take more responsibility over their own health (something Russian citizens are still not accustomed to).

\section{Conclusions and policy implications}

The Russian healthcare and social sectors face numerous problems and challenges, including those inherited from the Soviet era. The healthcare reforms coupled with the overall improvement of the economic situation in the country, brought some positive changes but still there is more to be done to adequately address healthcare sector problems (including those not being officially recognized). The content of the future Russian healthcare reform initiatives should not only focus on an adequate level of financing and search for an optimal model of financing, but also on the implementation of cost-efficiency and cost-control mechanisms. Further reforms should 
concentrate on the development of an effective and coherent framework that would tackle existing problems in equity in access and financing; provide incentives for better allocation and distribution; develop a clear policy addressing informal and quasi-formal payments; implement a system of quality controls; recognize the existence of informal payments and develop a clear policy regarding such payments; address poverty alleviation and implement targeted and mean-testing social benefits provision; and stimulate healthy competition between insurance companies. In general, the financial reforms for the Russian healthcare sector should have a more planned character with continuity between the steps of the implementation. Future reforms should utilize in its core an evidence-based policy-making approach, and include timely impact evaluation analyses. 


\section{Аннотация}

\section{«Финансовые реформы российского сектор зАравоохранения и хичные платежи пользоватемей медицинских услуг»}

Эта Аиссертация посвящена финансовым реформам российского зАравоохранения и личным платежам пользователей медицинских услуг и охватывает переходный период с 1991 по 2011 год. Финансовые реформы здравоохранения в Российской Федерации (РФ) начались в начале 1990-х с созданием и введением системы обязательного медицинского страхования $(\mathrm{OMC})$ - типичной тенденцией в странах ЦентраАьной и Восточной Европы с переходной экономикой. Российское правительство столкнулось со множеством проблем, унаследованных от предылущей советской системы зАравоохранения: отсутствие эффективных механизмов, которые бы обеспечивали схожий спектр медицинских услуг доступных Аля граждан в разных регионах РФ; межрегиональные неравенства в доступе гражАан к этим медицинским услугам (включая фактическую и финансовую доступность), особенно в группах населения с различным уровнем Аоходов; недостаточное финансирование зАравоохранения в целом; отсутствие рабочих механизмов, которые бы гарантировали необходимое качество медицинских услуг; проблемы с эффективностью использования финансовых средств; непомерные государственные обязательства, связанные со значительным количеством социальных и медицинских мьгот и пособий; а также существование неофициальных платежей. Столкнувшись с невозможностью финансового обеспечения существующих государственных обязательств, гарантированных законодательством, российское правительство осуществило ряА финансовых реформ, которые привнесли многочисленные изменения в порядок предоставАения как социальных, так и медицинских услуг.

Принимая во внимание перечень существовавших проблем, Аоставшихся в наследство от советского периода, в 1990-х годах российскому правительству было сложно найти оптимальную модель финансирования зАравоохранения. Так, в соответствии с российским законодательством, все граждане РФ имеют право и гарантированный равный доступ к бесплатному медицинскому обслуживанию. ОАнако в реальности, несмотря на существующие системы ОМС и социальной защиты, основанных на принципе солиларности, значительная Аоля финансирования зАравоохранения можилась непосредственно на плечи домохозяйств. Во время переходного периода с 1990-х по 2000- 
е года, правительственные расходы на здравоохранении уменьшались и стали увеличиваться в реальном выражении только с 2006 года. В целом, совокупная доля домашнего Аохода, потраченного на медицинские услуги и мечение, увеличилась в период с 1994 до 2005 и только немного уменьшилась начиная с 2006 года. Таким образом, недостатки в государственном финансировании здравоохранения были компенсированы за счет мичных платежей пользователей медицинских услуг, сомнительных полуформальных платежей, а также Аополнены значительными неофициальными платежами.

Как описано в гмаве 1 данной диссертации, Ава десятилетия непрерывных финансовых реформ здравоохранения РФ главным образом характеризуются переключением между Авумя моделями финансирования здравоохранения РФ - многоканальным и одноканальным, а также пересмотром списка тех миц, которым положены социальные мьготы и пособия. Изменения в предоставцении медицинских услуг могли созАать Аополнительное бремя Аля бюАжетов многих российских АОмохозяйств и пов иять на качество оказанной помощи, а также на неравенство в доступе граждан к медицинским услугам. Так как характер внедрения реформ был хаотичным и непоследовательным, исследование влияния реформ на мичные платежам пользователей медицинских услуг своевременно и необходимо. Кроме того, несмотря на многочисленные изменения в финансировании российского сектора зАравоохранения и порядке предоставлении социальных пособий, эмпирических исследований о возможном эффекте финансовых реформ все еще недостаточно. Поэтому, целью Аанной Аиссертации является изучение изменений в мичных платежах пользователей медицинских услуг российской системы зАравоохранения в свете финансовых реформ российского сектора зАравоохранения.

Эта Аиссертация основана на ряле исследований, которые изучали эффекты финансовых реформ в российском секторе зАравоохранения. Исследования используют широкий спектр количественных методов Аля получения эмпирических подтвержАений о

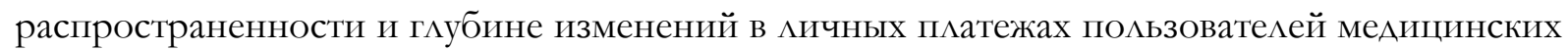
услуг российской системы здравоохранения. Гмава 2 основана на результатах систематического митературного обзора эмпирических Аоказательств эффектов финансовых реформ в российском зАравоохранении. Полученный список публикаций был усовершенствован рядом критериев уместности и ограничений. Язык публикаций был ограничен до русского и английского. Следующие три главы (ГАавы 3, 4, 5) основаны на анализе базы данных Высшей школы экономики “Российский мониторинг экономического 
положения и зАоровья населения НИУ ВШЭ” (RLMS-HSE, 2013). Сбор Аанных выполнен при помощи личных интервью. Аанные о детях получены от взрослых членов Аомохозяйства. База Аанных содержит информацию об использовании медицинских услуг, включая Аичные платежи за эти услуги, а также платежи за назначенные и рецептурные мекарства, и охватывает все типы медицинских услуг (поликлиническая помощь, стационарная помощь, услуги стоматологии, а также медосмотры). В диссертации используется несколько статистических методов исследования: описательная статистика, параметрический и непараметрический регрессионный анализ, и кластерный анализ. Ниже приведено краткое содержание и обозначены основные результаты каждой из глав.

ГАава 2 Аает оценку финансовым реформам в российском секторе зАравоохранения, основываясь на результатах систематического обзора митературы. В целом, 31 научная публикация и статья на английском языке и 6 статей на русском языке соответствовали критериям уместности и были включены в обзор. В целом, доказательств, преАставленных в рассмотренных исследованиях, было недостаточно, чтобы провести полную Аоказательную оценку влияния финансовых реформ российского сектора зАравоохранения. ГАавной причиной такой невозможности стало ограниченное количество исследований в целом, а также индивидуальные ограничения каждого из исследований, в частности. Несмотря на это, проанализированных доказательств было Аостаточно Аля того, чтобы сАелать несколько заключений.

На основании результатов обзора митературы, можно заключить, что изначальная цель привлечения дополнительных внебюджетных средств через взимание страховых взносов была достигнута. Привлечение Аополнительных средств способствовало подАержанию устойчивости системного финансирования, а также имело положительное стабилизирующее влияние во время экономического кризиса в стране. Межрегиональные неравенства в доступе гражАан к медицинским услугам (фактическая и финансовая Аоступность), особенно в группах населения с различным уровнем доходов, а также неравенства среди доходных групп по социальному и экономическому статусу, и существование неформальных платежей препятствуют универсальному доступу и Аостижению равенству в финансировании и доступу к медицинским услугам. В целом, пациенты могут получить медицинские услуги бесплатно, Аибо после официальной оплаты за услуги, или осуществцяя неформальный (теневой) платеж в виде подарка или денег. Пациенты часто платят сами, чтобы получить более быстрый Аоступ к необходимым 
услугам или чтобы получить кучшее качество предостав яемых услуг, в то время как Аругие пользователи медицинских услуг вынуждены платить даже за те услуги, которые Аолжны предоставляться бесплатно.

Пользователи медицинских услуг оценивают качество ухода как “плохое” и “Аовольно неудовлетворительное”. ГАавными причинами такой оценки явцяются: АОАгое время ожилания и очереди; неудовлетворенность качеством медперсонала; высокая стоимость услуг; отсутствие необходимых мекарств и оборудования; плохое качество питания; недостаточные навыки врачей; плохие санитарные условия; Аорогое медикаментозное мечение; нарушение прав пациентов; существование незаконных платежей и плохое состояние зданий учреждений зАравоохранения; необходимость платить за более внимательное и качественное качество ухода. В целом, пациенты плохо проинформированы о реформах, и средства массовой информации являются основным источником информации. Большинство пациентов отмечают, что они поддерживают реформы, но удовлетворение страховой системой не высоко. Поставщики медицинских услуг также плохо проинформированы о текущих реформах, особенностях работы в новой системе медицинского страхования, а также правах пациентов. В то же время, они выражают общий интерес к юридическим аспектам системы зАравоохранения и проблемам качества предоставления услуг зАравоохранения. Подавляющее большинство поставщиков медицинских услуг выступает за продолжение экономических реформ в секторе зАравоохранения, но не выражает мичного интереса в участии в Аанных реформах.

ГАава 3 оценивает монетизацию социальных мьгот в 2005 году, которая заменила большинство натуральных мьгот денежными компенсациями, а также изменила список предоставляемых мекарств бесплатно. В данной главе дана оценка влияния реформы социальных пособий 2005 года на мичные платежи пациентов на выписанные или рекомендованные мекарства, основанная на использовании статистического метода «разАичия в различиях» (difference-in-difference), используя регрессионные модели с подкачкой нуля. Кроме того, в Аанное главе Аается оценка влияния возможности ежегодного выбора межАу натуральными мьготами и денежной компенсацией (возможной с 2006 года) на Аичные платежи пациентов на выписанные или рекомендованные мекарства.

Можно также заключить, что большинство опрашиваемых респондентов были в состоянии купить и найти выписанные или рекомендованные мекарства, и эта тенденция была 
последовательной на протяжении шести мет (2002-2007), рассмотренных в анализе. Число респондентов, которые выбрали монетизацию вместо натуральных Аьгот состав яет 43.7\% и 47.3\% в 2006 г. и 2007 г. соответственно. В 2008 это число респондентов выросло Ао 58.7\% и приблизительно 16.4\% респондентов выбрало монетизацию Аьгот вместо натуральных мьгот. В целом, реформа не оказывала прямое влияние на цичные платежи получателей мьгот. ОАнако реформа имела положительное влияние на вероятность Аьготников получить мекарства. Аополнительный ежегодный выбор межАу натуральным Аьготами и денежными компенсациями также не оказал статистически значимого влияния на Аичные платежи пациентов на выписанные или рекомендованные мекарства. Кроме того, реформа привнесла больше ясности в финансовые и аАминистративные аспекты предоставления Аьгот и некоторую Аогику рентабельности, ответственности и прозрачности в системе предоставления мьгот. ОАнако, скоропалительное проведение реформы привели к недооценке общего количества Аьготников и привело к Аефициту бюджета, а также несбалансированности в системе спроса-предложения, а также проблемам с поставками мекарств.

ГАава 4 посвящена неформальным платежам за медицинские услуги в российском зАравоохранении. Основываясь на результатах предылущих исследований за прошлое Аесятилетие, неформальные платежи в российском секторе зАравоохранения существуют во всех типах медицинских учреждений: в государственных и муниципальных, а также частных больницах и поликлиниках. Значительное количество пользователей платит за услуги, которые фактически Аолжны предоставцяться бесплатно. В зависимости от типа собственности и года сбора Аанных, число пользователей, которые заплатили неформально межит в Аиапазоне от $3.2 \%$ Ао $36.1 \%$, и доля неофициальных платежей составляет Ао $34.4 \%$ всех платежей за услуги зАравоохранения.

Основываясь на данных 2009, число пользователей, которые заплатили неформально за медицинские услуги варьирует от 1.4\% до 17.0\%, в зависимости от типа медицинских услуг, что составляет примерно 7.3\% среди всех пользователей зАравоохранения. Самый высокий уровень неформальных платежей приходится на стоматологические услуги (17\%), особенно в частных клиниках (27.6\%), а то время как в государственных и муниципальных стоматологиях данная доля составляет 10.1\%. В больницах $12.7 \%$ пользователей платит за полученные услуги неофициально. За поликлинические услуги эта АОАя составляет $4.3 \%$ и 
1.4\% за профилактические осмотры. По сравнению с Аругими европейскими странами уровень неформальных платежей в российском секторе зАравоохранения ниже.

По результатам кластерного анализа, было вылелено несколько вариантов неформальной оплаты медицинских услуг. Первый вариант объединяет случаи, когАа сотрудники медицинских учреждений сами просят пользователей здравоохранения заплатить: точная сумма, которая должна быть заплачена неофициально сообщается непосредственно переА предоставлением медицинской услуги, и пациент платит Аибо после предоставАения услуги (в поликлинике), Аибо до оказания услуги (в стационаре). Второй вариант объединяет случаи, когАа пользователи медицинских услуг зАравоохранения сами инициируют неформальный платеж: точная сумма, которая должна будет заплачена неофициально, неизвестна, и определяется самим пользователем. Оба варианта сходны в причинах, стоящих за неформальными платежами - получение доступа к услуге (в поликлинике) или получение более качественного и внимательного ухода (в стационаре). Пациенты платят неофициально также в знак благодарности за оказанные медицинские услуги. В целом, пациенты чаще всего платят неофициально наличными. Пациенты также платят подарками, но их денежный эквивалент более низкий.

В ГАаве 5 представлены данные об изменении уровня катастрофических платежей за медицинские услуги в течение прошлого десятилетия (2001-2011). В РФ все ещё сохраняются неравенства в доступе гражАан к медицинским услугам (включая фактическую и финансовую Аоступность), особенно в группах населения с разАичным уровнем доходов. За последние 11 мет, Аоля платежей за медицинские услуги как процент домашнего потребления выросла с от 4\% до 5.3\%. Общее количество Аомашних хозяйств, где по крайней мере один из членов домохозяйства был вынужден воздержаться от использования медицинских услуг (из-за отсутствия финансовых ресурсов) уменьшилось. Аекарства также стали более доступны Аля населения. Стоматологическая помощь выявлена как самая неАОступная из всех виАов услуг, и АОАя АОмашних хозяйств, гАе по крайней мере один из членов домохозяйства был вынужден воздержаться от использования стоматологическая услуг составила 9-12\%. В целом, частота катастрофических платежей увеличилась за последнее десятилетие Аля всех домашних хозяйств, при этом у более бедных Аомашних хозяйства чаще всего возникает необходимость совершать катастрофические платежи за медницкие услуги. В то же время, частота обедняющих платежей за медницкие услуги за последнее десятилетие уменьшилась. Аомашние хозяйства, проживающие в сельской 
местности, а также Аомохозяйства с большим числом детей (особенно в семьях с одним родителем), более уязвимы для эффектов обеднения, связанных с расходами на услуги зАравоохранения. Проживание в городе, проживание в расширенном Аомашнем хозяйстве с высокообразованными членами семьи, а также наличие пенсионеров в Аомашнем хозяйстве, наоборот, защищает от обедняющих эффектов, связанных с расходами на услуги зАравоохранения.

Отказ от медицинских услуг остается важной проблемой в РФ, главным образом из-за недоступности и финансовых ограничений домашних хозяйств, особенно среди бедных Аомашних хозяйств. Результаты подтверждают, что увеличение расходов на финансирование услуг зАравоохранения затрагивает все типы домашних хозяйств, и Аля Аальнейшего снижения бремя катастрофических и обедняющих платежей, необходимо Аальнейшее снижение общего уровня бедности и внеАрение целевых и направленных мер социальной подмержки.

В ГАаве 6 сформулированы основные результаты диссертации, а также общие заключения и рекомендации.

После Авух Аесятилетий экспериментирования, оптимальная модель финансирования зАравоохранения в РФ так и не найдена. Реформы проводятся непоследовательно, и система финансирования непрозрачна. К сожалению, контроль затрат все еще не находится в центре продолжающихся реформ. ИАет постоянное переключение межАу одно- и многоканальным финансированием, главным образом через обязательное социальное медицинское страхование. Вопрос, устранит ми одноканальное финансирование старые и вновь созданные проблемы, все еще остается без ответа. Кроме того, переход российского сектора зАравоохранения к полной страховой модели финансирования так и не закончен, и страховые взносы все еще собираются в виде налога.

Ава десятилетия финансовых реформ зАравоохранения помогли приблизиться к рыночным принципам предоставления медицинских услуг. Реформы ввели страховой механизм зАравоохранения, который установиц четкое разделение в системе отношений покупательпоставщик. ОАнако приоритеты реформ все еще меняются с каждым новым главой министерства зАравоохранения и могут быть описаны поговоркой - “новая метла по-новому метёт”. Большинство финансовых реформ имело вертикальный характер внеАрения и 
сроки проведения реформ были очень коротки, что привело к недооценке числа тех, кто прямо или косвенно будет затронут финансовыми реформами, что в итоге привело к дефициту бюджета и несба^ансированности в системе спроса-предложения. Зачастую, как пациенты, так и медицинские работники были очень плохо проинформированы о содержании реформ и средства массовой информации были главным источников информации о проходящих реформах. Поэтому, будущие реформы Аолжны включать общенациональные информационные кампании, направленные на осведомление о правах пациентов, а также на разъяснение сути и содержания реформ зАравоохранения. Если будет выбрана такая стратегия, информационные кампании АОАжны предназначаться как Аля пользователей, так и Аля поставщиков медицинских услуг, так как обе стороны инициируют неформальные платежи, как было показано в данной диссертации.

Пользователи медицинских услуг в РФ платят неформально чтобы получить доступ к необходимому мечению/обслуживанию (поликлиники), получить более качественный и внимательный уход (стационары), а также чтобы выразить благодарность медицинским работникам. На основании результатов Аанной Аиссертации, можно заключить, что российские пользователи услуг зАравоохранения готовы к введению частичных или полных платежей за медицинские услуги не входящие в пакет базовой программы обязательного медицинского страхования. Также, Аля Аальнейшего устранения неформальных платежей рекомендуется исключение всех прямых финансовых операций межАу пользователями и поставщиками медицинских услуг и осуществление таких операций посреАством страховщика (например, через отправление счетов за предоставленные услуги по почте).

В целом, проблемы российского сектора здравоохранения подтвержАают необходимость изменения структуры расходов, стимулирования улучшения эффективности и внедрения механизмов сдерживания затрат, стимуляции более оптимального использования и распределения финансовых средств. Страховые компании и фонды должны стать более активными игроками на рынке обязательном социального медицинского страхования и защищать пользователей не только после, но и до, и во время предоставления медицинских услуг. Кроме того, важно, чтобы существовац работающий канал обратной связи и с поставщиками услуг и со страховыми компаниями Аля пользователей медицинских услуг, чтобы они могли своевременно подавать жалобы относительно проблем с которыми они сталкиваются (на пример, проблемы с Аоступом, осложнения после оказанных услуг, Алительное время ожидания, вынуждение заплатить неформально). Более того, важно 
внедрение комплекса мер направленных на повышение ответственность граждан за собственное заоровье.

\section{Заключения и рекомендации}

Реформы здравоохранения вместе с общим улучшением экономической ситуации в стране имели ограниченный положительный эффект, но многочисленные проблемы так и остались в системах зАравоохранения и социальной защиты. Будущих реформы зАравоохранения Аолжны не только сосредоточиться на обеспечении соответствующего уровня финансирования и поиске оптимальной модели финансирования, но также и на внедрении механизмов экономической эффективности и контроля затрат. Аальнейшие реформы Аолжны иметь последовательный характер, решить существующие проблемы неравенства в доступе и финансировании медицинских услуг, обеспечить стимулы Аля кучшего распределения и использования финансовых средств, решить проблему с неформальными платежами, пересмотреть содержание пакета услуг, входящих в базовый пакет обязательного медицинского страхования, а также снизить уровень бедности и внедрить меры социальной подАержки. Будущие реформы также Аолжны проводить своевременную оценку реформ и мероприятий. 


\section{Thank you words}

My $\mathrm{PhD}$ journey is almost over and it is actually a great pleasure to look back and rediscover all the bright moments, my challenges, the lessons I have learnt, people that I have met and the countries I have visited. They made my academic journey fascinating and memorable. My family has always encouraged me to listen to my heart, follow my dreams, and do what I want, even if it means that we are all countries or continents apart. Without their support, I would never have had enough courage to leave my fatherland to discover a new world of academia, as well as my new motherland here, in the Netherlands. Therefore, I would start by writing my "thank you" words in Russian.

Мамочка, большое спасибо тебе за то, что ты всегда в меня верила и была рядом, и дала те крылья, которые помогли мне совершить этот Алительный научный полёт. Анжелика, ты всегда подцерживала меня говоря простую фразу: “Всё будет хорошо!”. На самом деле, так оно и есть, только, правильнее будет - «Уже всё хорошо!». Саша, твоё упорство и стойкая веру в принципы всегда придавали мне силы в момент слабости и сомнений. Елена Михайловна, именно Ваша мудрость подтолкнула меня к научной карьере и Ваш мюбимый принцип - «я не знаю, чего хочу, но не остановлюсь пока не получу этого» зачастую придавац мне энергии и научного задора. Ирина, Аима, Настёна, ЭАя, Аена, Аюба, Аня, Кори, Марина Яковлевна, настоящую Аружбу невозможно переоценить. Мои родные, ваша поццержка просто неоценима, и я вас всех очень сильно Аюблю! Спасибо! Я уверен, больше всех сейчас переживац бы и гордился мной мой папа. Папа, мне тебя очень сильно не хватает, и эта диссертация посвящена тебе. I am also eternally grateful to my big American family (Mary, Laura, Sam, Anita, Sean, Polly, Brady and Rowan). Thank you and I love you all! My PhD trip would not be possible at all without two special people - Wim and Milena. Dear Wim and Milena, thank you so much for taking the time to supervise me and guide me towards the successful completion of my PhD track. Dear Wim, a lot has been said by my fellow colleagues, junior researchers of ASSPROCEE2007 project in their "Thank you words" sections of PhD manuscripts. Without repetition, I would like to thank you for your guidance and mentorship, and helping me in every step of my academic career. Dear Milena, pursuing a $\mathrm{PhD}$ track is a challenge, but conducting it in a foreign country is an additional challenge as well. I would like to thank you for your support and understanding, and helping me to adapt to a culture of what now is my new motherland. Besides academic coaching, you provided me with an invaluable cultural coaching as well. Dear Wim and Milena, you gave me freedom to learn by doing. I made a few mistakes along the way, but I have surely learnt a lot. I am grateful to you both for your infinite patience and trust in me. 
I would also like to thank my dear officemates (Marla and Saskia), who spent countless hours with me both inside and outside our office. I am very happy we became friends. Thank you so much for your cultural tips, endless discussions, moral support, true care, and lovely Efteling trips. Reza, Safura, Mahdi and Hosna, I am very happy that besides my own Russian family, now I have my own Iranian family as well. Thank you so much for your kindness, openness, warmth and closeness of a family, sharing your culture with me, and your unforgettable delicious meals.

My dearest friend Bocić, I would like to express my eternal gratitude for being my soul mate, research mate and simply being there for me. You helped me to shape and sharpen my scientific vision, by examples of your own work. Thank you! I am also grateful to all junior researchers of ASSPROCEE2007 project (Petra, Sonila, Tania, Andriy, Marzena, Elka, Jelena, and Marija). Guys, you made my scientific journey unforgettable. Florian, Anil and Param, Olya, Mikey, without you our family of junior researchers would be incomplete! A big thank you to all senior researchers of the project as well!

I would also like to thank all my colleagues at HSR department, KEMTA, department of International Health, as well as those who had previously worked at BEOZ; fellow members of the University Council (Maastricht University); fellow MTEC students; members of the ProVUM $\mathrm{PhD}$ student association (Maastricht University); members of the Education office (Maastricht University); my teachers of Dutch and German (Maastricht University language center); all trainers at various Universities across Europe, who helped me to develop and enhance my research and analytical skill; anonymous reviewers and distinguished members of my $\mathrm{PhD}$ assessment committee. Thank you all!

As hard as office and research life can be, my $\mathrm{PhD}$ journey would not be possible without short get away trips now and then. I know that I am always welcome and have a home in Serbia (Sonja, Katarina), Germany (thanks, Kai, Wil, Christian, Dirk, Stephan, Axel, Bernhard, Barbara, Carlos, Mark, Catarina); UK (thanks, Hippo, Max, Juan, Roberto, Claudia, and Andrew); Spain and Austria (Eusebio, Max); Greece (thanks, Inge, Karla, and Dimitros); as well as Switzerland (Fabian). Guys, you helped me get back on track in no time and forget what the word "stress" actually stands for. My special thanks to my dearest friends Javi, Stefan, and Ross, who devoted their time to support me during the hard times and always gave a shoulder to lean on. Dear Annelies, Emjee, Helga, Daneida, Basema, Christina, Sergio, Carine, Cipriana, Lori, Kai, Kevin, Eva, Dasha, Kasia, Elena, Katarina, Roy, Irina, Marisela, Marco, Suus, Brigitte, Silvia, Iza, Hans, Dick, Aggie, Federica, Matt, Anita, Hannerieke, Arnold, Arkadij, Ksenia, Ruud, Maria, Olga, Angela, Janneke, Lodewijk, Cindy, Cynthia, Dirk, Sassie, Nynke, Siebren, Volkan, Anton, Silke, Ross, Arno, Helmut, Mirjam, and all my friends, colleagues and family members, thank you all so much! 


\section{Curriculum Vitae}

Vladimir Sergeevich Gordeev was born on 8 April 1982 in Kirov, USSR. He studied Internal Medicine at Kirov State Medical Academy (graduated in 2005 with cum laude). He then studied MSc Public Health at Maastricht University with specialization Health Policy, Economics and Management (graduated in 2007 with cum laude). He also obtained an MA in Economics and Management at Vyatka State University, majoring in Financial Management and graduating in 2008 with cum laude.

For five and half years, he worked at Maastricht University as a research fellow, researcher and as a $\mathrm{PhD}$ candidate at the department of Health Services Research. His $\mathrm{PhD}$ research was conducted within the project Assessment of patient payment policies and projection of their efficiency, equity and quality effects: the case of Central and Eastern Europe (ASSPRO CEE 2007), funded by the European Commission and coordinated by Maastricht University. His research within the project has been focused on financial reforms of the Russian healthcare sector and related patients' out-of-pocket patient expenditure, which has provided the basis for this dissertation.

Currently, he is a research fellow at the London School of Hygiene and Tropical Medicine. Initially, he worked at the European Centre on Health of Societies in Transition where his core research activities related to the ESRC funded project Economic shocks and health resilience: lessons from the Russian Federation. In October 2014, he has joined the School of Public Health Research at the London School of Hygiene and Tropical Medicine (SPHR@L), part of the wider National Institute for Health Research School for Public Health Research (NHS), to work on UK Communities in Control study. 